\title{
RISKS AND RISK PREMIUMS IN COMMODITY MARKETS
}

Department of Applied Finance and Actuarial Studies, Faculty of Business and Economics, Macquarie University Sydney, Australia

and

Chair of Finance, Faculty of Economic Sciences,

Georg-August-Universität Göttingen, Germany

\section{Rangga Handika, MCom}

Thesis submitted to the Chair of Finance, Faculty of Economic Sciences, Georg-August-Universität Göttingen, Germany, in fulfilment of requirement for the degree of Doctor in Philosophy

Göttingen, 14 January 2014 
Betreuungsausschuss

Erstbetreuer $\quad$ : Prof. Dr. Olaf Korn

Weitere Betreuer : Prof. Dr. Jörg-Markus Hitz

Prof. Dr. Stefan Trück

Tag der mündlichen Prüfung : 19.02.2014 


\section{TABLE OF CONTENTS}

Table of Contents $\quad 2$

$\begin{array}{ll}\text { List of Figures } & 5\end{array}$

List of Tables

$\begin{array}{ll}\text { Abstract } & 8\end{array}$

1. Introduction 9

1.1. Motivation 9

1.2. Research Objectives and Contributions to the Literature 10

1.3. Summary of the Chapters 11

1.4. List of Academic Presentations $\quad 15$

1.5. Contributing Authors for Each Chapter 16

$\begin{array}{ll}\text { 1.6. Thesis Structure } & 17\end{array}$

2. Risk Premiums in Interconnected Australian Electricity Futures Markets 21

Rangga Handika and Stefan Trück

2.1. Introduction 22

2.2. The Australian Electricity Market 25

2.3. Modelling Framework 26

2.4. Empirical Analysis 32

2.4.1. The Data 32

2.4.2. Realized Risk Premiums in the Futures Market 36

2.4.3. Explaining the Futures Risk Premium 44

2.5. Summary and Conclusions $\quad 50$

3. The Dynamics of Risk Premiums in Australian Electricity Markets 56 Rangga Handika and Stefan Trück 
3.2. The Australian Electricity Market 59

3.3. Ex-Post Risk Premiums in Electricity Markets 61

3.4. Descriptive Analysis of Risk Premiums 63

3.4.1. The Data 63

3.4.2. Risk Premiums $\quad 64$

3.5. Determinants of Realized Futures Premiums 73

3.6. Summary and Conclusions $\quad 80$

4. Modelling Price Spikes in Electricity Markets - the Impact of Load, Weather and $\begin{array}{ll}\text { Capacity } & 85\end{array}$

Rangga Handika, Chi Truong, Stefan Trück and Rafat Weron

4.1. Introduction $\quad 86$

4.2. The Australian National Electricity Market $\quad 89$

4.3. Explanatory Variables $\quad 91$

$\begin{array}{ll}\text { 4.4. Methodology } & 92\end{array}$

4.4.1. The Heckman Selection Model 93

4.4.2. The Lognormal and Box-Cox Transformation 94

4.4.3. Measures to Compare Forecast Accuracy 95

4.5. Empirical Results $\quad 96$

4.5.1. Data and Models $\quad 96$

4.5.2. Estimation Results 101

4.5.2.1. Heckman Selection Model with Log Transformation 101

4.5.2.2. Heckman Selection Model with Box Cox Transformation 102

4.5.2.3. OLS Model Estimated with All Electricity Prices 103

4.5.2.4. Standard OLS Results for Price Spike Sub-sample 105 


\section{Convenience Yield Risk Premiums}

Rangga Handika, Olaf Korn and Stefan Trück

5.1. Introduction

5.2. Extracting Convenience Yield Risk Premiums

5.3. Empirical Study

5.3.1. Data

5.3.2. Estimates of Risk Premiums

5.3.2.1. Base Case

5.3.2.2. Influence of Sub-periods

5.3.2.3. Influence of Maturity Choice

5.3.2.4. Influence of Interest Rate Risk

5.3.3. Benefits for Investors

5.3.3.1. Monetary Utility Gains 


\section{List of Figures}

\section{Risk Premiums in Interconnected Australian Electricity Futures Markets}

Fig. 1 Daily electricity spot prices for base and peak load periods from January 1, 2000 to June 30, 2012 for the NSW market.

Fig. 2 Distribution of realized risk premiums in the QLD and VIC markets for Q1 2003 Q2 2012 base load (left panel) and peak load (right panel) futures contracts based on the Epanechnikov Kernel density estimation.

Fig. 3 Realized risk premiums for NSW, QLD, SA and VIC base load contracts from Q1 2003 to Q2 2012.

Fig. 4 Realized risk premium for base load and peak load contracts averaged over all markets from Q1 2003 to Q2 2012.

\section{The Dynamics of Risk Premiums in Australian Electricity Markets}

Fig. 1 Average of realized futures premiums for Q1, Q2, Q3 and Q4 Futures Contracts in all regions at different time intervals (from 12 months up to 1 month prior to the beginning of the delivery period of the contract) for quarterly base load futures contracts.

Fig. 2 Average of realized futures premiums for Q1, Q2, Q3 and Q4 Futures Contracts in all regions at different time intervals (from 12 months up to 1 month prior to the beginning of the delivery period of the contract) for quarterly peak load futures contracts.

Modelling Price Spikes in Electricity Markets - the Impact of Load, Weather and Capacity

Fig. 1 Half-hourly electricity price $(\mathrm{A} \$ / \mathrm{MWh})$ for the QLD market during the considered time period April 1, 2002 - June 30, 2010

Fig. 2 Figure 2: Scatter plot for the relationship between the log transformation of observed price spikes (dependent variable) and the explanatory variables market load (upper left panel), relative air temperature (upper right panel), reserve margin (lower left panel, humidity (lower right panel) for QLD market. 


\section{List of Tables}

\section{Risk Premiums in Interconnected Australian Electricity Futures Markets}

Tab. 1 Descriptive statistics of daily base and peak load electricity spot prices from January 1, 2000 to June 30, 2012.

Tab. 2 Average quarterly spot prices for NSW, QLD, SA and VIC base and peak loads contracts from January 1, 2000 to June 30, 2012.

Tab. 3 Realized futures premiums for NSW, QLD, SA and VIC base load and peak load contracts for the time period Q1 2003 to Q4 2012.

Tab. 4 Estimated correlation between realized risk premiums for base load and peak load contracts in the NSW, QLD, SA and VIC markets.

Tab. 5 Realized futures risk premiums for each quarter in NSW, QLD, SA and VIC.

Tab. 6 Results of regression analysis (4) for realized futures risk premium of quarterly base load and peak load contracts in NSW, QLD, SA and VIC.

Tab. 7 Results for stepwise regression for realized futures risk premium of quarterly base load and peak load contracts in NSW, QLD, SA and VIC.

Tab. 8 Results for the applied seemingly unrelated regression (SUR) model for realized risk premium of quarterly base load and peak load contracts in NSW, QLD, SA and VIC.

Tab. 9 Residuals correlation matrix, LM test statistic and p-values of the test for contemporaneous correlation of error terms for NSW, QLD, SA, and VIC markets. 49

\section{The Dynamics of Risk Premiums in Australian Electricity Markets}

Tab. 1 Descriptive statistics of daily base and peak load electricity spot prices from January 1, 2005 to June 30, 2012 for different quarters and markets.

Tab. 2 Realized risk premiums, t-stats and p-values for significance of the premium for quarterly base load futures contracts with time to delivery ranging from approximately twelve months up to the last month before the beginning of the delivery period.

Tab. 3 Realized risk premiums, t-stats and p-values for significance of the premium for quarterly peak load futures contracts with time to delivery ranging from approximately twelve months up to the last month before the beginning of the delivery period.

Tab. 4 Results of regression analysis (4) for realized futures risk premium for each quarter during base load period in NSW, QLD, SA and VIC.

Tab. 5 Results of regression analysis (4) for realized futures risk premium for each quarter during peak load period in NSW, QLD, SA and VIC.

Modelling Price Spikes in Electricity Markets - the Impact of Load, Weather and Capacity

Tab. 1 Descriptive statistics of half-hourly electricity prices for NSW, QLD, SA, VIC for the period April 1, 2002 - June 30, 2010.

Tab. 2 Sample sizes (number of observations) details for each state.

Tab. 3 Estimation results for Heckman selection method for the log transformation of spot electricity prices. 
Tab. 4 Optimal Box-Cox parameter estimates for each state based on Maximum-Likelihood estimation (Davidson and MacKinnon, 1993). 103

Tab. 5 Estimation results for Heckman selection method for the Box-Cox transformation of spot electricity prices.

Tab. 6 Estimation results using OLS for the entire sample of electricity spot prices from April 1, 2002 to June 30, 2010.

Tab. 7 Estimation results using OLS for the sub-sample of price spikes, i.e. prices greater than $\mathrm{A} \$ 300 / \mathrm{MWh}$ only.

Tab. 8 MAE, MAPE and log likelihood of the estimated models for the OLS using the entire sample, OLS applied to price spikes only and the Heckman selection model.

\section{Convenience Yield Risk Premiums}

Tab. 1 Sample periods and descriptive statistics of monthly spot returns for the considered commodities.

Tab. 2 Estimates for convenience yield risk premiums based on monthly returns obtained from the constructed futures portfolios for different groups of commodities: metals (gold, silver and copper), grains (corn, soybeans and wheat) and energy (oil and gas).

Tab. 3 Estimates of convenience yield risk premiums for metals (gold, silver and copper), grains (corn, soybeans and wheat), energy (oil and gas) for different sub-periods. 125

Tab. 4 Estimates of convenience yield risk premiums for metals (gold, silver and copper), grains (corn, soybeans and wheat), energy (oil and gas) for alternative contract choice.

Tab. 5 Impact of interest rate risk on estimates for convenience yield risk premiums. 131

Tab. 6 Annualized monetary utility gains (MUGs) of the created convenience yield sensitive portfolios for each of the commodities.

Tab. 7 Correlations between returns from the created convenience yield sensitive portfolios across different classes of commodities and against returns of the spot factor for the same commodity. 


\begin{abstract}
This $\mathrm{PhD}$ thesis investigates risks and risk premiums in commodities markets. Two chapters discuss the risks premium in interconnected electricity markets. One chapter develops a model for price spikes, and the risks of extreme outcomes for spot electricity prices. The last chapter investigates convenience yield risk premiums in various commodity markets. The research follows the thesis by publication format and has four completed research papers.

The first paper provides an empirical analysis of the relationship between spot and futures prices in interconnected regional Australian electricity markets. We find positive and significant risk premiums for several of the considered regions. Using a general equilibrium model and applying a seemingly unrelated regression (SUR) approach, we also find that price levels, as well as skewness and kurtosis of spot prices are determinants of the realized risk premiums in these markets.

The second paper investigates the dynamics of futures premiums in Australian electricity markets. We examine how premiums behave depending on the time-to-delivery of the considered contracts as well as for different delivery periods. We find that futures premiums tend to increase when: (i) the time is closer to maturity of the contract, (ii) spot price is high, and (iii) the number of price spikes increases.

The third paper examines the impact of explanatory variables such as load, weather and capacity constraints, on the occurrence and magnitude of price spikes in Australian electricity markets. Applying the Heckman correction model, we find that the market load, relative air temperature and reserve margins are significant variables for the occurrence of price spikes. Electricity loads and relative air temperature are also significant variables impacting on the magnitude of a price spike. The Heckman selection model also outperforms a standard OLS regression approach.

The fourth paper presents a comprehensive examination of convenience yield risk premiums in various commodity markets. Constructing a security that is only sensitive to convenience yield risk, we find that convenience yield risk premiums are positive and, that risk premiums are very large for metals and grains while there are no significant convenience yield risk premiums for oil and gas.
\end{abstract}




\section{INTRODUCTION}

\subsection{Motivation}

The financial and economic analysis of commodity markets has become an increasingly important issue in recent years. For example, Daskalaki and Skiadopoulos (2011) quote a \$ 9 billion increase in commodity investments during the three year period from 2006 to 2009 . Other studies (Casassus and Dufresne, 2005; Basu and Miffre, 2013; Narayan et al., 2013), document a tremendous growth in commodity and commodity derivative markets over the last decades. Therefore, we can conclude that commodity markets have become an essential component of the literature on financial economics.

Furthermore, commodity derivative markets also play an important role in investments. For instance, commodity futures are effective hedging instruments against inflation, sophisticated portfolio diversifiers, relatively liquid and cheap to trade (Miffre and Rallis, 2007). Bailey and $\mathrm{Ng}$ (1991) argue that organized commodity markets can provide traders with an efficient medium for executing their hedging and speculative strategies. A recent paper by Narayan et al. (2013) notes two important functions of commodity futures markets: (i) facilitating the transfer of commodity price risks, and (ii) forecasting the spot price.

In short, the growth and role of commodity markets are essential in today's financial markets. This implies that advanced studies about risks and risk premiums in commodity markets will provide an important contribution to modern finance literature. Moreover, these studies will also provide practical insight into the application of investments analysis and risk management.

The thesis discusses risks and risk premiums in commodity markets in three research areas:

(i) Risk premiums in electricity markets. Electricity is a very unique commodity because of its non-storability (first and second paper).

(ii) Modelling price spikes, one of the key risk factor in spot electricity markets (third paper).

(iii) Convenience yield risk premiums, and a detailed analysis of convenience yield risk premiums in various commodity markets (not merely the convenience yield level) (fourth paper). 


\subsection{Research Objectives and Contributions to the Literature}

The first paper studies risk premiums in interconnected Australian electricity markets. It fills a gap in the literature on Australian electricity markets, as the relationship between electricity spot and futures markets has not yet been thoroughly analysed. There are studies on Australian electricity markets (like Worthington et al., 2005; Higgs and Worthington, 2008; Becker et al., 2007; Higgs, 2009; Thomas et al, 2011). However, these studies are limited to the behaviour of electricity spot prices. Considering that seasonality is one of the key characteristics of electricity spot and futures prices, we also include the quarterly analysis of risk premiums. The application of the seemingly unrelated regression (SUR) method to investigate risk premiums in electricity futures prices, is also a new contribution to the literature. So far, existing studies, for example, Bessembinder and Lemmon (2002), Redl et al. (2009), usually examine the observed premiums for each market separately. The results of this paper trigger the idea of a dynamic analysis of premiums, which is the main topic of Chapter 3.

The second paper investigates the dynamics of risk premiums in interconnected Australian electricity markets. Additionally, it provides a new contribution, as existing studies of electricity risk premiums are static rather than dynamic. Furthermore, the paper fills a gap by analyzing determinants of electricity risk premiums at different time-to-maturity levels of futures contracts; an area not previously researched. We find that one of the key determinants of realized risk premiums in these markets is the occurrence of price spikes. This leads us to a deeper investigation of the determinants of the occurrence and magnitude of price spikes, which is the central theme of the Chapter 4.

The third paper examines the impact of explanatory variables such as load, weather and capacity constraints, on both the occurrence and magnitude of price spikes in regional Australian electricity markets. The most novel contribution of this paper is the application of the Heckman correction model, a two-stage estimation procedure that allows us to investigate the impact of the considered variables on extreme price observations only, while correcting for a selection bias due to non-random sampling in the analysis. So far no study on modelling price spikes in electricity markets has particularly focused on the selection bias, when dealing with extreme observations only. We find that the developed model tends to outperform a standard OLS models with respect to explaining and forecasting the magnitude of electricity price spikes. 
The first three papers discuss risks and risk premium in electricity markets, with electricity being a unique commodity due to its non-storability. Another important issue in commodity markets is the existence of convenience yields. The convenience yield is considered to be one of the most important features in commodity derivatives markets, and may well be a key risk factor for the pricing of commodity derivatives. Therefore, Chapter 5 of the thesis develops a model and thoroughly investigates the existence and determinants of convenience yield risk premiums. Existing studies in commodity markets usually examine convenience yields, while knowledge on convenience yield risk premiums is limited. The fourth paper of this thesis fills this gap by investigating convenience yield risk premiums in various commodity markets. We construct a portfolio that is sensitive only to convenience yield risk, to empirically extract the convenience yield risk premium. This direct method (based on two-factor and three-factor pricing models), and the positive convenience yield risk-premiums hypothesis are a novel contribution to the literature on commodity markets. Indeed, a better understanding of the convenience yield risk premium is of central importance for risk management, and for hedging decisions of companies, as well as for investment decisions of financial institutions.

\subsection{Summary of the Chapters}

Chapter 2 provides the first paper of the thesis titled 'Risk Premiums in Interconnected Australian Electricity Futures Markets'. Electricity, as a flow commodity, exhibits price behaviour that is almost unique in financial markets. Indeed, electricity is strongly characterised by its very limited transportability and storability (Lucia and Schwartz, 2002). Therefore, market participants are required to hedge these risks at least partially by entering forward and futures contracts for electricity because of the extremely volatile behaviour of electricity spot prices. The non-storability of electricity limits the standard no-arbitrage approach in modelling futures prices (Bessembinder and Lemon, 2002; Longstaff and Wang, 2004). We present a pioneering study examining the relationship between spot and futures prices in regional electricity markets in Australia. To the best of our knowledge this is also the first study to investigate the dependence between risk premiums in interconnected electricity markets. The National Electricity Market (NEM) began operating as a wholesale market in Australia in December 1998. The NEM includes the states of New South Wales (NSW), Queensland (QLD), South Australia (SA), Victoria (VIC) and Tasmania (TAS). 
Existing studies on the Australian NEM discuss the costs of supplying electricity (Bateson and Swan, 1989; Swan, 1990), the effects of profit regulation (Kim, 1997), the timing of the uptake of various electricity generation technologies under a carbon tax scheme (Reedman et al., 2006) or modelling the behaviour of electricity spot prices (Worthington et al., 2005; Higgs and Worthington, 2008; Becker et al., 2007; Higgs, 2009; Thomas et al, 2011). The relationship between spot and futures prices across different regional Australian markets has not yet been investigated. We argue that an analysis of these markets is essential because Australian electricity markets are significantly more volatile and spike-prone than other comparable markets (Higgs and Worthington, 2008). Furthermore, the Australian NEM operates on one of the world's longest interconnected power systems, comprising several regional networks supplying electricity to retailers and end-users. Therefore, the analysis of the relationship between spot and futures prices will provide some important insights into risk premiums and risk aversion of market participants in these extremely volatile markets. First, we investigate the magnitude of futures risk premiums at different time instances. Then, we examine the correlation between realized futures risk premiums observed across different regional electricity markets. We also investigate whether the bias, i.e. the difference between quoted futures prices and realized spot electricity prices, can be explained by the behaviour of spot prices during the month or quarter previous to the delivery period. We apply an extended version of the model initially suggested by Bessembinder and Lemmon (2002). We also apply a seemingly unrelated regression (SUR) model to investigate the determinants of observed futures risk premiums in interconnected Australian electricity markets.

Chapter 3 than takes a different angle and examines 'The Dynamics of Risk Premiums in Australian Electricity Markets'. There is considerable controversy about the existence of futures premiums in commodity markets (So, 1987; Deaves and Krinsky, 1995). Some studies report positive premiums, while others find negative risk premiums in electricity markets. For instance, positive risks premiums were identified in Pennsylvania, New Jersey, Maryland (PJM) (Longstaff and Wang, 2004) and in the European Energy Exchange (EEX) market (Redl et al., 2009). In contrast, other studies report negative premiums for the PJM (Bessembinder and Lemmon, 2002) and the Scandinavian Nord Pool market (Botterud et al., 2010). However, none of these studies discusses the dynamics of the premiums through time and with respect to the time-to-delivery of the contracts examined. The studies usually merely focus on investigating the existence of electricity premiums. Recent research by Hadsell and Shawky (2007), Haugom and Ullrich (2012), Pietz (2009) also investigates the dynamics of 
electricity futures premiums. Hadsell and Shawky (2007) report that electricity premiums are time-varying, and may depend on differences in spot price and volatility level across zones. Haugom and Ullrich (2012) focus on the dynamic modelling of short term electricity premiums by using recursive estimation and rolling windows. Pietz (2009) examines the dynamics of electricity premiums by detecting a term structure of risk premium in the German EEX market. Our work differs from Pietz (2009) in several aspects: we examine risk premiums for different regional markets and, taking into account strong seasonal effects for contracts referring to different delivery quarters. We further try to explain the dynamics of the observed risk premiums using a model with various explanatory variables, including the time-to-delivery of the futures contracts as well as characteristics of electricity spot prices such as price levels, volatility, realized skewness and kurtosis. The paper investigates the dynamics of risk premiums in electricity markets across four states in Australia. Our study focuses on the ex-post futures premium, the excess of the futures price over the realised spot price, see e.g. Redl et al. (2009). First, we examine the magnitude of futures risk premiums at different time instances. Then, we investigate the determinants of those dynamic risks premiums. According to Huisman and Kilic (2012), we cannot rely on one model for all electricity markets. We argue that time to maturity of the contract (Bailey and $\mathrm{Ng}, 1991$; Bessembinder and Chan, 1992; Wilkens and Wimschulte, 2007; Bhar and Lee, 2011; Gorton et al., 2012), spot price levels (Raynauld and Tessier, 1984; Wilkens and Wimschulte, 2007; Chevillon and Riffalrt, 2009), volatility in the spot market (Kho, 1996; Todorov, 2010; Benth et al., 2013) and the occurrence of price spikes (Coulon et al., 2013) are among the key determinants of dynamic futures premiums in electricity markets. Therefore, this paper contributes to the literature on commodity markets by capturing and modelling the dynamics of electricity futures premiums. It provides insights to manage the dynamic, rather than static, risks in electricity markets.

Chapter 4 is titled 'Modelling Price Spikes in Electricity Markets - the Impact of Load, Weather and Capacity' and discuss a new method of modelling price spikes. Indeed, there are a number of studies investigating factors that contribute to the large variation of electricity prices in general, and the occurrence of price spikes in particular. Shawky et al. (2003) suggest that the large variation of electricity market prices is a result of inelastic demand, seasonal effects, and the non-storability of electricity. Another study by Mount et al. (2006) analyses electricity suppliers' bidding data. They find that the electricity supply curve exhibits a hockey stick shape; elastic when demand is lower than a certain threshold, but 
virtually inelastic in supply when demand is higher than a threshold level, leading to price spikes. Kanamura and Ohashi (2008) model electricity supply using a linear function for the normal regime and another linear function for the spike regime. Their model is based on the distinct characteristics of electricity in two different regimes. Many other studies, including e.g. Huisman (2009), Janczura and Weron (2010) document that spot prices behave quite differently in a more volatile spike regime in comparison to a normal price regime. Therefore, we argue that a model that attaches all weight to spike observations and zero weight to nonspike observations may perform better in modelling and explaining price spikes. We propose the use of a Heckman selection model to examine factors impacting on the occurrence and magnitude of price spikes. Note that a recent paper by Dahen and Dione, (2010) presents a similar method for modelling losses arising from operational risk. Using spike observations only causes a selection bias, as the sample is no longer randomly selected. Therefore, in the Heckman selection model, a two-stage estimation procedure is used to correct for this bias, see e.g., Hill et al. (2008), or, Greene (2008), for further details. In a first step, this paper presents a probit model that determines the probability of the occurrence of a price spike. In this step, the model also calculates the so-called inverse Mills ratio that, in a second step, is then incorporated into the estimation process for the magnitude of a price spike. Our proposed model contributes to the finance literature by developing a new method of modelling price spikes that is useful for forecasting and managing price risks in spot electricity markets.

Finally, Chapter 5 provides the last paper in the thesis titled 'Convenience Yield Risk Premiums'. This paper investigates convenience yield risk premiums in various commodity markets. The convenience yield can be considered as one of the most important features in commodity derivatives markets and may well be one of the key risk factors that impact on the pricing of such contracts. While there is an extensive body of literature examining convenience yields in commodity markets, existing research provides only limited knowledge about the convenience yield risk premium. However, a better understanding of this risk premium may well be of central importance for risk management and hedging decisions of companies, as well as for investment decisions of financial institutions. To the best of our knowledge, this is the first study to examine convenience yield risk premiums in various commodity markets, directly and in detail. Our study may affect recent practices in trading strategies, asset management and risk management. A lot of work has been done on investigating the nature and determinants of convenience yields in commodity markets, 
initiated by the work of Kaldor (1939) and Working (1949). Important studies in this area include Brennan (1991), Routledge, Seppi, and Spatt (2000), Casassus et al. (2005), or Bollinger and Kind (2010). There are also studies which develop and test commodity derivatives pricing models, see e.g., Gibson and Schwartz (1990), Schwartz (1997), Casassus and Collin-Dufresne (2005), Casassus et al. (2012), estimating a market price of convenience yield risk. However, these estimates are notoriously imprecise. In contrast, we follow a more direct approach based on such models, and hope to improve knowledge that is useful for pricing models. Our approach is also motivated by the literature on the variance risk premium. In this literature, studies exist which test stochastic volatility models and estimate a market price of variance risk (analogous to the commodity derivatives literature). However, much progress has been made by more direct approaches to investigate the variance risk premium, see e.g., Coval and Shumway (2001), Bakshi and Kapadia (2003) or Carr and Wu (2009). The idea of these studies is to find portfolios which are sensitive only to the specific risk factor (stochastic variance or volatility) and to analyze the performance of these portfolios. Our project consists of an analogous investigation for the stochastic convenience yield, that is, for portfolios which are sensitive to convenience yield risk only. We provide important insights on the existence and determinants of a convenience yield risk premium that has not been analysed yet in the literature on commodity markets.

\subsection{List of Academic Presentations}

Chapter 2 contains the first paper titled 'Risk Premiums in Interconnected Australian Electricity Futures Markets'. This paper was presented at:

- The $30^{\text {th }}$ USAEE/IAEE North American Conference, October 2011

- The MQ University FBE HDR Expo 2011, November 2011

- Quantitative Methods in Finance Conference (QMF), UTS, December 2011

- The $3^{\text {rd }}$ IAEE Asian Conference, Kyoto, Japan, February 2012

- The $19^{\text {th }}$ Multinational Finance Society (MFS), Krakow, Poland, June 2012, and

- The International Finance and Banking (FIBA) Conference, Bucharest, Romania, March 2013.

This paper is currently under review with Energy Economics journal and received an overall 'Major Revision' evaluation. We have revised and resubmitted the manuscript. 
Chapter 3 is the second paper titled 'The Dynamics of Risk Premiums in Australian Electricity Markets'. The paper has also been presented at invited seminars at the following institutions:

- The Wroclaw Institute of Technology, June 2011

- Applicable Semiparametrics Conference, Berlin, October 2013

- IBS Hyderabad, India, November 2013

- The $4^{\text {th }}$ Annual Conference of Economic Forum of Entrepreneurship and International Business, Paris, January 2014.

Chapter 4 is the third paper titled 'Modelling Price Spikes in Electricity Markets - the Impact of Load, Weather and Capacity'. This paper was presented at:

- The Wroclaw Institute of Technology, June 2012

- The AFAS-CFR PhD Workshop MQ Sydney Australia, October 2012 (best presenter)

- The MQ University FBE HDR Expo 2012, November 2012.

Chapter 5 is the fourth paper titled 'Convenience Yield Risk Premiums'. The paper has been presented a he following conferences and invited seminars:

- The Energy Finance Christmas Workshop, Sydney, Australia, December 2012

- The $51^{\text {st }}$ Meeting of the EWGFM and the $1^{\text {st }}$ Conference of the RCEM, London, UK, May 2013

- The Faculty Research Seminar, Goettingen, Germany, June 2013

- The MQ University FBE HDR Expo 2013, November 2013

- Energy Finance Conference, Essen, Germany, October 2013, and

- The Zeppelin University Friedrichschafen, Germany, February 2014.

Chapter 6 concludes the entire $\mathrm{PhD}$ thesis research.

\subsection{Contributing Authors for Each Chapter}

This section specifies the contributing authors for each chapter. The authors of Chapter 2 are Rangga Handika (contribution: 70\%) and Stefan Trück (contribution: 30\%). The authors of Chapter 3 are Rangga Handika (contribution: 80\%) and Stefan Trück (contribution: 20\%). The authors of Chapter 4 are Rangga Handika (contribution: 70\%), Chi Truong (contribution: 10\%), Stefan Trück (contribution: 10\%) and Rafal Weron 
(contribution: 10\%). The authors of Chapter 5 are Rangga Handika (contribution: 60\%), Olaf Korn (contribution: 30\%) and Stefan Trück (contribution: 10\%).

\subsection{Thesis Structure}

This thesis consists of six chapters. Chapters 2, 3, and 4 present three empirical essays investigating Australian electricity markets. Chapter 2 examines the relationship between spot and futures prices. Chapter 3 discusses and models the dynamics of electricity futures premiums. Chapter 4 proposes a new method of modelling price spikes. Then, Chapter 5 investigates convenience yield risk premiums in various commodity markets. Chapter 6 concludes the thesis with summary and implications of theory and practice in commodity markets. 


\section{Bibliography}

Archaya, VV, Lochstoer, LA \& Ramadorai, T 2013, 'Limits to Arbitrage and Hedging: Evidence from Commodity Markets', Journal of Financial Economics, no. 109, pp. 441 -465 .

Bailey, W \& Ng, E 1991, 'Default Premiums in Commodity Markets: Theory and Evidence', The Journal of Finance, vol. 46 no. 3, pp. $1071-1093$.

Bakshi, G \& Kapadia, N 2003, 'Delta-Hedged Gains and the Negative Market Volatility Risk Premium', The Review of Financial Studies, vol. 16 no. 2, pp. $527-566$.

Basu, D \& Miffre, J 2013, 'Capturing the Risk Premium of Commodity Futures: The Role of Hedging Pressure', Journal of Banking and Finance, no. 37, pp. 2652 - 2664.

Bateson, J \& Swan, PL 1989, 'Economies of Scale and Utilization: An Analysis of the MultiPlant Generation Costs of the Electricity Commission of New South Wales', The Economic Record, vol. 65, pp. $329-344$.

Becker, R, Hurn, S \& Pavlov, V 2007, 'Modelling Spikes in Electricity Prices', The Economic Record, vol. 83 no. 263, pp. 371-382.

Benth, FE, König, RB \& Kiesel, R 2013, 'An Empirical Study of the Information Premium on Electricity Markets', Energy Economics, no. 36, pp. 55 - 77.

Bessembinder, H \& Chan, K 1992, 'Time Varying Risk Premia and Forecastable Returns in Futures Markets', Journal of Financial Economics, no. 32, pp. 169 - 193.

Bessembinder, H \& Lemmon, ML 2002, 'Equilibrium Pricing and Optimal Hedging in Electricity Forward Markets', The Journal of Finance, vol. 57 no. 3, pp. 1347 - 1381.

Bhar, D \& Lee, D 2011, 'Time-Varying Market Price of Risk in the Crude Oil Futures Market', The Journal of Futures Markets, vol. 31 no. 8, pp. $779-807$.

Botterud, A, Kristiansen, T \& Ilic, M 2010, 'The Relationship between Spot and Futures Prices in the Nord Pool Electricity Market', Energy Economics, no. 32, pp. 967 - 978.

Brennan, MJ 1991, 'The Price of Convenience and the Valuation of Commodity Contingent Claims', in the Stochastic Models and Option Values, D. Lund and B. Oksendal (eds.) (North-Holland).

Carr, P \& Wu, L 2009, 'Variance Risk Premiums', The Review of Financial Studies, vol. 22 no. 3, pp. $1311-1341$.

Casassus, J \& Dufrense, PC 2005, 'Stochastic Convenience Yield Implied from Commodity Futures and Interest Rates', The Journal of Finance, vol. 60 no. 5, pp. 2283 - 2331.

Casassus, J, Dufresne, PC \& Routledge, BR 2005, 'Equilibrium Commodity Prices with Irreversible Investment and Non-linear Technology', Working Paper 11864 National Bureau of Economic Research.

Casassus, J, Liu, P and Tang, K 2012, 'Maximal Affine Models for Multiple Commodities: A Note', Discussion Paper, Ponticia Universidad Catolica de Chile.

Chevillon, G \& Rifflart, C 2009, 'Physical Market Determinants of the Price of Crude Oil and the Market Premium', Energy Economics, no. 31, pp. 537 - 549.

Coulon, M, Powell, WB \& Sircar R 2013, 'A Model for Hedging Load and Price Risk in the Texas Electricity Market', Energy Economics, http://dx.doi.org/10.1016/j.eneco.2013.05.020

Coval, JD \& Shumway, T 2001. 'Expected Option Returns', The Journal of Finance, vol. 56 no. 3, pp. $983-1009$.

Dahen, H \& Dione, G 2010, 'Scaling Models for the Severity and Frequency of External Operational Loss Data', The Journal of Banking \& Finance, no. 34, pp. 1484 - 1496. 
Daskalaki, C \& Skiadopoulos, J 2011, 'Should Investors Include Commodities in their Portfolios after All? New Evidence', Journal of Banking and Finance, no. 35, pp. 2606 $-2626$.

Deaves, R \& Krinsky, I 1995, 'Do Futures Prices for Commodities Embody Risks Premiums', The Journal of Futures Markets, vol. 15 no. 6, pp. $637-648$.

Dewally, M, Ederington, LH \& Fernando, CS 2013, 'Determinants of Trader Profits in Commodity Futures Markets', Review of Financial Studies, RFS Advance Access.

Doran, JS \& Ronn, EI 2008, 'Computing the Market Price of Volatility Risk in the Energy Commodity Markets', Journal of Banking and Finance, no. 32, pp. 2541 - 2552.

Gibson, R \& Schwartz, ES 1990, 'Stochastic Convenience Yield and The Pricing of Oil Contingent Claims', The Journal of Finance, vol. 45 no. 3, pp. 959 - 976.

Gorton, GB, Hayashi, F \& Rouwenhorst, KG 2012, 'The Fundamentals of Commodity Futures Returns', Review of Finance, no. 17, pp. 35 - 105.

Grauer, FLA \& Litzenberger, RH 1979, 'The Pricing of Commodity Futures Contracts, Nominal Bonds and Other Risky Assets under Commodity Price Uncertainty', The Journal of Finance, vol. 34 no. 1, pp. $69-83$.

Greene, WH 2011, Econometric Analysis $7^{\text {th }}$ Edition, Pearson Prentice Hall, USA.

Hadsell, L \& Shawky, HA 2006, 'Electricity Price Volatility and the Marginal Cost of Congestion: An Empirical Study of Peak Hours in the NYISO Market 2001-2004', The Energy Journal, vol. 27 no. 2, pp. $157-179$.

Hadsell, L \& Shawky, HA 2007, 'One-Day Forward Premiums and the Impact of Virtual Bidding on the New York Wholesale Electricity Market Using Hourly Data', The Journal of Futures Markets, vol. 27 no. 11, pp. 1107 - 1125.

Haff, IH, Lindqvist, O \& Lǿland, A 2008, 'Risk Premium in the UK Natural Gas Forward Market', Energy Economics, no. 30, pp. 2420 - 2440.

Haugom, E \& Ullrich, CJ 2012, 'Market Efficiency and Risk Premia in Short-Term Forward Prices', Energy Economics, no. 34, pp. 1931 - 1941.

Higgs, H 2009, 'Modeling Price and Volatility Inter-Relationship in the Australia Wholesale Spot Electricity Markets', Energy Economics, no. 31, pp. 748 - 756.

Higgs, H \& Worthington, A 2008, 'Stochastic Prices Modeling of High Volatility, Mean Reverting, Spike-Prone Commodities: The Australia Wholesale Spot Electricity Market', Energy Economics, no. 30, pp. 3172 - 3185.

Hill, RC, Griffiths, WE \& Lim, GC 2011, Principles of Econometrics $4^{\text {th }}$ Edition, John Wiley \& Sons Inc., New Jersey USA.

Hirshleifer, D 1989, 'Determinants of Hedging and Risk Premia in Commodity Futures Markets', Journal of Financial and Quantitative Analysis, vol. 24 no. 3, pp. 313 - 331.

Huisman, R, 2009, An Introduction to Models for the Energy Markets. Risk Books.

Huisman, R \& Kilic, M 2012, 'Electricity Futures Prices: Indirect Storability, Expectations, and Risk Premiums', Energy Economics, no. 34, pp. 892 - 898.

Janczura, J, \& Weron, R 2010, 'An Empirical Comparison of Alternate Regime-Switching Models for Electricity Spot Prices', Energy Economics, no. 32, pp. 1059 - 1073.

Kaldor, N 1939, 'Speculation and Economic Stability', The Review Of Economic Studies, vol. 7 no. 1 , pp. $1-27$.

Kanamura, T \& Ohashi, K 2008, 'On Transition Probabilities of Regime Switching in Electricity Prices', Energy Economics, no. 30, pp. 1158 - 1172.

Kho, BC 1996, 'Time-varying Risk Premia, Volatility, and Technical Trading Rule Profits: Evidence from Foreign Currency Futures Markets', Journal of Financial Economics, no. 41 , pp. $249-290$. 
Kim, PR 1997, 'The Effect of Profit Regulations on Combined Two-Part and Peak-Load Pricing', The Economic Record, vol. 73, pp. $238-247$.

Longstaff, FA \& Wang, AW 2004, 'Electricity Forward Prices: A High Frequency Empirical Analysis', The Journal of Finance, vol. 59 no. 4, pp. 1877 - 1900.

Lucia, JJ \& Schwartz, ES 2002, 'Electricity Prices and Power Derivatives: Evidence from the Nordic Power Exchange', Review of Derivatives Research, no. 5, pp. 5 - 50.

Miffre, J \& Rallis, G 2007, 'Momentum Strategies in Commodity Futures Markets', Journal of Banking and Finance, no. 31, pp. $1863-1886$.

Mount, TD, Ning, Y \& Cai, X 2006, 'Predicting Price Spikes in Electricity Markets Using a Regime-Switching Model with Time-Varying Parameteres', Energy Economics, no. 28, pp. $62-80$.

Narayan, PK, Narayan, S \& Sharma, SS 2013, 'An Analysis of Commodity Markets: What Gain for Investors?', Journal of Banking and Finance, no. 37, pp. 3878 - 3889.

Pietz, M 2009, 'Risk Premia in the German Electricity Futures Market', Working Paper Series CEFS.

Raynauld, J \& Tessier, J 1984, 'Risk Premiums in Futures Markets: An Empirical Investigation', The Journal of Futures Markets, vol. 4 no. 2, pp. $189-211$.

Redl, C, Haas, R, Huber, C \& Böhm, B 2009, 'Price Formation in Electricity Forward Markets and the Relevance of Systematic Forecast Errors', Energy Economics, no. 31, pp. $356-364$.

Reedman, L, Graham, P \& Coombes, P 2006, 'Using a Real-Options Approach to Model Technology Adoption Under Carbon Price Uncertainty: An Application to the Australian Electricity Generation Sector', The Economic Record, vol. 82, pp. $64-73$.

Schwartz, ES 1997, 'The Stochastic Behavior of Commodity Prices: Implications for Valuation and Hedging', The Journal of Finance, vol. 52 no. 3, pp. 923 - 973.

Shawky, AH, Marathe, A \& Barrett, CL 2003, 'A First Look at the Empirical Relation between Spot and Futures Electricity Prices in the Unites States', The Journal of Futures Markets, vol. 23 no. 10, pp. 931 - 955.

So, JC 1987, 'Commodity Futures Risk Premium and Unstable Systematic Risk', The Journal of Futures Markets, vol. 7 no. 3, pp. 311 - 326.

Swan, PL 1990, 'Real Rates of Return in Electricity Supply: New South Wales, Tasmania and Victoria', The Economic Record, vol. 66, pp. 93 - 109.

Thomas, S, Ramiah, V, Mitchell, H \& Heaney, R 2011, 'Seasonal Factors and Outlier Effects in Returns on Electricity Spot Prices in Australia's National Electricity Market', Applied Economics, vol. 43 no. 3, pp. 355 - 369.

Todorov, V 2010, 'Variance Risk-Premium Dynamics: The Role of Jumps', Review of Financial Studies, vol. 23 no. 1, pp. $345-383$.

Wilkens, S \& Wimschulte, J 2007, 'The Pricing of Electricity Futures: Evidence from the European Exchange', The Journal of Futures Markets, vol. 27 no. 4, pp. 387 - 410.

Wilks, DS 1997. 'Resampling Hypothesis Tests for Autocorrelated Fields', Journal of Climate, vol. 10, pp. 65 - 82.

Working, H 1949, 'The Theory of Price of Storage', The American Economic Review, vol. 39 no. 6 , pp. $1254-1262$.

Worthington, A, Kay-Spratley, A \& Higgs, H 2005, 'Transmission of Prices and Price Volatility in Australian Electricity Markets', Energy Economics, no. 27, pp. 337 - 350. 


\title{
2. Risk Premiums in Interconnected Australian Electricity Futures Markets
}

\begin{abstract}
We provide an empirical analysis of the relationship between spot and futures prices in interconnected regional Australian electricity markets. Examining ex-post risk premiums in futures markets, we find positive and significant risk premiums for several of the considered regions. Therefore, electricity futures prices cannot be considered as an unbiased estimator of the average realized spot price during the delivery period. Market participants are willing to pay a significant additional compensation to hedge their exposure to price shocks and spikes in the spot market. We further demonstrate seasonal effects in the observed premiums as well as strong and positive correlations between the risk premiums across the considered markets. Overall, the observed premiums indicate risk aversion of market participants, in particular for the Queensland and Victoria electricity market. We also relate realized premiums to variables such as spot price levels, volatility, skewness and kurtosis prior to the delivery period. Due to the high correlation of the observed premiums across the regions, we apply a seemingly unrelated regression (SUR) approach. We find that in particular spot price levels, but also skewness and kurtosis of spot prices contribute significantly to the explanation of the realized risk premiums.
\end{abstract}




\subsection{Introduction}

The deregulation of electricity markets worldwide has led to a significant change in market structure from monopolies to liberalized markets. With the introduction of power exchanges, as pointed out by Shawky et al. (2003), the behaviour of electricity market prices now tends to be much more affected by the nature of electricity production and consumption: inelastic demand, seasonal effects, and the non-storability of electricity. Consequently, electricity as a flow commodity exhibits price behaviour that is almost unique in financial markets. Electricity spot prices can be characterized by mean-reversion, seasonality, extreme volatility and brief but quite pronounced price spikes, see e.g. Lucia and Schwartz (2002), Burger et al. (2004), Weron (2006), Bierbrauer et al. (2007), Huisman et al. (2007), Kanamura and Ohashi (2008), Karakatsani and Bunn (2008). Lucia and Schwartz (2002) suggest that electricity is strongly characterised by its very limited transportability and storability. Given the extremely volatile behaviour of electricity spot prices, market participants are required to hedge these risks at least partially by entering forward and futures contracts for electricity. Early studies on electricity forward markets (Bessembinder and Lemon, 2002; Longstaff and Wang, 2004) point out that the non-storability of electricity limits the standard no-arbitrage approach in modelling futures prices: inventories cannot be used to smooth out electricity supply and demand shocks (Bowden and Payne, 2008). Therefore the dynamic relationship between electricity spot and futures prices reflects expectations about the future supply and demand characteristics of electricity as well as risk aversion amongst agents, with heterogeneous requirements for hedging the uncertainty of future spot prices (Shawky et al., 2003).

This paper presents a pioneering study examining the relationship between spot and futures prices in regional electricity markets in Australia. To the best of our knowledge this is also the first study to investigate the dependence between risk premiums in interconnected electricity markets. The National Electricity Market (NEM) began operating as a wholesale market in Australia in December 1998. The NEM includes the states of New South Wales (NSW), Queensland (QLD), South Australia (SA), Victoria (VIC) and Tasmania (TAS). Tasmania joined the NEM in 2005 and is connected to the other NEM regions via an undersea inter-connector to VIC. Existing studies on the Australian NEM include Bateson and Swan (1989), Swan (1990), Kim (1997), Worthington et al. (2005), Reedman et al. (2006), Higgs and Worthington (2008), Becker et al. (2007), Higgs (2009), and Thomas et al. 
(2011). However these authors focus on the costs of supplying electricity (Bateson and Swan, 1989; Swan, 1990), the effects of profit regulation (Kim, 1997), the timing of the uptake of various electricity generation technologies under a carbon tax scheme (Reedman et al., 2006) or modelling the behaviour of electricity spot prices (Worthington et al., 2005; Higgs and Worthington, 2008; Becker et al., 2007; Higgs, 2009; Thomas et al, 2011). The relationship between spot and futures prices across different regional Australian markets has not yet been investigated. Analysis of these markets is of particular interest for a number of reasons: first, as pointed out by Higgs and Worthington (2008), Australian electricity markets are significantly more volatile and spike-prone than other comparable markets. Second, the Australian NEM operates on one of the world's longest interconnected power systems comprising several regional networks supplying electricity to retailers and end-users. Consequently, analysis of the relationship between spot and futures prices may provide important insights into risk premiums and risk aversion on the part of market participants in extremely volatile markets. Further, analysis of observed risk premiums in different interconnected markets will help participants to understand whether risk premiums, i.e. expectations about future supply and demand are transferred across regional electricity markets. Therefore, this study focuses on the futures risk premium, defined as the excess of the futures price over the expected realized spot price in the markets under consideration. Using an extended version of the general equilibrium model initially suggested by Bessembinder and Lemon (2002), we also examine whether the bias in electricity futures prices can be explained by the behaviour of the spot price during periods prior to delivery.

First, we start by investigating the magnitude of futures risk premiums at different time instances. The literature suggests that in electricity markets short term futures prices often exceed the actual average spot price during the delivery period (Botterud et al., 2002; Longstaff and Wang, 2004; Hadsell and Shawky, 2006; Diko et al., 2006; Bierbrauer et al., 2007; Daskalakis and Markellos, 2009; Redl et al., 2009, Redl and Bunn, 2013). On the other hand, this stream of literature usually argues that there is no exact relationship between the current spot price and forward prices due to the non-storability of electricity. However, as suggested by Bessembinder and Lemmon (2002) or Redl et al. (2009) the behaviour of electricity spot prices and demand, e.g. volatility and skewness of prices or demand prior to the delivery period of the futures contracts, may have a significant impact on risk premiums observed in the market. Botterud et al. (2010) suggest that in Scandinavian electricity markets 
spot and the futures prices are related to the physical state of the system, such as demand, reservoir levels, and hydro inflows.

We find that futures risk premiums in Australian electricity markets are positive and economically significant different from zero. However, when pooling all quarterly contracts together, from a statistical point of view, only the premiums in the QLD and VIC market are significantly different from zero. We also distinguish between base and peak load contracts and investigate the seasonal behaviour of risk premiums by separately examining contracts for different seasons. Considering the quarters separately, significant positive premiums can be detected for the first quarter in the QLD and VIC markets, while for the third quarter the premiums are significantly greater than zero for three of the considered markets. Furthermore, in our study we also examine the dependence of futures risk premiums observed across different regional electricity markets and find that they are significantly correlated. We further observe that adjoining regions usually exhibit higher degrees of correlation than markets that are geographically more distant.

In a second step we also investigate whether the bias in futures prices can be explained by the behaviour of spot prices during the month or quarter previous to delivery. To examine this issue we apply an extended version of the model initially suggested by Bessembinder and Lemmon (2002) including explanatory factors such as realized skewness and kurtosis of the spot prices. Further, since observed risk premiums in the considered markets are highly correlated, we apply a seemingly unrelated regression (SUR) model to investigate the issue. The obtained results are not entirely clear-cut. We find that the level of the spot price during the month or quarter prior to the delivery period has a significantly positive impact on the realised risk premium. This is true for most of the contracts and states considered. On the other hand, the majority of the other considered explanatory variables are insignificant: only in the NSW market skewness and kurtosis of the spot electricity contracts during the month prior to delivery are significant. This confirms similar results in previous studies by e.g. Redl et al. (2009), Botterud et al. (2010) or Furio and Meneu (2010) who also find only limited evidence for an impact of spot price variance and skewness on the futures risk premium.

The remainder of the paper is organised as follow. Section 2 provides a brief overview on spot and futures trading in the Australian NEM. Section 3 reviews previous studies on the relationship between electricity spot and futures markets and explains the theoretical framework adopted in this paper. Section 4 describes the data and discusses the empirical results. Section 5 concludes and provides suggestions for future research. 


\subsection{The Australian Electricity Market}

The Australian electricity market has experienced significant changes over the last two decades. Prior to 1997 the market consisted of vertically integrated businesses operating in each of the states and there was no connection between individual states. The businesses were owned by governments and operated as monopolies. Overall, there were twenty-five electricity distributors protected from competition. To promote energy efficiency and reduce the costs of electricity production, in the late 1990s the Australian government commenced significant structural reform which had the following objectives, among others: the separation of electricity generation from transmission, the merger of twenty-five electricity distributors into a smaller number, and the functional separation of electricity distribution from its retail supply. Retail competition was introduced as part of reform: states' electricity purchases could be made through the competitive retail market and customers were now free to choose their retail supplier.

The NEM is now an interconnected grid comprising several regional networks which supply electricity to retailers and end-users. The link between electricity producers and electricity consumers is established through a pool which is used to aggregate the output from all generators in order to meet forecast demand. The pool is managed by the Australian Energy Market Operator (AEMO) which follows the National Electricity Law in conjunction with market participants and regulatory agencies. Unlike many other markets, the Australian spot electricity market is not a day-ahead market, instead electricity is traded in a constrained real-time spot market where prices are set each 5 minutes by the AEMO. Generators submit offers every five minutes and this information is used to determine the number of generators required to produce electricity in a more cost-efficient way based on the existing demand. The final price is determined every half-hour for each of the regions as an average over the 5minute spot prices for each trading interval. Based on the half-hourly spot prices, a daily average spot price for each regional market can also be calculated. AEMO determines the half-hourly spot prices for each of the regional markets separately.

In recent years a market for electricity derivatives has also developed rapidly including electricity forward, futures and option contracts. Anderson et al. (2007) note that there are three types of Australian electricity forward contracts: (i) bilateral over-the-counter (OTC) transactions between two entities directly; (ii) bilateral over-the-counter (OTC) transactions on standard products executed through brokers; and (iii) derivatives traded on the Sydney 
Futures Exchange (SFE). In our study we will concentrate on futures contracts traded in the SFE during 2003-2012. Note that the SFE also offers a number of alternative derivatives including option contracts or $\$ 300$ cap products that will not be considered in this study.

As in almost every electricity exchange, futures contracts traded in the SFE refer to the average electricity price during a delivery period. For a base period futures contract, the contract unit is one Megawatt of electricity per hour (MWh) for each hour from 00:00 hours to 24:00 hours over the duration of the contract. For a quarterly base load contract, the size (in MWh) will vary depending on the number of days within the quarter. For example, for a quarter with 90 days, a contract refers to 2,160 MWh during the delivery period while for a quarter with 92 days, a contract refers to 2,208 MWh. Peak period contracts are also traded. Given that electricity prices show strong intra-day variation and are heavily affected by demand in every precise moment (Lucia and Schwartz, 2002), the distinction between the whole day and the peak delivery period of electricity is important for market participants. In Australia the peak period refers to the hours from 07:00 to 22:00 on weekdays (excluding public holidays) over the duration of the contract quarter. By implication the off peak period covers from 22:00 to 07:00 on weekdays and all hours on Saturday, Sunday and public holidays. Therefore, the size of a quarterly peak period futures contract will vary depending on the number of days and peak-load hours within the quarter: for example a contract with 62 weekdays during a quarter (so-called 62 day contract quarter) will equate to $930 \mathrm{MWh}$.

The contracts do not require physical delivery of electricity but are settled financially. Therefore, market participants can participate in electricity futures markets and increase market liquidity without owning physical generation assets. The cash settlement price of a base (peak) period contract is calculated by taking the arithmetic average of the NEM final base (peak) load spot prices on a half hourly basis, rounded to two decimal places over the contract quarter. A provisional cash settlement price is declared on the first business day after expiry of the contract while the final cash settlement takes place on the fourth business day after expiry.

\subsection{Modelling Framework}

In the following section we describe the theoretical framework applied in our empirical analysis in order to investigate the relationship between spot and futures prices. Generally, 
there are two theories explaining the relationship between spot and futures prices in commodity markets, see e.g. Botterud et al. (2002), Redl et al. (2009).

The first theory argues that the cost and convenience of holding inventories explains the difference between the spot and futures price of a commodity. This theory is well known as the 'cost of carry' approach and goes back to Kaldor (1939). According to the 'cost of carry' approach, the forward price can be determined as a function of the current spot price, the interest rate and cost of storage. As mentioned previously, electricity as a flow commodity is produced and consumed instantaneously and continuously. Therefore, a standard cost of carry approach towards spot and forward markets cannot be applied.

Instead the literature usually follows the second theory that considers equilibrium in expectations, and risk aversion amongst agents with heterogeneous requirements for hedging the uncertainty of future spot prices (Keynes, 1930). Using this approach, the electricity forward price is determined as the expected spot price plus an ex-ante risk premium of the market. The difference between the forward and the expected spot price can then be interpreted as compensation for bearing the spot price risk (Bessembinder and Lemmon, 2002; Longstaff and Wang, 2004). However, as the ex-ante premium is basically unobservable, empirical analysis often concentrates on the realized or ex-post forward premium

$$
\operatorname{PREM}_{t, T}=F_{t, T}-S_{T}
$$

Hereby, $\mathrm{F}_{\mathrm{t}, \mathrm{T}}$ denotes the forward price quoted at time $\mathrm{t}$, for delivery at time or period $\mathrm{T}$, while $S_{\mathrm{T}}$ refers to the (average) spot price realized at time or period T. As illustrated by Redl et al. (2009) the realized forward premium equals the ex-ante premium plus a random error in the (rational) spot price expectation that is a result of shocks to the electricity price between $t$ and $\mathrm{T}$. Based on a random error distribution with zero mean, the realized premium can then be considered as a consistent estimator of the ex-ante premium. Decomposing ex-post premiums, one could argue that only a part of the premium reflects compensation for the spot price risk while the other part can be considered as due to errors in expectations by market participants about the actual spot price during the delivery period.

In their seminal paper, Bessembinder and Lemmon (2002) suggest a general equilibrium model where the ex-ante one-month forward premium in the Pennsylvania, New Jersey, Maryland (PJM) and California Power Exchange (CALPX) markets is modelled as dependent on the mean, standard deviation and variance of electricity demand: 


$$
\operatorname{PREM}_{\mathrm{it}}=\alpha_{0}+\alpha_{1} \mathrm{MEAN}_{\mathrm{it}}+\alpha_{2} \mathrm{STD}_{\mathrm{it}}+\alpha_{3} \mathrm{VAR}_{\mathrm{it}}+\eta_{\mathrm{it}}
$$

Hereby, PREM $_{i t}$ equals the forward premium as the one-month-forward price for delivery in month $t$ minus the cost-based estimate of the expected spot price in month $t$ for market $i, M N_{i t}$ is the average normalized load for month $t$ in the market $i, S D_{i t}$ is the standard deviation of the daily load during month $t$ in market $\mathrm{i}$, and $\mathrm{VAR}_{\mathrm{it}}$ is the square of STD $_{\text {it. }}$ Based on their theoretical model, the authors suggest that the forward premium should increase with mean demand and should be convex, initially decreasing and then increasing in demand risk. Thus, one would expect a negative coefficient for the standard deviation and a positive coefficient for the variance. In their empirical study, the authors find significant forward premiums in the market. With respect to explaining the premium, however, they obtain rather insignificant results for the coefficients. While the level of demand seems to have a significantly positive impact on the forward premium, both the standard deviation and variance of the demand are insignificant. Note that also Haugom and Ullrich (2012) suggest that they are unable to find support for the Bessembinder and Lemmon (2002) model, since their rolling and recursive estimations provide highly unstable values of the estimated parameters. However, the Bessembinder and Lemmon (2002) model can still be considered as the foundation of examining risk premiums in electricity futures markets, that has been used widely in recent studies, e.g., Pietz (2009), Redl et al. (2009), Lucia and Torro (2011), Ullrich (2012).

A similar approach has been suggested by Redl et al. (2009) who examine the ex-post premium in the European Energy Exchange (EEX) and Scandinavian Nordpool electricity markets. They suggest a slightly different model for considering monthly forward contracts that incorporates the volatility and skewness of daily spot prices in the month prior to the delivery period as well as a consumption and generation index. Therefore, they suggest the following model for the realized forward premium:

$$
\operatorname{PREM}_{\mathrm{t}, \mathrm{T}}=\mathrm{F}_{\mathrm{t}, \mathrm{T}}-\mathrm{S}_{\mathrm{T}}=\mathrm{b}_{1}+\mathrm{b}_{2} \operatorname{Var}\left(\mathrm{S}_{\mathrm{t}}\right)+\mathrm{b}_{3} \operatorname{Skew}\left(\mathrm{S}_{\mathrm{t}}\right)+\mathrm{b}_{4} \operatorname{Cons}_{\mathrm{T}}+\mathrm{b}_{5} \operatorname{Gen}_{\mathrm{T}}+\varepsilon_{\mathrm{t}}
$$

In this model, PREM $_{\mathrm{t}, \mathrm{T}}$ denotes the ex-post forward premium measured by the difference $F_{t, T}-S_{T}$, where $F_{t, T}$ is the futures price on the last trading day in month $t$ (before the start of the delivery period) for delivery in month $\mathrm{T}, \mathrm{S}_{\mathrm{T}}$ is the observed average spot price in 
month $T, \operatorname{Var}\left(\mathrm{S}_{\mathrm{t}}\right)$ is the variance of daily spot prices in month $t, \operatorname{Skew}\left(\mathrm{S}_{\mathrm{t}}\right)$ is the skewness of daily spot prices in month $t$, Cons $_{\mathrm{T}}$ is the consumption index in month $\mathrm{T}$ and $\mathrm{Gen}_{\mathrm{T}}$ is the generation index of hydro and nuclear power generation in month $\mathrm{T}$.

Empirical studies have generally found significant positive premiums in electricity forward markets. Longstaff and Wang (2004) find positive risk premiums of up to 14 percent for the PJM day-ahead market while Redl et al. (2009) find positive premiums for monthahead forward contracts in the Nordpool and EEX market. They report premiums ranging from 8 percent for considered baseload forward contracts in the Nordpool market and 9 percent for baseload and 13 percent for peak load contracts in the EEX market. Pietz (2009) finds positive futures premiums in the EEX market for six different monthly futures contracts. He reports premiums ranging from -0.03 to 5.45 Euro/MWh, however, only for few contracts the premiums are statistically significant. Botterud et al. (2010) report premiums ranging from 1.3 to 4.4 percent for the Nord Pool market when considering forward contracts from one week up to six weeks ahead.

A number of other studies confirm the significance of forward premiums in various electricity markets. Significant premiums are reported, for example, by Hadsell and Shawky (2006) for the NYISO, Diko et al. (2006) for the APX, Bierbrauer et al. (2007) for the EEX, Weron (2008) for the Nordpool, Kolos and Ronn (2008) and Daskalakis and Markellos (2009) for the EEX, Nordpool and Powernext markets. Interestingly, the studies provide quite different results on the actual sign (positive or negative) of the risk premium even for the same markets: while Redl et al. (2009) find significant positive premiums for monthly baseload and peakload futures contracts in the EEX market, Kolos and Ronn (2008) find a negative forward premium for monthly, quarterly and yearly contracts at the EEX during the 2002-2003 trading period. Bierbrauer et al. (2007) find positive ex-ante risk premiums for short-term futures contracts while observed premiums are negative for contracts with delivery periods more than six months ahead. Diko et al. (2006), investigating EEX peak load contracts, find that forward premiums decrease as the time to maturity increases. More recently, Lucia and Torro (2011) report significant and positive realized futures premiums ranging from 1.17 to 4.42 percent in the Nord Pool market. Haugom and Ullrich (2012) find positive and significant daily ex-post forward premiums in the PJM market, while Veraart and Veraart (2013) find positive ex-post futures premiums in the EEX market for the 20102012 time period. Therefore, the majority of authors seem to find rather positive risk premiums in electricity futures markets, even for the same market. 
Empirical studies on the significance of variance and skewness in the risk premium so far provide rather mixed results, see e.g. Bessembinder and Lemmon (2002), Douglas and Popova (2008), Lucia and Torro (2008), Redl et al. (2009), Botterud et al. (2010), and Furio and Meneu (2010). Bessembinder and Lemmon (2002) find a positive coefficient for the standard deviation and a negative coefficient for the variance of the daily load in the PJM and CALPX markets. However, their results are not statistically significant. Douglas and Popova (2008) estimate a negative coefficient for the variance and a positive coefficient for the skewness of the recent spot price in the PJM market. Most of their results are statistically significant. Lucia and Torro (2008) observe a positive coefficient for the variance and a negative coefficient for the skewness of spot prices during the delivery period in the Nord Pool power market from mid 2003 until the end of 2007. However, they find a negative coefficient for the variance and a positive coefficient for the skewness when considering futures prices from early 1998 to mid 2002. Their results are statistically significant for the skewness while for the variance, significant results are obtained only for the so-called preshock periods from 1998-2002. Redl et al. (2009) find positive coefficients for both variance and skewness of spot prices in the month prior to the delivery period when examining the EEX market. However, they also obtain a positive coefficient for the variance and a negative coefficient for the skewness parameter for the Nord Pool market. Their results are statistically significant only for the estimated variance coefficient (EEX peak period) and the skewness coefficient (EEX base period). Botterud et al. (2010) find mainly negative coefficients for both variance and skewness of the spot price in the week prior to the delivery period in the Nord Pool market. However, only the coefficient for the variance one week prior to the delivery period is statistically significant. Finally, Furio and Meneu (2010) find negative coefficients for both variance and skewness in the Spanish electricity market. Only the coefficient for the variance is found to be statistically significant.

As mentioned previously, to date no study has investigated the significance of risk premiums or the influence of spot price characteristics on the forward premium in regional Australian electricity markets. The analysis of this relationship may be of particular interest given the comparably high frequency of price spikes and periods of extreme volatility in the spot market. In such volatile markets one may expect to find significant premiums in the futures market as well as empirical evidence for the theory that equilibrium futures prices are bid up to compensate for skewness or extreme variance in the spot price distribution, as has been suggested by Bessembinder and Lemmon (2002) and other authors. 
Therefore, in our empirical analysis we examine the following model for the ex-post futures premium in the considered markets:

$$
\operatorname{PREM}_{\mathrm{t}, \mathrm{Q}}=\mathrm{b}_{1}+\mathrm{b}_{2} \operatorname{Mean}\left(\mathrm{S}_{\mathrm{tq}}\right)+\mathrm{b}_{3} \operatorname{Std}\left(\mathrm{S}_{\mathrm{tq}}\right)+\mathrm{b}_{4} \operatorname{Var}\left(\mathrm{S}_{\mathrm{tq}}\right)+\mathrm{b}_{5} \operatorname{Skew}\left(\mathrm{S}_{\mathrm{tq}}\right)+\mathrm{b}_{6} \operatorname{Kurt}\left(\mathrm{S}_{\mathrm{tq}}\right)+\varepsilon_{\mathrm{t}}
$$

Hereby PREM $\mathrm{t}_{\mathrm{t}, \mathrm{Q}}$ denotes the difference between the quote for the futures contract with delivery in quarter $\mathrm{Q}$ on the last trading day $\mathrm{t}$ before the beginning of the delivery period and the average spot price during the delivery period (quarter Q). Mean $\mathrm{tq}_{\mathrm{tq}}$ is the average spot price during period t denoting either the last month or last quarter before the delivery period $\mathrm{Q}$. Further $\operatorname{Std}_{\mathrm{tq}}$ is the realized standard deviation, $\operatorname{Var}_{\mathrm{tq}}$ the realized variance, $\mathrm{Skew}_{\mathrm{tq}}$ the realized skewness and $\mathrm{Kurt}_{\mathrm{tq}}$ the realized kurtosis of the spot price during period $\mathrm{t}$, again, denoting either the last month or last quarter before the delivery period Q.

Since Australian electricity markets are interconnected, it is likely that unobserved variables (the errors) among different markets are correlated at the same point in time. This situation leads a strong economic argument that contemporaneous correlation exists. Therefore, utilizing a joint estimation procedure may be more suitable than applying separate least square regression models for each market (Hill et al., 2011). According to Hill et al. (2011), a panel framework (either fixed or random effect) is more appropriate when the panel data is short and wide, i.e. when the number of cross sectional units is large and the number of time periods is small. The authors argue that if the number of time series observations is sufficiently large and the number of cross sectional units is small, we can estimate a separate equation for each individual. The authors also suggest that if the error terms among (separate) equations, at the same point in time, are correlated, it may be favourable to use Seemingly Unrelated Regression (SUR) and to perform a test for contemporaneous correlations. Our quarterly data set contains 46 observations (from Q1 2003 to Q2 2012) and four states, NSW, QLD, SA and VIC, which means that the time series is sufficiently larger than the number of units. Therefore, in our analysis we argue that the SUR approach is more appropriate than a panel (fixed or random effect) framework.

SUR is a generalized least square (GLS) method that estimates the equations jointly, accounting for contemporaneous correlations among the errors of the NSW, QLD, SA and VIC electricity premium equations. Further technical details of the SUR procedure can be found in Greene (2011). The SUR model can be formulated as follows: 
$\operatorname{PREM}_{\mathrm{i}, \mathrm{t}, \mathrm{Q}}=\mathrm{b}_{\mathrm{li}}+\mathrm{b}_{2 \mathrm{i}} \operatorname{Mean}\left(\mathrm{S}_{\mathrm{i}, \mathrm{tq}}\right)+\mathrm{b}_{3 \mathrm{i}} \operatorname{Std}\left(\mathrm{S}_{\mathrm{i}, \mathrm{tq}}\right)+\mathrm{b}_{4 \mathrm{i}} \operatorname{Var}\left(\mathrm{S}_{\mathrm{i}, \mathrm{tq}}\right)+\mathrm{b}_{5 \mathrm{i}} \operatorname{Skew}\left(\mathrm{S}_{\mathrm{i}, \mathrm{tq}}\right)+\mathrm{b}_{6 \mathrm{i}} \operatorname{Kurt}\left(\mathrm{S}_{\mathrm{i}, \mathrm{tq}}\right)+\varepsilon_{\mathrm{i}, \mathrm{t}}$

PREM $_{\mathrm{i}, \mathrm{t}, \mathrm{Q}}$ denotes the difference between the quote for the futures contract with delivery in quarter $\mathrm{Q}$ on the last trading day $\mathrm{t}$ before the beginning of the delivery period and the average spot price during the delivery period (quarter Q) in market i. $\mathrm{Mean}_{\mathrm{i} . \mathrm{tq}}$ is the average spot price during period t denoting either the last month or last quarter before the delivery period $\mathrm{Q}$ at market $\mathrm{i}$. Further, $\mathrm{Std}_{\mathrm{i}, \mathrm{tq}}$ is the realized standard deviation, $\operatorname{Var}_{\mathrm{i}, \mathrm{tq}}$ the realized variance, $\mathrm{Skew}_{\mathrm{i}, \mathrm{tq}}$ the realized skewness and Kurt $\mathrm{i}_{\mathrm{t} \text { tq }}$ the realized kurtosis of the spot price during period $t$, again denoting either the last month or last quarter before the delivery period Q in market i. The i subscript for the coefficients (including the intercept) indicates that the coefficients will differ across each market.

\subsection{Empirical Analysis}

\subsubsection{The Data}

Our sample includes electricity spot and futures prices in four Australian regional markets: NSW, QLD, SA and VIC. These states show by far the highest electricity demand in Australia (Higgs, 2009) and are the only regions that also offer futures contracts traded on an exchange. In our analysis we consider daily electricity spot prices for the period from January 1, 2000 to June 30, 2012 provided by AEMO. Note that for the Australian market only quarterly and yearly futures contracts are traded on an exchange. Data for quarterly base load and peak load futures contracts from 2003 to 2012 were obtained from d-cypha Trade Limited $^{1}$. Base load futures are settled during the delivery quarter with reference to the average half-hourly spot price, while peak load futures are cash settled with reference to the average of only those half hours during the quarter between $7 \mathrm{am}$ to $10 \mathrm{pm}$ on working weekdays. In the following, both spot and futures prices are quoted in Australian dollars per Megawatt hour (\$/MWh).

Table 1 shows descriptive statistics of daily electricity spot prices for the base and peak (7am-10pm working weekdays) periods from January 1, 2000 to June 30, 2012 in the

\footnotetext{
${ }^{1}$ http://www.d-cyphatrade.com.au
} 
considered regions. Note that data from July 2012 onwards was excluded from this analysis, since on July 1, 2012 a carbon tax of $\$ 23$ per ton of $\mathrm{CO}_{2}$ emission became effective, significantly increasing spot electricity prices. Since the newly introduced tax might also have an impact on the relationship between spot and futures prices and realized risk premiums we decided to exclude data after June 2012 from the analysis.

We find that average daily electricity spot prices range from $35.12 \$ / \mathrm{MWh}$ in VIC to 44.05 \$/MWh in SA for the base load, while they range from 49.71 \$/MWh in VIC to 67.12 $\$ / M W h$ in SA during the peak period. In both cases the lowest average daily prices are observed in VIC, followed by QLD and NSW, while the highest prices can be observed in the SA market. Also, there are significant differences in the standard deviation between the regional markets with a range from 60.78 for VIC up to 104.19 for SA for the base period and 119.63 for QLD to 219.77 for SA during the peak period.

\begin{tabular}{ccccc}
\hline Descriptive Statistics & NSW Base & QLD Base & SA Base & VIC Base \\
\hline Mean & 38.53 & 36.93 & 44.05 & 35.12 \\
Standard Deviation & 72.10 & 65.21 & 104.19 & 60.78 \\
Minimum & 11.65 & -13.98 & -103.16 & -8.94 \\
Maximum & $1,394.18$ & $1,487.33$ & $2,533.96$ & $2,376.06$ \\
Skewness & 12.08 & 12.73 & 14.04 & 21.57 \\
Kurtosis & 175.35 & 211.18 & 238.18 & 648.46 \\
Number of Observation & 4,565 & 4,565 & 4,565 & 4,565 \\
\hline Descriptive Statistics & NSW Peak & QLD Peak & SA Peak & VIC Peak \\
\hline Mean & 55.78 & 53.08 & 67.12 & 49.71 \\
Standard Deviation & 149.63 & 119.63 & 219.77 & 125.19 \\
Minimum & 13.73 & -32.58 & -85.45 & 11.30 \\
Maximum & $2,538.49$ & $2,726.58$ & $4,654.74$ & $4,304.45$ \\
Skewness & 10.86 & 12.12 & 12.20 & 20.65 \\
Kurtosis & 136.51 & 193.70 & 173.18 & 560.14 \\
Number of Observation & 3,179 & 3,178 & 3,179 & 3,178 \\
\hline
\end{tabular}

Table 1: Descriptive statistics of daily base and peak load electricity spot prices from January 1, 2000 to June 30, 2012. The table provides the mean, standard deviation, minimum, maximum as well as the number of observations for the considered NSW, QLD, SA and VIC regions.

As expected, spot electricity prices are driven by demand and supply mechanisms such that electricity prices and volatility are generally higher during the peak load period, where demand is usually significantly higher and more volatile. As indicated by Table 1, negative prices could also be observed in the QLD, SA and VIC markets. According to the AEMO Information Centre (2011), negative spot prices can be explained by electricity generators 
bidding negative prices since they want to ensure that their supplies are dispatched, as it is actually cheaper for them to continue running rather than ramping down their power plants. Generating units cannot usually be switched on and off in a short time due to efficiency and safety reasons (Hu et al., 2005). Therefore producers might actually be better off paying retailers for the consumption of electricity for a short period of time. This is also referred to as a tactical strategy (Thomas et al., 2011) to ensure that the generators will get the contract. For a modelling framework that can also be used to model negative price spikes, see e.g. Fanone et al. (2011).

Figure 1 provides a plot of the time series of electricity spot prices in NSW during base and peak periods. We can see considerable variations in the spot price, particularly during the peak period. We find that the most pronounced features of Australian electricity prices are short periods of significantly increased volatility as well as infrequent but very extreme price spikes. These spikes yield daily electricity prices of up to $\$ 2,500$ markets during the base period and even more than $\$ 4,000$ during the peak period in VIC and SA markets. They are less extreme for NSW and QLD markets, but here prices of up to $\$ 1,500$ and $\$ 2,700$ respectively could be observed during the base and peak load periods.

NSW_BASE

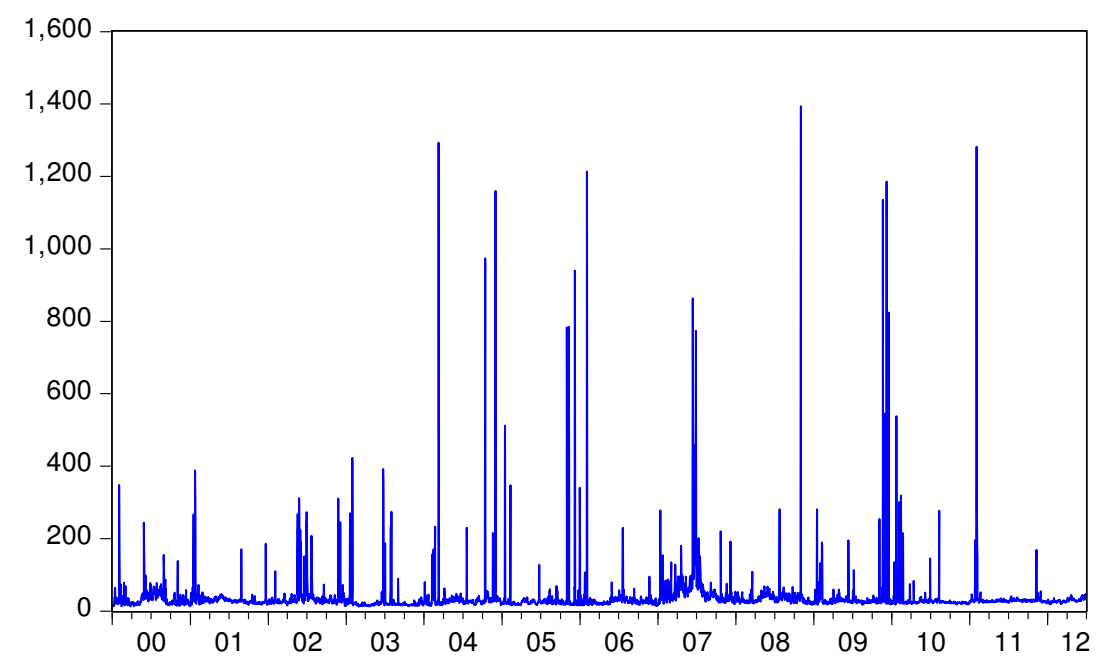




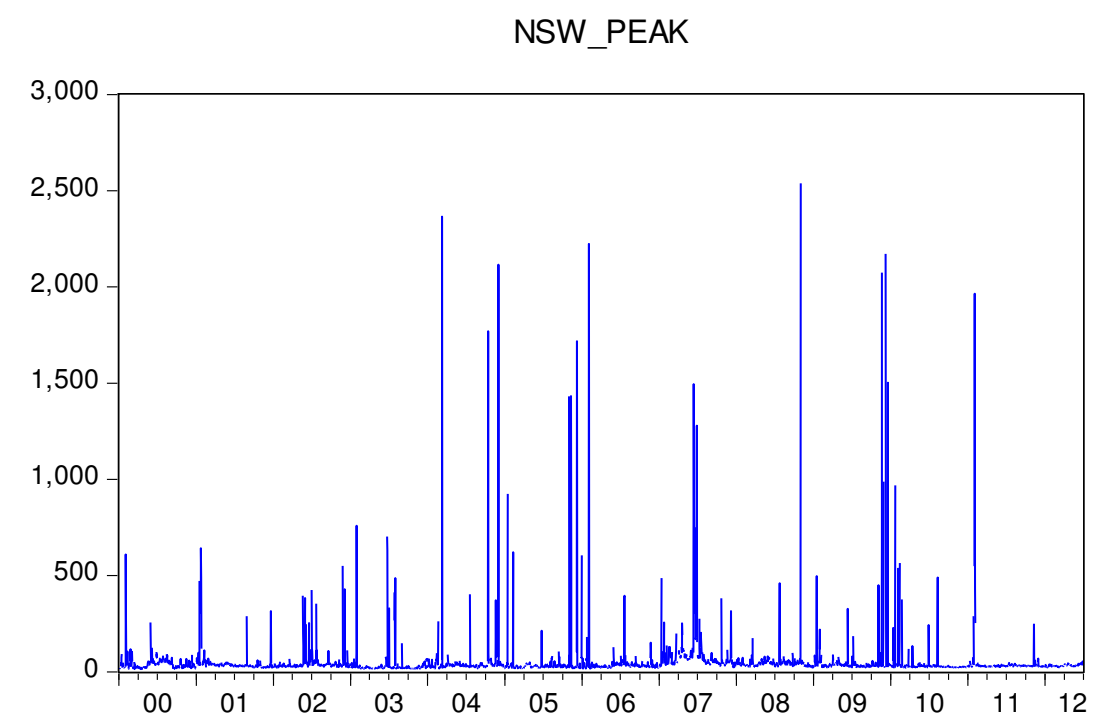

Figure 1: Daily electricity spot prices for base and peak load periods from January 1, 2000 to June 30, 2012 for the NSW market.

We also examine seasonality in the market by calculating average spot prices for the calendar months. Table 2 displays the average spot prices of base and peak load contracts for each quarter. We find strong evidence of seasonality in electricity spot prices: the highest average prices can be observed during the second quarter for NSW and during the first quarter for QLD, SA and VIC. On the other hand, the lowest prices for base load contracts are observed in the third quarter for NSW, QLD and SA and in the fourth quarter for VIC. The highest average prices for peak load contracts are observed during the first quarter for QLD, SA and VIC and during the fourth quarter for NSW. The lowest average prices for peak load contracts can be observed in the third quarter for NSW, QLD and SA and during the fourth quarter for VIC. Note that strong seasonal effects in electricity prices have been reported by many authors, see e.g. Bessembinder and Lemmon (2002), Lucia and Schwartz (2002), Weron (2006), and Bierbrauer et al. (2007) to name a few. 


\begin{tabular}{ccccc}
\hline \multicolumn{5}{c}{ BASE PERIOD } \\
\hline Quarter & NSW & QLD & SA & VIC \\
\hline Quarter 1 & 39.08 & 42.58 & 61.74 & 39.00 \\
Quarter 2 & 40.46 & 37.48 & 38.81 & 38.39 \\
Quarter 3 & 34.60 & 31.35 & 36.34 & 33.64 \\
Quarter 4 & 39.82 & 35.87 & 38.53 & 28.98 \\
\hline Base & NSW & QLD & SA & VIC \\
\hline \multicolumn{5}{c}{ PEAK PERIOD } \\
\hline Quarter & NSW & QLD & SA & VIC \\
\hline Quarter 1 & 59.70 & 66.91 & 115.08 & 64.95 \\
Quarter 2 & 53.45 & 49.75 & 48.51 & 51.70 \\
Quarter 3 & 43.60 & 39.67 & 44.70 & 42.52 \\
Quarter 4 & 66.61 & 55.61 & 59.22 & 38.80 \\
\hline
\end{tabular}

Table 2: Average quarterly spot prices for NSW, QLD, SA and VIC base and peak loads contracts from January 1, 2000 to June 30, 2012.

\subsection{Realized Risk Premiums in the Futures Market}

In the next step we analyse the ex-post or realized futures risk premium in the markets under consideration. We calculate the premium as the difference between the quote for the futures contract on the last trading day before the beginning of the delivery period and the realized average spot price during the delivery period. Here we do not distinguish between different quarters such that for each market the realized premiums for the first (Q1), second (Q2), third (Q3) and fourth quarter (Q4) are jointly examined. However, we distinguish between regional markets as well as between base and peak load futures contracts. Thus, for the considered time period from Q1 2003 to Q2 2012 we have 38 base load contracts and the same number of peak load contracts for each market.

Results for the futures risk premiums realized in each market are provided in Table 3. We find that for all markets we observe a positive ex-post premium indicating that futures quotes immediately before the beginning of the delivery period are on average higher than the average spot price realized during the delivery period. The size of the premium varies dependent on the market under consideration but is also different for base load in comparison to peak load contracts. For the base load period we find that the premium is the highest in QLD where the futures quote per MWh exceeds the realized spot price during the delivery period by $\$ 7.19$. Note that for a quarter with, for example, 90 days where a contract refers to $2,160 \mathrm{MWh}$ this corresponds to a price difference of approximately $\$ 15,528$ per contract. The 
average realized premium is the lowest for NSW at $\$ 3.36$ while in SA and VIC the corresponding figures are $\$ 5.18$ and $\$ 4.89$, respectively. For peak load contracts we also find positive premiums that range from \$3.31 in NSW up to \$13.29 in the QLD market. The sign of the premiums observed indicates that buyers such as retailers or large customers are willing to pay an additional premium in the futures market in order to avoid potentially extreme losses that might occur when the spot market exhibits extreme prices due to high volatility or price spikes.

We also conduct statistical tests to investigate whether the realized risk premiums are statistically significant. Table 3 provides the t-statistics for the premiums. Interestingly, only the QLD and VIC market exhibit risk premiums that are significantly greater than zero at the 5 percent, respectively at the 10 percent significance level for both base and peak load contracts. The realized premiums for the NSW and SA markets are not statistically significant. We conclude that for Australian electricity markets there is a tendency of futures quotes to be higher than average realized spot prices during the delivery period, but only in the QLD and VIC region these premiums are significantly greater than zero.

\begin{tabular}{ccccc}
\hline Futures Premium & NSW Base & QLD Base & SA Base & VIC Base \\
\hline Average & 3.36 & 7.19 & 5.18 & 4.89 \\
Standard Deviation & 22.99 & 19.92 & 19.67 & 16.30 \\
\# of Observation (n) & 38 & 38 & 38 & 38 \\
t-Statistic & 0.90 & $2.23 * *)$ & 1.62 & $1.85 *)$ \\
\hline & & & & \\
\hline Futures Premium & NSW Peak & QLD Peak & SA Peak & VIC Peak \\
\hline Average & 3.31 & 13.29 & 6.64 & 8.30 \\
Standard Deviation & 45.55 & 36.69 & 42.13 & 29.15 \\
\# of Observation (n) & 38 & 38 & 38 & 38 \\
t-Statistic & 0.45 & $2.23 * *)$ & 0.97 & $1.75 *)$ \\
\hline
\end{tabular}

Table 3: Realized futures premiums for NSW, QLD, SA and VIC base load and peak load contracts for the time period Q1 2003 to Q4 2012. The asterisk indicate a significant risk premium at the *) 10 percent significance level, **) 5 percent significance level, ***) 1 percent significance level.

Note that our results on positive risk premiums for nearest term futures contracts are in line with the suggestions of theoretical models regarding the sign of the risk premium. According to Benth et al. (2008), economic intuition would suggest that a long-term negative and short-term positive risk premium should be observed in electricity markets. Long-term contracts with maturities greater than several months will be mainly used by producers to 
hedge their future electricity production. Producers may be willing to accept prices lower than the actual expected spot price in order to guarantee that the electricity produced can be sold in the market, which will result in a negative long-term risk premium. On the other hand, in the short-term, retailers or consumers aiming to hedge the risk of price spikes may be willing to pay an additional premium for locking in prices in the short term. Such behaviour will result in a positive short-term risk premium as it can be observed in our study and also for a variety of other markets, see e.g. Longstaff and Wang (2004); Hadsell and Shawky (2006); Diko et al. (2006); Bierbrauer et al. (2007); Daskalakis and Markellos (2009); Redl et al. (2009). However, there are also empirical studies reporting negative electricity premiums, for example in the PJM (Bessembiner and Lemmon, 2002) and Nord Pool (Botterud et al., 2010) markets.
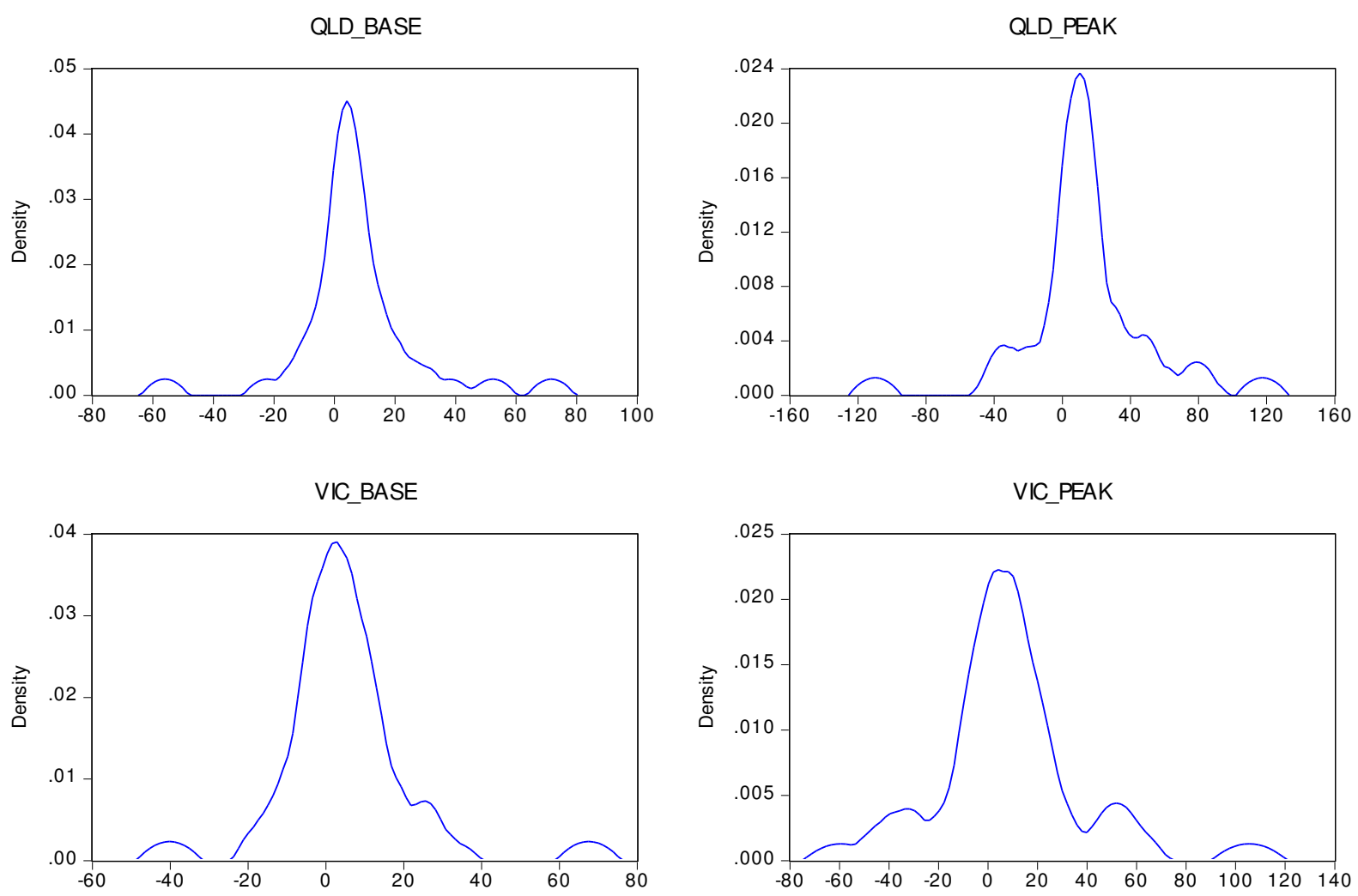

Figure 2: Distribution of realized risk premiums in the QLD and VIC markets for Q1 2003 Q2 2012 base load (left panel) and peak load (right panel) futures contracts based on the Epanechnikov Kernel density estimation. The density estimate illustrates the positive mean and median of the distribution as well as the high volatility and a number of extreme positive and negative outcomes for the premium.

Figure 2 provides a plot of the probability distribution of the ex-post risk premium observed for base load and peak load futures contracts in the QLD and VIC markets. Hereby 
the probability density is estimated using the Epanechnikov kernel estimator that spreads the probability mass symmetrically around the actual observation (Kvam and Vidakovic, 2007). The plot illustrates that even though the mean and median of the distribution are positive, the premiums exhibit high volatility with a number of negative realizations for both the QLD and VIC market. Notably, for both base load and peak load contracts we observe one instance where the realized premium is highly negative with approximately \$60 (QLD) and \$40 (VIC) for the base period \$120 (QLD) and \$70 (VIC) for the peak period. This suggests that riskaverse market participants might be discouraged from exploiting the average positive futures risk premium due to the risk of potential significant losses.

Figure 3 plots the realized futures risk premiums for electricity base load futures contracts from Q1 2003 to Q2 2012. The figure illustrates the high volatility of realized risk premiums over time, while premiums are highly correlated across different markets. The premiums usually show the same sign and sometimes also a similar magnitude. The figure also illustrates some seasonal patterns: while the risk premium usually seems to be positive for the first and third quarter of the year, it sometimes becomes highly negative for the second and fourth quarter.

Figure 4 provides a plot of the average realized risk premiums for base and peak load contracts from Q1 2003 to Q2 2012 across all markets. The figure further illustrates very similar behaviour for the ex-post premiums for base and peak load contracts. While the realized premiums are more volatile and higher in terms of absolute values for peak load contracts, premiums for base and peak load contracts for the same period usually show the same sign. The figure also illustrates more clearly the seasonal pattern detected in the risk premiums. 


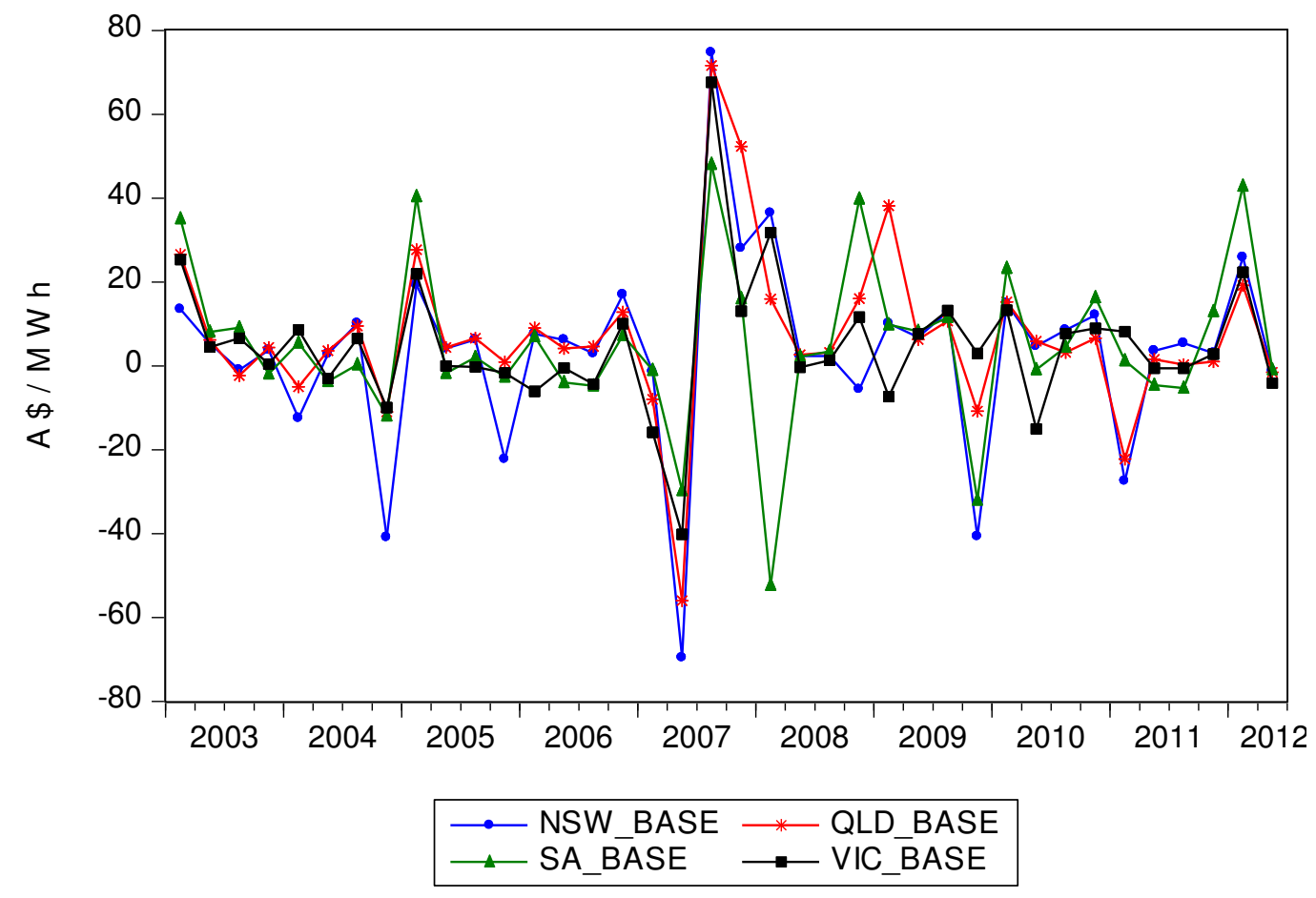

Figure 3: Realized risk premiums for NSW, QLD, SA and VIC base load contracts from Q1 2003 to Q2 2012.

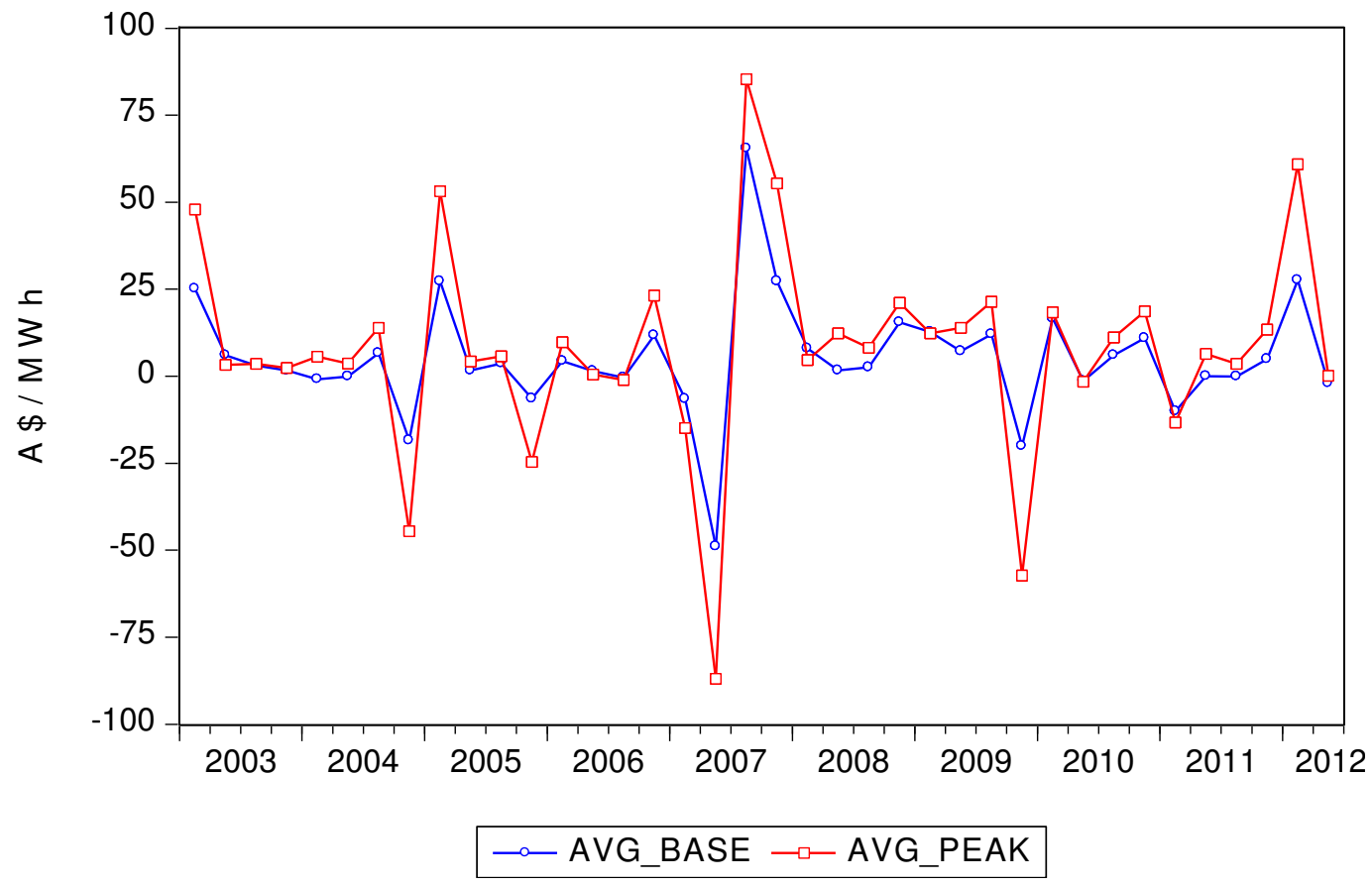

Figure 4: Realized risk premium for base load and peak load contracts averaged over all markets from Q1 2003 to Q2 2012. 
All Quarters

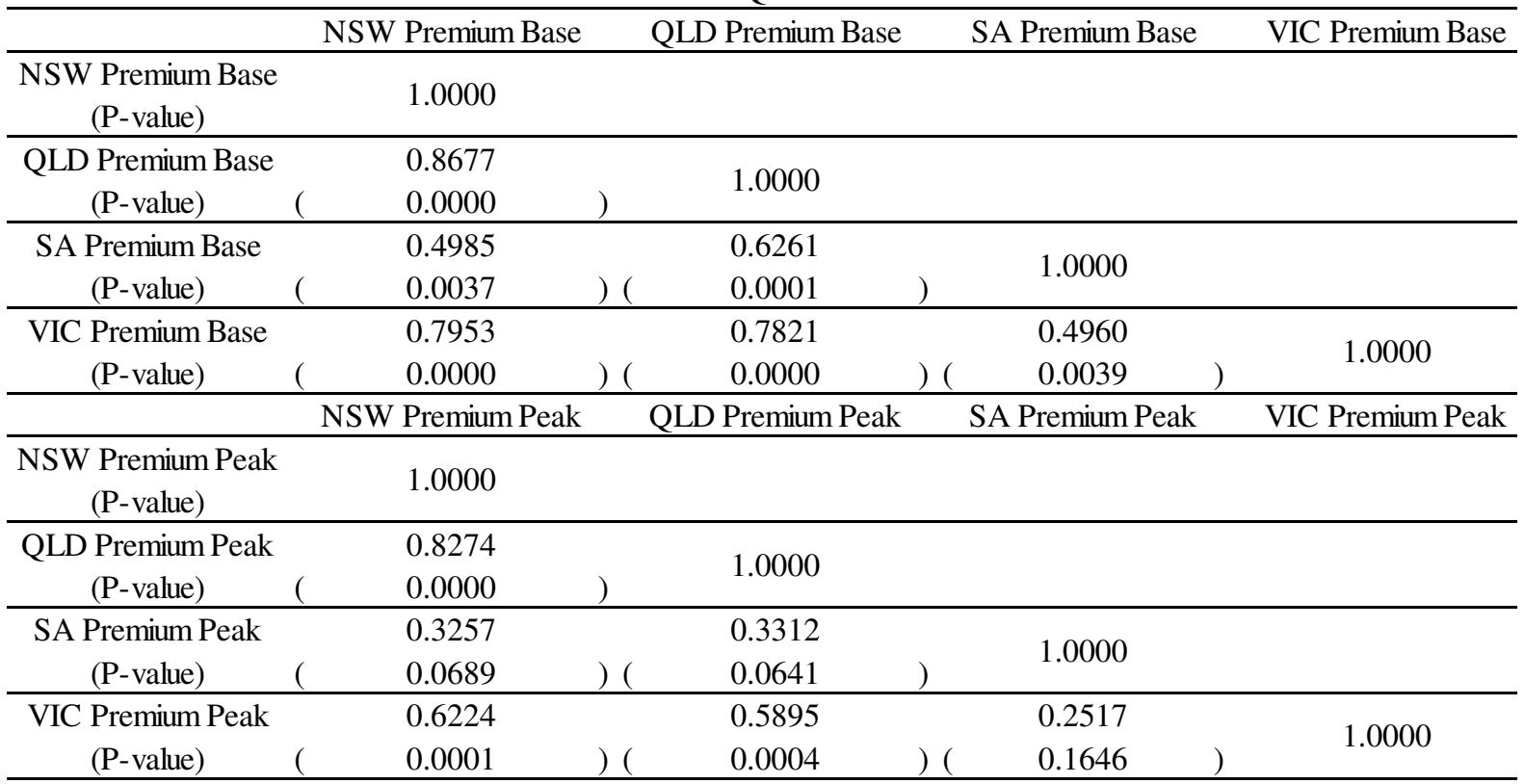

Table 4: Estimated correlation between realized risk premiums for base load and peak load contracts in the NSW, QLD, SA and VIC markets.

To further investigate the relationship between realized futures risk premiums, in a next step we examine the correlation between the premiums across the markets under consideration. Table 4 presents the estimated correlation coefficients for the ex-post risk premiums for both base load and peak load contracts. We observe strong and significant positive correlations in the futures risk premium across the markets. We further observe that adjoining regions such as, for example, NSW-QLD or NSW-VIC usually exhibit higher degrees of correlation than markets that are geographically more distant, e.g. QLD-SA or NSW-SA. Given the nature of the Australian market operating as an interconnected grid this does not come as a surprise. Within the national power grid, electricity can be transmitted between different regions via so-called interconnectors. The interconnectors may be of particular importance when the price of electricity in adjoining regions is low enough to displace local supply, but also when the energy demand in a particular region is higher than the amount of electricity that can be provided by local generators. Therefore, one could expect adjoining regions to exhibit similar price behaviour and also, therefore, higher correlations between realized risk premiums.

Note that overall correlations between the realized premiums seem to be lower for peak load contracts. This can probably be explained by the higher volatility and number of price spikes during peak periods. In cases where there are a number of price spikes during the same 
quarter in one market, this can have significant impact on the realized risk premiums. Recall that a quarterly peak load futures contract refers to less than 1,000 MWh while a base load contract refers to more than 2,000 MWh. Therefore, the usual brief periods of spikes or extreme prices will have a higher impact on average prices, and, therefore on realized risk premiums in each market for the peak period. This could explain the lower degree of correlation in risk premiums for peak load contracts.

\begin{tabular}{|c|c|c|c|c|}
\hline \multicolumn{5}{|c|}{ Quarter 1} \\
\hline Premium & NSW Base & QLD Base & SA Base & VIC Base \\
\hline Average & 8.64 & 11.66 & 11.16 & 10.19 \\
\hline t Statistic & 1.47 & $1.99 * *)$ & 1.27 & $2.04 * *)$ \\
\hline Premium & NSW Peak & QLD Peak & SA Peak & VIC Peak \\
\hline Average & 17.35 & 24.67 & 12.68 & 19.04 \\
\hline t Statistic & 1.60 & $2.09 * *)$ & 0.58 & $1.71 *)$ \\
\hline \multicolumn{5}{|c|}{ Quarter 2} \\
\hline Premium & NSW Base & QLD Base & SA Base & VIC Base \\
\hline Average & -3.50 & -2.30 & -2.72 & -5.19 \\
\hline t Statistic & -0.47 & -0.38 & -0.82 & -1.20 \\
\hline Premium & NSW Peak & QLD Peak & SA Peak & VIC Peak \\
\hline Average & -6.05 & -3.63 & 0.15 & -8.15 \\
\hline t Statistic & -0.41 & -0.31 & 0.03 & -1.14 \\
\hline \multicolumn{5}{|c|}{ Quarter 3} \\
\hline Premium & NSW Base & QLD Base & SA Base & VIC Base \\
\hline Average & 13.56 & 11.94 & 7.64 & 10.83 \\
\hline t Statistic & $1.75 *)$ & 1.57 & 1.42 & 1.48 \\
\hline Premium & NSW Peak & QLD Peak & SA Peak & VIC Peak \\
\hline Average & 19.79 & 18.30 & 12.58 & 16.77 \\
\hline t Statistic & $1.91 *)$ & $2.43 * *)$ & $1.82 *)$ & 1.46 \\
\hline \multicolumn{5}{|c|}{ Quarter 4} \\
\hline Premium & NSW Base & QLD Base & SA Base & VIC Base \\
\hline Average & -5.08 & 8.02 & 4.87 & 4.24 \\
\hline t Statistic & -0.62 & 1.27 & 0.72 & $1.71 *)$ \\
\hline Premium & NSW Peak & QLD Peak & SA Peak & VIC Peak \\
\hline Average & -18.36 & 14.43 & 1.19 & 6.16 \\
\hline t Statistic & -0.92 & 0.97 & 0.08 & 1.32 \\
\hline
\end{tabular}

Table 5: Realized futures risk premiums for each quarter in NSW, QLD, SA and VIC. Results are reported for base load and peak load contracts for Q1 2003 to Q2 2012. The asterisk indicate a significant risk premium at the *) 10 percent significance level, **) 5 percent significance level, $* * *) 1$ percent significance level. 
Given the obvious seasonality in the risk premiums observed, in a next step we examine the ex-post futures risk premiums for each quarter separately in Table 5. Note that with 38 observations in total, we only observe risk premiums for around nine (Q3 and Q4) or ten (Q1 and Q2) contracts for each of the quarters. Therefore, results for the size of the premium and statistical tests have to be considered with care. We find that realized base load and peak load futures risk premiums are positive in all markets for contracts referring to Q1 and Q3 while they are almost invariably negative for Q2. For Q4 the results are rather mixed, suggesting a negative premium for NSW and a positive premium for QLD, SA and VIC. Overall, seasonality throughout the year seems to have a strong impact on the risk premium. In most cases the magnitude of the premium is higher for peak load contracts, where the average realized premiums range from $-\$ 18.36$ for $\mathrm{Q} 4 \mathrm{NSW}$ contracts to $\$ 24.67$ for Q1 QLD contracts. Recall that a peak load contract refers to delivery of approximately $930 \mathrm{MWh}$ during a quarter. Therefore, market participants in QLD on average paid an additional $\$ 22,943$ per purchased Q1 futures contract in comparison to what they would have paid in the spot market. For base load contracts the highest average premium is observed for Q3 NSW contracts with \$13.56, while the highest negative premium is observed for Q2 VIC contracts with $-\$ 5.19$. While average realized premiums seem to be quite large for several of the quarters and markets, from a statistical perspective, base load risk premiums are significantly greater than zero only for Q1 in QLD and VIC at the 5 percent significance level and for Q3 in NSW at the 1 percent significance level. For peak load contracts, the Q1 premiums in QLD and VIC are significant at the 5 percent, respectively 1 percent, level, while Q3 premiums are greater than zero for QLD at the 5 percent significance level and for NSW and SA at the 10 percent level of significance. Note, however, that for none of the quarters with average negative risk premiums, these premiums are significant.

As mentioned before, the literature provides a number of reasons for the comparably large premiums in electricity futures markets. According to Benth et al. (2008), closer to the delivery period of the futures contract, retailers or consumers aiming to hedge the risk of price spikes may be willing pay an additional premium for locking in prices in the short term. This explains the large positive risk premiums for several of the contracts observed in our study. Our results are also in line with studies on other markets, see e.g. Longstaff and Wang (2004); Hadsell and Shawky (2006); Diko et al. (2006); Bierbrauer et al. (2007); Redl et al. (2009). 
According to Shawky et al. (2003), the non-storability and presence of relatively few big players in electricity markets requires a high premium for market participants. Furthermore due to high volatility, the skewed distribution of electricity spot prices, and the risk of extreme price spikes, buyers of electricity might be willing to pay a large premium in the futures market in order to avoid the risk of substantial losses when buying in the spot market (Bessembinder and Lemmon, 2002; Longstaff and Wang, 2004). Note that for Australian electricity markets, Anderson et al. (2007) conducted interviews with retailers who argue that if they had not bought electricity futures contracts, the spot price may have risen even higher than the futures price. These findings also imply that the futures risk premium can be seen as compensation for market participants bearing the high risk of extreme spot prices.

\subsection{Explaining the Futures Risk Premium}

In the following section we investigate whether the bias in futures prices can be explained by the behaviour of the spot price during the month or quarter prior to delivery of the futures contract. As pointed out in Section 3, our reasoning follows work by e.g. Bessembinder and Lemmon (2002), Lucia and Torro (2008), Redl et al. (2009) and Botterud et al. (2010). We use equation (4) in order to examine whether realized futures risk premiums in regional markets can be explained by the level, standard deviation, variance, skewness and kurtosis of electricity spot prices prior to the delivery period of the futures contract.

The explanatory variables in the regression model were based on the spot price behaviour either during the last month or the last quarter prior to the delivery period. With respect to the explanatory power of the model, we obtained clearer results when the calculated moments were based on the last month's spot prices instead of the last quarter. In the following we will therefore only report results based on spot price behaviour during the month prior to the delivery period ${ }^{2}$. While futures contracts refer to a quarterly delivery period, we find that market participants seem to use rather information on the spot price during the most recent month for their hedging decisions.

\footnotetext{
${ }^{2}$ Results for the regression using moments based on the spot price behaviour during the quarter prior to the delivery period are available upon request to the authors.
} 


\begin{tabular}{|c|c|c|c|c|c|c|c|c|c|c|c|c|c|c|c|c|}
\hline Coefficient & & $\begin{array}{c}\text { Constant } \\
\text { (t-Stat) }\end{array}$ & & $\begin{array}{l}\text { Mean } \\
\text { (t-Stat) }\end{array}$ & & & $\begin{array}{l}\text { Stdev } \\
\text { (t-Stat) }\end{array}$ & & $\begin{array}{c}\text { Var } \\
(\mathrm{t}-\mathrm{Stat})\end{array}$ & & $\begin{array}{c}\text { Skew } \\
\text { (t-Stat) }\end{array}$ & & $\begin{array}{c}\text { Kurt } \\
\text { (t-Stat) }\end{array}$ & $\mathrm{R}^{2}$ & $\mathrm{dj} \mathrm{R}^{2}$ & F-stat \\
\hline Premium & & & & & & & Using la & st & onth data for & $r$ ind & ependent & t variab & les & & & \\
\hline \multirow{2}{*}{ NSW Base } & & -8.11 & & 0.54 & $* * *)$ & & -0.29 & & 0.000774 & & -15.09 & $* *)$ & 3.22 & **) 0.42 & 0.33 & 4.61 \\
\hline & 1 & -1.20 & )( & 3.62 & ) & 1 & -0.92 & )( & 0.63 & )( & -2.13 & )( & 2.70 & ) & & \\
\hline \multirow{2}{*}{ QLD Base } & & -1.61 & & 0.43 & $* *)$ & & -0.03 & & 0.000011 & & -3.49 & & 0.31 & 0.35 & 0.25 & 3.43 \\
\hline & ( & -0.21 & )( & 2.38 & ) & 1 & -0.11 & )( & 0.01 & )( & -0.49 & )( & 0.25 & ) & & \\
\hline \multirow{2}{*}{ SA Base } & & 2.06 & & 0.23 & & & 0.04 & & -0.000387 & & -0.24 & & -0.49 & 0.10 & -0.04 & 0.71 \\
\hline & 1 & 0.17 & )( & 0.59 & ) & 1 & 0.08 & )( & -0.43 & )( & -0.11 & )( & -0.78 & ) & & \\
\hline \multirow{2}{*}{ VIC Base } & & -8.22 & & 0.60 & $* *)$ & & -0.82 & & 0.006839 & & -1.71 & & 0.74 & 0.38 & 0.28 & 3.90 \\
\hline & ( & -1.09 & )( & 2.44 & ) & 1 & -1.23 & ) ( & 1.01 & ) ( & -0.65 & )( & 1.16 & ) & & \\
\hline \multirow{2}{*}{ NSW Peak } & & 2.77 & & 0.44 & $* *)$ & & -0.22 & & 0.000233 & & -36.83 & $* *)$ & 8.57 & $* * *) 0.31$ & 0.21 & 2.91 \\
\hline & ( & 0.18 & )( & 2.51 & ) & 1 & -0.73 & )( & 0.44 & )( & -2.37 & ) & 2.81 & ) & & \\
\hline \multirow{2}{*}{ QLD Peak } & & 9.63 & & 0.24 & & & -0.04 & & 0.000086 & & -0.99 & & -0.71 & 0.17 & 0.04 & 1.28 \\
\hline & 1 & 0.71 & )( & 1.12 & ) & 1 & -0.12 & )( & 0.16 & )( & -0.09 & ) & -0.30 & ) & & \\
\hline \multirow{2}{*}{ SA Peak } & & 2.47 & & 0.40 & & & -0.26 & & 0.000024 & & -5.45 & & 0.64 & 0.06 & -0.09 & 0.41 \\
\hline & ( & 0.10 & )( & 0.68 & ) & ( & -0.56 & )( & 0.07 & )( & -0.42 & )( & 0.19 & ) & & \\
\hline \multirow{2}{*}{ VIC Peak } & & -11.63 & & 0.76 & $* * *)$ & & -0.57 & & 0.001421 & & -9.80 & & 2.83 & 0.33 & 0.22 & 3.13 \\
\hline & 1 & -1.17 & )( & 3.21 & ) & 1 & -1.10 & )( & 0.54 & )( & -1.07 & )( & 1.28 & ) & & \\
\hline
\end{tabular}

Table 6: Results of regression analysis (4) for realized futures risk premium of quarterly base load and peak load contracts in NSW, QLD, SA and VIC. Explanatory variables are based on the spot price behaviour during the month prior to the delivery period of the futures contract. The asterisks indicate a significant risk premium at the *) 10 percent significance level, **) 5 percent significance level, $* * *) 1$ percent significance level.

Since several of the explanatory variables considered were not statistically significant, we also apply a stepwise regression analysis to the data. Hereby, we use stepwise backward regression, starting with a model that includes all explanatory variables and then sequentially removing the insignificant variables from the model. Results for the estimated models including all variables and the optimal model based on the stepwise regression with an exit significance level of 0.1 are reported in Tables 6 and 7 .

Examining the explanatory power of the models in Table 6 we find considerable differences across the considered regional markets and contracts. For base load contracts, results for the coefficient of determination range from 0.10 for SA up to 0.38 , respectively 0.42 , for VIC and NSW. The explanatory power of the regression model for peak load contracts is usually slightly lower and ranges from 0.06 for SA to 0.33 for NSW. While these results indicate only a limited explanatory power of the model, the coefficients of determination are still roughly in the same range or even higher than what has been reported in earlier studies. For example, using a similar approach, Lucia and Torro (2008) find values for $\mathrm{R}^{2}$ ranging from 0.01 to 0.30 for short term risk premiums in the Nordpool market while Redl et al. (2009) obtain values of $\mathrm{R}^{2}$ between 0.02 and 0.11 when modelling monthly futures contracts in the European EEX and Nordpool markets. 
Note that for some of the considered markets, none of the variables turns out to be significant. However, for most markets the average spot price during the month prior to the beginning of the delivery period is significant, while estimated coefficients are positive for all markets and contracts. This indicates that the higher the spot price prior to the delivery period, the more pronounced is the realized risk premium, i.e. the more the futures quote will overestimate the average spot price during the delivery period. While not being significant, estimated coefficients for the standard deviation are negative and coefficients for the realized variance are positive. This somehow confirms the convex, initially decreasing and then increasing relationship of the risk premium with price risk suggested by Bessembiner and Lemmon (2002).

On the other hand, estimated coefficients for skewness are negative for all markets and contracts. Also coefficients are significant at the 5 percent level for risk premiums exhibited by NSW base and peak load contracts. The negative sign of these coefficients suggests a general tendency for the realized risk premium to decrease with increasing skewness of the spot prize prior to the delivery period. These results somehow contradict the relationship between skewness and the forward premium as it has been suggested by, e.g. Bessembiner and Lemmon (2002): since positive skewness implies the possibility of higher upward spikes, both the forward price and the forward premium should be positively related to skewness. On the other hand, our results are in line with several other empirical studies, e.g. Lucia and Torro (2008) and Botterud et al. (2010) in the Nord Pool market or Furio and Meneu (2010) in the Spanish electricity market. These authors also find negative coefficients for the skewness parameter, while, similar to our results the coefficients in these studies are usually not significant. Estimated coefficients for kurtosis are mainly positive, however, only significant for risk premiums inherent in NSW base and peak load contracts. Note that also a higher kurtosis suggests an increased risk of price spikes and extreme observations. Therefore, the effects of increasing skewness and kurtosis, i.e. the effects of a higher probability for extreme prices in the spot market on the risk premium are not clear cut for the considered markets.

Table 7 provides results for included variables and explanatory power of the model, when a stepwise regression is applied. The obtained results confirm previous results for the model with all variables and suggest that for several markets and considered contracts, only the level of the spot price is significant. Applying stepwise regression we obtain coefficients of determination ranging from 0.30 to 0.39 for base load and between 0.23 and 0.28 for peak 
load contracts. Note that for the NSW market where the variables spot price level, skewness and kurtosis are included, we also obtain the highest explanatory power for the estimated regression models. On the other hand, the stepwise regression results suggest that for SA base load as well as for QLD and SA peak load contracts the considered models do not provide significant explanatory power.

We also conduct residual diagnostic checks to test the robustness of our regression results. In particular we conduct White tests for heteroskedasticity (White, 1980) and DurbinWatson tests for autocorrelation in the residuals ${ }^{3}$. Note that we do not conduct these tests for the SA (base and peak periods) and QLD (peak only) regions, since none of the considered variables was significant and the model only provides very limited explanatory power. The results for the White test suggest that there are no issues with heteroskedasticity in the residuals for the NSW and QLD markets. For VIC base load contracts, the test suggests heteroskedastic residuals at the 5 percent significance level such that White's heteroskedasticity-consistent estimator (HCE) was applied to adjust the t-statistics (as indicated by an asterisk *) in Table 7. Conducted Durbin Watson tests suggest that there is no presence of autocorrelation in the residuals.

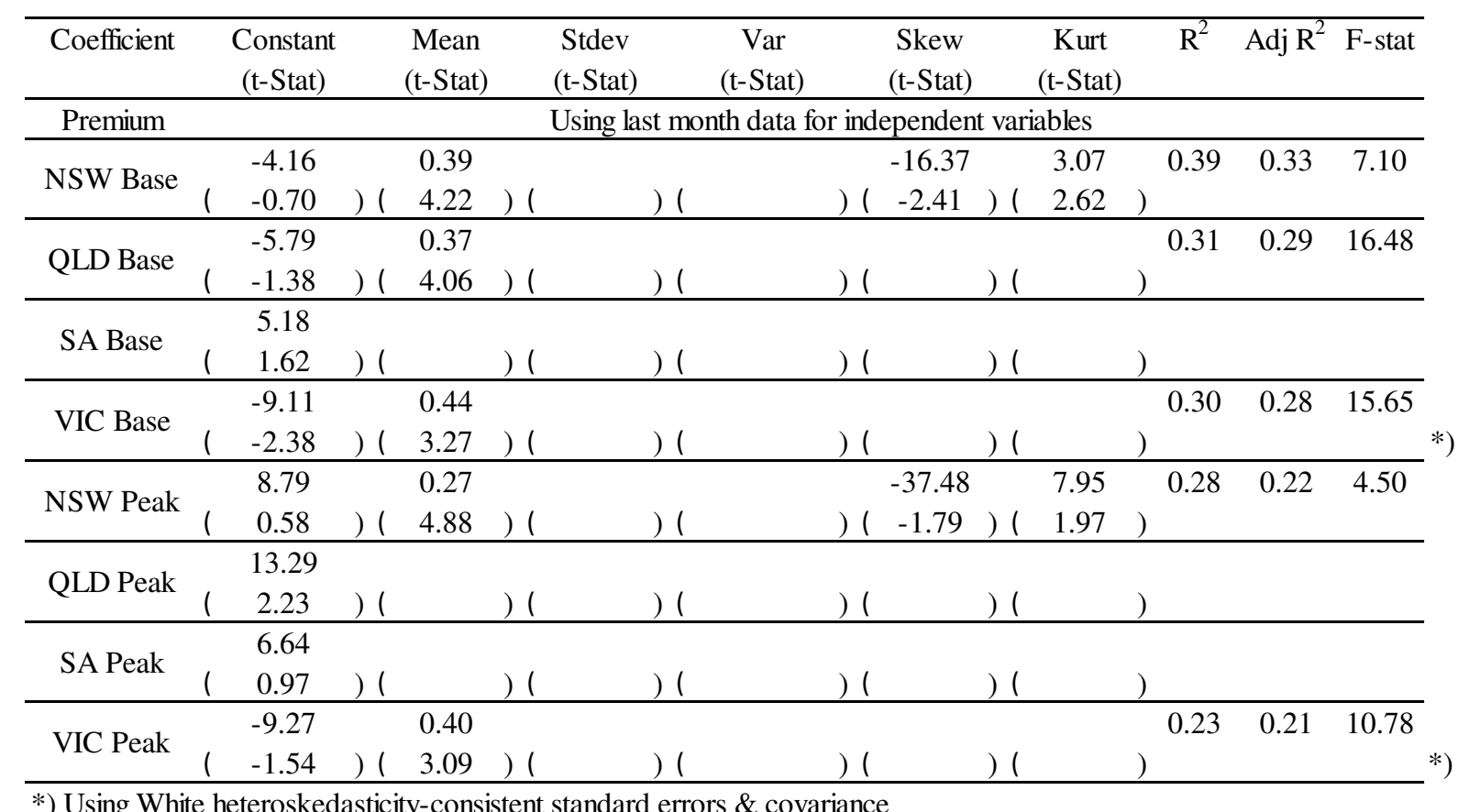

*) Using White heteroskedasticity-consistent standard errors \& covariance

Table 7: Results for stepwise regression for realized futures risk premium of quarterly base load and peak load contracts in NSW, QLD, SA and VIC. Explanatory variables are based on the spot price behaviour during the month prior to the delivery period of the futures contract.

\footnotetext{
${ }^{3}$ Results for these tests are not reported here but are available upon request to the authors.
} 


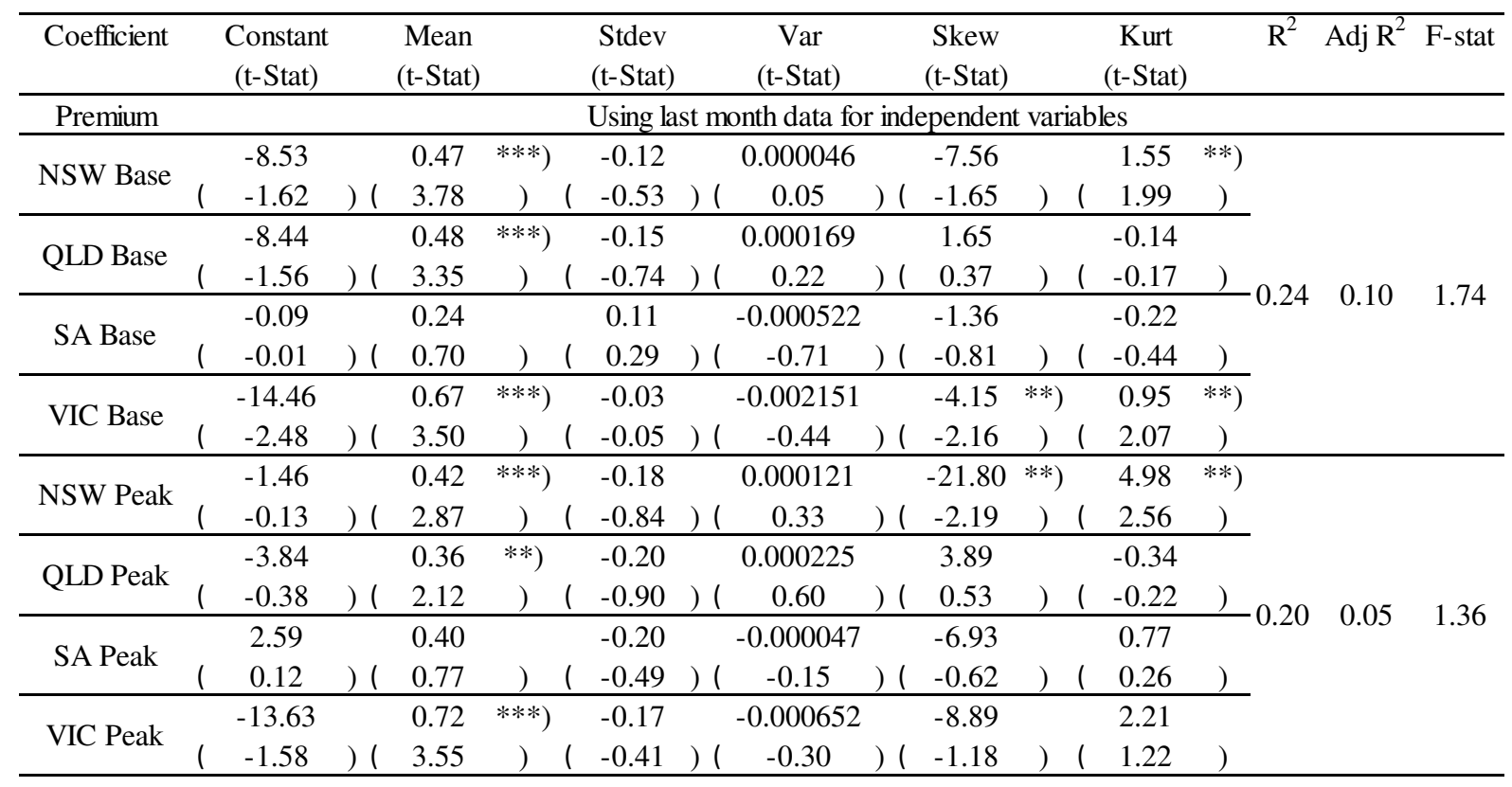

Table 8: Results for the applied seemingly unrelated regression (SUR) model for realized risk premium of quarterly base load and peak load contracts in NSW, QLD, SA and VIC. Explanatory variables are based on the spot price behaviour during the month prior to the delivery period of the futures contract.

Recall that in Section 4.2 we found high correlations between observed risk premiums across the regional markets. Therefore, we decided to also apply a seemingly unrelated regression (SUR) model to the data, see equation (5). The SUR estimation technique estimates the equations jointly, accounting for contemporaneous correlations between the errors as well as for different variances of the error terms in the four markets. Results for the applied SUR model are reported in Table 8. We can see that also for this model spot price levels during the month prior to delivery are positive and statistically significant at the 1 percent or, at least at the 5 percent level for all markets except the SA region. This is true for both base load and peak load risk premiums. The estimated coefficients for the standard deviation are mostly negative (except for base load contracts in SA), while the sign of the coefficients for the variance varies and is positive for NSW and QLD, but negative for SA and VIC. Therefore, for the NSW and QLD market, our results are in line with the suggested convex relationship between risk premiums and price risk in the spot market suggested by Bessembiner and Lemmon (2002). Skewness and kurtosis of spot prices during the month prior to delivery are positive and statistically significant at the 5 percent significance level for NSW (both base and peak) and VIC (base only). The explanatory power of the model is 0.24 for risk premiums associated with base load contracts and 0.20 for peak load contract risk premiums. 
Finally, we test for the significance of contemporaneous correlations between the four different electricity markets. We use the Lagrange Multiplier (LM) test to examine the null hypotheses of zero correlation (Hill et al., 2011):

$$
\mathrm{H}_{0}: \sigma_{\mathrm{NSW}, \mathrm{QLD}}=\sigma_{\mathrm{NSW}, \mathrm{SA}}=\sigma_{\mathrm{NSW}, \mathrm{VIC}}=\sigma_{\mathrm{QLD}, \mathrm{SA}}=\sigma_{\mathrm{QLD}, \mathrm{VIC}}=\sigma_{\mathrm{SA}, \mathrm{VIC}}=0
$$

with a chi-square distribution test statistic:

$$
\mathrm{LM}=\mathrm{T}\left(\mathrm{r}_{\mathrm{NSW}, \mathrm{QLD}}^{2}+\mathrm{r}_{\mathrm{NSW}, \mathrm{SA}}^{2}+\mathrm{r}_{\mathrm{NSW}, \mathrm{VIC}}^{2}+\mathrm{r}_{\mathrm{QLD}, \mathrm{SA}}^{2}+\mathrm{r}_{\mathrm{QLD}, \mathrm{VIC}}^{2}+\mathrm{r}_{\mathrm{SA}, \mathrm{VIC}}^{2}\right)
$$

The SUR residuals correlation matrix as well as results for conducted LM tests are provided in Table 9. Our results illustrate that the null hypothesis of zero correlation is rejected at all significance levels, so we conclude that contemporaneous correlation exists across the four different electricity markets. Therefore, the panel SUR method should be preferred over applying a separate ordinary least squares (OLS) regression model for each market.

\begin{tabular}{ccccc}
\hline \multicolumn{5}{c}{ Residuals Correlation Matrix } \\
\hline BASE & NSW & QLD & SA & VIC \\
\hline NSW & 1.0000 & & & \\
QLD & 0.8467 & 1.0000 & & \\
SA & 0.4104 & 0.4678 & 1.0000 & \\
VIC & 0.7006 & 0.6901 & 0.4954 & 1.0000 \\
\hline PEAK & NSW & QLD & SA & VIC \\
\hline NSW & 1.0000 & & & \\
QLD & 0.8365 & 1.0000 & & \\
SA & 0.2785 & 0.2228 & 1.0000 & \\
VIC & 0.5484 & 0.5361 & 0.2278 & 1.0000 \\
\cline { 1 - 4 } & \multicolumn{3}{c}{ p-value } & \\
\cline { 2 - 4 } & PERIOD & LM & $\mathbf{4 . 5 9 E - 1 2}$ & \\
\cline { 2 - 4 } & BASE & $\mathbf{6 4 . 8 7}$ & $\mathbf{2 . 8 0 E - 0 7}$ &
\end{tabular}

Table 9: Residuals correlation matrix, LM test statistic and p-values of the test for contemporaneous correlation of error terms for NSW, QLD, SA, and VIC markets.

Overall, we find that a significant fraction of the variation in realized futures risk premiums can be explained by the spot price behaviour during the month prior to delivery of the contract. Our results also partially support the framework suggested by Bessembinder and 
Lemmon (2002). Their model predicts that the forward bias reflected in the realized or expost forward premium should increase with the expected demand for electricity and therefore, also with the mean price level. The authors also suggest that the equilibrium premium is convex, initially decreasing and then increasing in the variability of power demand and electricity spot prices. This means that in our model we would expect the coefficient for the standard deviation to be negative while the coefficient for the variance should be positive. Table 6 shows that in the estimated models for NSW, QLD, SA (peak) and VIC, the coefficients generally show the expected signs. Only for SA (base) the coefficient for standard deviation is negative and for variance is positive. Results for the conducted SUR regression in Table 8 also confirm the significant impact of spot price levels on the risk premium. They also provide some indication of the convex relationship between volatility and the forward risk premium for NSW and QLD markets. Our results are also in line with Anderson et al. (2007) who reported that most retailers participating in Australian electricity markets are highly risk-averse.

\subsection{Summary and Conclusions}

This paper studies the relationship between spot and futures prices as well as realized risk premiums in regional Australian electricity markets. The National Electricity Market (NEM) in Australia began operating in December 1998 and operates in an interconnected grid comprising several regional networks in different states. Australian electricity markets can be considered as significantly more volatile and spike-prone than other comparable markets (Higgs and Worthington, 2008). While there have been a number of publications on the behaviour of electricity spot prices in Australia, we provide a pioneering study focusing on futures markets and risk premiums. In our analysis we focus on realized or ex-post futures risk premiums in the four major states of New South Wales (NSW), Queensland (QLD), South Australia (SA) and Victoria (VIC).

We find that Australian electricity markets exhibit significant risk premiums for several of the regions considered such that futures prices cannot be considered as unbiased estimators of realized spot prices. Since average realized futures risk premiums are positive for all markets, we conclude that there is a clear tendency for futures prices to overstate average spot prices during the delivery period. In particular, we find economically and statistically 
significant positive ex-post futures premium for futures contracts referring to the first quarter of the year in QLD and VIC as well as the third quarter of the year in NSW, QLD and SA. There also seems to be a strong impact of seasonality with significantly positive risk premiums during the first and third quarter and negative premiums during the second quarter. Observed premiums are quite substantial for several of the examined contracts: for example, on the last trading day prior to the beginning of the delivery period, market participants on average paid an additional \$22,943 per purchased Q1 futures contract in QLD, in comparison to what they would have paid in the spot market without hedging. Not taking into account seasonality or the behaviour during specific quarters, the QLD and VIC regions still yield statistically significant futures premiums with an average magnitude of A\$7.19 (QLD) and A \$4.89 (VIC) for base load and A \$13.29 (QLD) and A \$8.30 (VIC) for peak load contracts.

We also observe significant positive correlations between the observed risk premiums across different regional markets. This can be explained by interconnectors between the regional markets allowing for export or import of electricity from one market to the other. Correlations are higher for adjoining regions than for markets that are geographically more distant.

Further investigating the issue, we find that price formation in the considered markets seems to be influenced by historical spot price behaviour. Our results suggest that for some of the markets the bias can at least be partially explained by the level, volatility, skewness and kurtosis of spot prices during the month prior to delivery. In particular, we find that realized risk premiums significantly increase with the level of the spot price. Overall, our results suggest that retailers in Australian electricity markets are risk averse and willing to pay an additional risk premium in the futures market to avoid the risk of price shocks and spikes in the spot market.

Our results also suggest directions for future research. While on average we find positive realized futures risk premiums in all regional markets, in our analysis we only consider futures prices immediately prior to the start of the delivery period. Analysis examining the evolution of the risk premiums over time might provide additional insights into the dynamics of the premium and thus, market participants' changing views on the relationship between futures prices and expected or realized spot prices. Such analysis might also prove helpful to develop optimal trading and risk management strategies for electricity producers or retailers in Australian markets. Further, in our analysis we consider realized or ex-post futures risk premiums only. Alternatively, one could investigate ex-ante futures risk 
premiums, i.e. compare futures quotes to the expected, instead of the realized spot price, during the delivery period. We recommend such an analysis for future work. 


\section{Bibliography}

Anderson, EJ, Hu, X \& Winchester, D 2007, 'Forward Contracts in Electricity Markets: The Australian Experience', Energy Policy, no. 35, pp. 3089 - 3103.

AEMO Information Centre <aemo@reference-service.info>, 'Response to the General Information Query Question Q22582', 13 May 2011.

Australian Energy Market Operator 2010, 'About AEMO - Overview', http://www.aemo.com.au/corporate/aboutaemo.html, viewed 29 December 2010.

Bateson, J \& Swan, PL 1989, 'Economies of Scale and Utilization: An Analysis of the MultiPlant Generation Costs of the Electricity Commission of New South Wales', The Economic Record, vol. 65, pp. $329-344$.

Becker, R, Hurn, S \& Pavlov, V 2007, 'Modelling Spikes in Electricity Prices', The Economic Record, vol. 83, pp. 371-382.

Benth, F, Benth, S \& Koekebakker, S 2008, Stochastic Modelling of Electricity and Related Markets, $2^{\text {nd }}$ edition, World Scientific. Advanced Series on Statistical Science and Applied Probability.

Bessembinder, H \& Lemmon, ML 2002, 'Equilibrium Pricing and Optimal Hedging in Electricity Forward Markets', The Journal of Finance, vol. 57 no. 3, pp. 1347 - 1381.

Bierbrauer, M, Menn, C, Rachev, ST \& Trück, S 2007, 'Spot and Derivative Pricing in the EEX Power Market', The Journal of Banking \& Finance, no. 31, pp. 3462 - 3485.

Botterud, A, Bhattacharyya, AK \& Ilic, M 2002, 'Futures and Spot Prices - An Analysis of the Scandinavian Electricity Market', Working Paper, pp. $1-8$.

Botterud, A, Kristiansen, T \& Ilic, M 2010, 'The Relationship between Spot and Futures Prices In The Nord Pool Electricity Market', Energy Economics, no. 32, pp. 967 - 978.

Bunn, DW \& Gianfreda, A 2010, 'Integration and Schock Transmission across European Electricity Forward Markets', Energy Economics, no. 32, pp. 278 - 291.

Bowden, N \& Pane, JE 2008, 'Short Term Forecasting of Electricity Prices for MISO Hubs: Evidence From ARIMA-EGARCH Models', Energy Economics, no. 30, pp. 31863197.

Burger, M, Klar, B, Müller, A \& Schindlmayr, G 2004, 'A Spot Market Model for Pricing Derivatives in Electricity Markets', Quantitative Finance, vol. 4, pp. 109 - 122.

Daskalakis, G \& Markellos, RN 2009, 'Are Electricity Risk Premia Affected by Emission Allowance Prices? Evidence from the EEX, Nord Pool and Powernext', Energy Policy, no. 3, pp. 2594 - 2604.

Diko, P, Lawford, S \& Limpens, V 2006, 'Risk Premia in Electricity Forward Markets', Studies in Nonlinear Dynamics \& Econometrics, vol. 10 no. 3, pp. $1-22$.

Douglas, S \& Popova, J 2008, 'Storage and the Electricity Forward Premium', Energy Economics, no. 30, pp. 1712 - 1727.

Eydeland, A \& Geman, H 1999, Energy Modelling and the Management of Uncertainty, Riskbooks, London UK.

Fanone, E, Gamba, A, \& Prokopczuk, M 2011. 'The Case of Negative Day-ahead Electricity Prices'. Working Paper.

Furio, D \& Meneu, V 2010, 'Expectations and Forward Risk Premium in the Spanish Deregulated Power Market', Energy Policy, no. 38, pp. 784 - 793.

Greene, WH 2011, Econometric Analysis $7^{\text {th }}$ Edition, Pearson Prentice Hall, USA.

Hadsell, L \& Shawky, HA 2006, 'Electricity Price Volatility and the Marginal Cost of Congestion: An Empirical Study of Peak Hours in the NYISO Market 2001-2004', The Energy Journal, vol. 27 no. 2, pp. 157 - 179.

Haugom, E \& Ullrich, CJ 2012, 'Market Efficiency and Risk Premia in Short Term Forward Prices', Energy Economics, no. 34, pp. 1931 - 1941. 
Higgs, H 2009, 'Modeling Price and Volatility Inter-Relationship in the Australia Wholesale Spot Electricity Markets', Energy Economics, no. 31, pp. 748 - 756.

Higgs, H \& Worthington, A 2008, 'Stochastic Prices Modeling Of High Volatility, Mean Reverting, Spike-Prone Commodities: The Australia Wholesale Spot Electricity Market', Energy Economics, no. 30, pp. 3172 - 3185.

Hill, RC, Griffiths, WE \& Lim, GC 2011, Principles of Econometrics $4^{\text {th }}$ Edition, John Wiley \& Sons Inc., New Jersey USA.

Huisman, R, Huurman, C \& Mahieu, R 2007, 'Hourly Electricity Prices in Day-Ahead Markets', Energy Economics, no. 29, pp. 240 - 248.

$\mathrm{Hu}, \mathrm{X}$, Grozev, G \& Battern, D 2005, 'Empirical Observations of Bidding Patterns in Australia's National Electricity Market', Energy Policy, no. 33, pp. 2075 - 2086.

Kaldor, N 1939. 'Speculation and Economic Stability', The Review of Economic Studies, vol. 7 , no. 1 , pp. $1-27$.

Kanamura, T \& Ohashi, K 2008, 'On Transition Probabilities of Regime Switching in Electricity Prices', Energy Economics, no. 30, pp. 1158 - 1172.

Karakatsani, NV \& Bunn, DW 2008, 'Intra-Day and Regime-Switching Dynamics in Electricity Price Formation', Energy Economics, no. 30, pp. 1176 - 1797.

Keynes, JM 1930, A Treatise On Money. Macmillan, London.

Kim, PR 1997, 'The Effect of Profit Regulations on Combined Two-Part and Peak-Load Pricing', The Economic Record, vol. 73, pp. 238 - 247.

Kolos, SP \& Ronn, EI 2008, 'Estimating the Commodity Market Price of Risk for Energy Prices', Energy Economics, no. 30, pp. 621 - 641.

Kvam, PH \& Vidakovic, B 2007, Nonparametric Statistics with Applications to Science and Engineering, John Wiley \& Sons Inc., New Jersey USA.

Longstaff, FA \& Wang, AW 2004, 'Electricity Forward Prices: A High Frequency Empirical Analysis', The Journal of Finance, vol. 59, no. 4, pp. 1877 - 1900.

Lucia, JJ \& Schwartz, ES 2002, 'Electricity Prices and Power Derivatives: Evidence from the Nordic Power Exchange', Review of Derivatives Research, no. 5, pp. 5 - 50.

Lucia, JJ \& Torro, H, 2008, 'Short-Term Electricity Futures Prices: Evidence on the TimeVarying Risk Premium', Working Paper, pp. 1 - 34.

Lucia, JJ \& Torro, H, 2011, 'On the Risk Premium in Nordic Electricity Futures Prices', International Review of Economics and Finance, pp. $750-763$.

Pietz, M 2009, 'Risk Premia in the German Electricity Futures Market', Working Paper Series CEFS, pp. $1-36$.

Redl, C \& Bunn, DW 2013, 'Determinants of the Premium in Forward Contracts', Journal of Regulatory Economics, no. 43(1), pp. 90-111.

Redl, C, Haas, R, Huber, C \& Böhm, B 2009, 'Price Formation in Electricity Forward Markets and the Relevance of Systematic Forecast Errors', Energy Economics, no. 31, pp. $356-364$.

Reedman, L, Graham, P \& Coombes, P 2006, 'Using A Real-Options Approach to Model Technology Adoption under Carbon Price Uncertainty: An Application to the Australian Electricity Generation Sector', The Economic Record, vol. 82, pp. $64-73$.

Shawky, AH, Marathe, A \& Barrett, CL 2003, 'A First Look at the Empirical Relation between Spot and Futures Electricity Prices in the Unites States', The Journal of Futures Markets, vol. 23, no. 10, pp. $931-955$.

Swan, PL 1990, 'Real Rates of Return in Electricity Supply: New South Wales, Tasmania and Victoria', The Economic Record, vol. 66, pp. 93 - 109. 
Thomas, S, Ramiah, V, Mitchell, H \& Heaney, R 2011, 'Seasonal Factors and Outlier Effects in Returns on Electricity Spot Prices in Australia's National Electricity Market', Applied Economics, vol. 43 no. 3, pp. 355 - 369.

Ullrich, CJ 2012, 'Equilibrium Forward Risk Premiums in Electricity Markets', Journal of Energy Markets, vol. 6 no. 3, pp. $29-49$.

Veraart, AED \& Veraart, LAM 2013, 'Risk Premia in the Energy Markets', Creates, http://econ.au.dk/fileadmin/site_files/filer_oekonomi/Working_Papers/CREATES/2013 /rp13_02.pdf, viewed on 31 October 2013.

Weron, R 2006, Modeling and Forecasting Loads And Prices In Deregulated Electricity Markets, John Wiley \& Sons Inc., New Jersey USA.

Weron, R 2008. 'Market Price of Risk implied by Asian-style Electricity Options and Futures', Energy Economics, no. 30, pp. 1098 - 1115.

White, H 1980, 'A Heteroskedasticity-Consistent Covariance Matrix Estimator and a Direct Test for Heteroskedasticity', Econometrica, vol. 48, no. 4, pp. $817-838$.

Worthington, A, Kay-Spratley, A \& Higgs, H 2005, 'Transmission of Prices and Price Volatility in Australian Electricity Markets', Energy Economics, no. 27, pp. 337 - 350. 


\title{
3. The Dynamics of Risk Premiums in Australian Electricity Futures Markets
}

\begin{abstract}
We investigate the dynamics of futures risk premiums in four regional Australian electricity markets (NSW, QLD, SA and VIC). We analyse realized risk premiums for quarterly futures contracts for different time intervals during the twelve months prior to the beginning of the delivery period of the contracts. Using data from 2005 to 2012, we find that futures premiums exhibit dynamics through time and tend to become more statistically significant as the contracts get closer to the beginning of the delivery period. The magnitude and significance of the premiums, however, vary across different regions, and also depend significantly on the contract quarter, i.e. whether the contract refers to the first, second, third or fourth quarter of the year. In a second step, we investigate the determinants of realized futures premiums and propose a model to effectively capture the dynamics of the premiums. We argue that time-todelivery of contracts, spot price levels, volatility and variance of daily spot prices as well as the recent number of price spikes in the market are determinants for the dynamics of the observed premiums. For several of the markets and quarters, our model provides a reasonably high explanatory power. Overall, we find that futures premiums tend to be higher when contracts approach the beginning of the delivery period. Premiums also have a tendency to increase with spot price levels and with the frequency of price spikes observed in the spot market. Overall, our results illustrate the risk aversion of market participants and help to better understand the hedging behaviour and dynamics of risk premiums in Australian electricity markets.
\end{abstract}




\subsection{Introduction}

One consequence of the ongoing deregulation of power markets around the world is that electricity futures markets can provide an important tool for reducing risk exposure (Botterud et al., 2002). As pointed out by e.g. Weron (2006), Benth et al. (2008), the risks contained in electricity spot and futures markets are quite substantial. Further, it is not possible to smooth out electricity supply and demand shocks since electricity is non-storable (Bowden and Payne, 2008). Electricity is also strongly characterised by its very limited transportability (Lucia and Schwartz, 2002), and its seasonal patterns as well as mean reversion, price dependent volatilities, long term non-stationarity and the occurrence of price spikes (Burger et al., 2004; Huisman et al., 2007; Kanamura and Ohashi, 2008; Karakatsani and Bunn, 2008). These distinctive features of price behaviour in electricity markets have prompted numerous studies.

Considerable controversies are associated with the existence of futures premiums in commodity markets (So, 1987; Deaves and Krinsky, 1995). Commodity futures prices can exhibit either backwardation or contango. Backwardation occurs when futures prices are lower than spot prices, while the market is usually referred to exhibit contango, when futures prices are higher than spot prices. According to Keynes (1930), a risk-averse net short hedge will reward (pay a premium to) a risk-assuming speculator in the case of backwardation. In contango, however, a risk-averse net long hedge will reward a risk-assuming speculator (Cootner, 1960). Despite this, Dusak (1973) finds that commodity futures premiums are not economically and statistically significant and later research by Baxter et al. (1985) supports Dusak's finding. These contrary results present a conundrum in understanding the dynamics of commodity futures premiums.

For electricity markets, several studies support the existence of futures risk premiums, however, the results and implications of these studies are not clear-cut. Some studies report positive premiums, see e.g. Longstaff and Wang (2004); Hadsell and Shawky (2006); Diko et al. (2006); Bierbrauer et al. (2007); Daskalakis and Markellos (2009); Redl et al. (2009), while others find negative risk premiums, for example in the PJM (Bessembiner and Lemmon, 2002) and Nord Pool (Botterud et al., 2010) markets. Clearly, whether observed risk premiums are positive or negative may also be a question of the time to delivery of the contract. According to Benth et al. (2008), economic intuition would suggest that a long-term negative and short-term positive risk premium should be observed in electricity markets. 
Long-term contracts with maturities greater than several months will be mainly used by producers to hedge their future electricity production. Producers may be willing to accept prices lower than the actual expected spot price in order to guarantee that the electricity produced can be sold in the market, which may result in a negative long-term risk premium. On the other hand, in the short-term, retailers or consumers, aiming to hedge the risk of extreme price outcomes in the spot market, may be willing to pay an additional premium for their hedge. Also, as pointed out above, electricity is also a seasonal commodity and it can be expected that contracts referring to different quarters might have very different risk premiums, see e.g. Handika and Trück (2013). It can also be expected that the behaviour of spot prices such as high price levels, changes in volatility or price spikes will have an influence on observed risk premiums (Redl and Bunn, 2011). This influence could exist at any point in time when the contract is traded, but may potentially be even higher once the contract gets closer to the beginning of the delivery period. Unfortunately, so far the literature on risk premiums in electricity futures markets has not investigated these issues very thoroughly. This is true in particular for regional Australian electricity markets that are examined in this study.

This paper offers a new perspective on the topic of risk premiums in electricity markets, by examining observed premiums through time across several electricity markets in Australia. Our study focuses on the ex-post futures premium that measures the difference between the quoted futures price prior to the beginning of the delivery period and the realised spot price during delivery period of the futures contract (Redl et al., 2009). First, we investigate the magnitude of futures premiums at different time instances in order to examine the dynamics of futures premiums with respect to the time-to-delivery. We argue that futures premiums are dynamic rather than static. We analyze each region and each quarter separately in order to accommodate regional and seasonal properties of electricity markets. In a second step, we investigate the determinants of the observed risk premiums. Unfortunately, these dynamics are not easy to model. As pointed out by Huisman and Kilic (2012), most likely we cannot rely on a single model for explaining explaining risk premiums in different electricity markets. However, a number of determinants have been found to have an impact on these premiums in prior studies. Based on previous results in the literature, we therefore suggest that time to maturity (Bailey and Ng, 1991; Bessembinder and Chan, 1992; Wilkens and Wimschulte, 2007; Bhar and Lee, 2011; Gorton et al., 2012), spot prices levels (Raynauld and Tessier, 1984; Wilkens and Wimschulte, 2007; Chevillon and Riffalrt, 2009), spot price 
volatility (Redl et al., 2009 ; Todorov, 2010; Benth et al., 2013) as well as the occurrence of price spikes (Coulon et al., 2013; Redl and Bunn, 2013) are key determinants of dynamic futures premiums in electricity markets. Our analysis provides important and new insights on the behaviour and determinants of futures risk premiums in electricity markets.

The remainder of the paper is organized as follows. Section 2 provides a brief overview of spot and futures trading in the Australian National Electricity Market (NEM). Section 3 discusses ex-post futures premium dynamics and their potential determinants. Section 4 describes the data and reports the futures premiums at different time intervals for each market and quarter. Section 5 investigates determinants of the observed futures premiums using a regression analysis. Section 6 concludes and provides suggestions for future work.

\subsection{The Australian Electricity Market}

The Australian electricity market has experienced significant changes during the last two decades. Prior to 1997 the market consisted of vertically integrated businesses operating within each of the states, without any connection between individual states. The businesses were owned by state governments and operated as monopolies. Overall, there were approximately twenty-five electricity distributors, all protected by governments from competition. To promote energy efficiency and reduce the costs of electricity production, in the late 1990s the Australian government commenced significant structural reform which, among others, had the following objectives: the separation of transmission from electricity generation, the merger of twenty-five electricity distributors into a smaller number of distributors, and the functional separation of electricity distribution from the retail supply of electricity. Retail competition was also introduced: a state's electricity purchases could be made through a competitive retail market and customers were now free to choose their retail supplier.

The NEM began operating as a wholesale market in December 1998. It is now an interconnected grid comprising several regional networks which supply electricity to retailers and end-users. As mentioned above, the NEM includes the states of QLD, NSW, VIC, SA and the ACT, while TAS is connected to the state of VIC via an undersea inter-connector. The link between electricity producers and consumers is established through a pool which is used to aggregate the output from all generators in order to meet the forecast demand. The 
pool is managed by the Australian Energy Market Operator (AEMO) under the National Electricity Law in conjunction with market participants and regulatory agencies. Unlike many other markets, the Australian spot electricity market is not a day-ahead market, instead electricity is traded in a constrained real time spot market where prices are set each five minutes by the AEMO. Therefore, generators submit offers every five minutes. This information is used to determine the number of generators required to produce electricity in a more cost-efficient way based on existing demand. The final price is determined every halfhour for each of the regions as an average over the 5-minute spot prices for each trading interval. Based on the half-hourly spot prices, a daily average spot price for each regional market can also be calculated. AEMO determines the half-hourly spot prices for each of the regional markets separately.

In recent years, the market for electricity derivatives has developed rapidly including electricity forward, futures and option contracts. Anderson et al. (2007) note that there are three types of Australian electricity forward contracts: (i) Bilateral over-the-counter (OTC) transactions between two entities directly, (ii) Bilateral over-the-counter (OTC) transactions on standard products executed through brokers, and (iii) Derivatives traded on the Sydney Futures Exchange (SFE). In our study we concentrate on futures contracts traded in the SFE during the time period 2005-2012. Note that the SFE also offers a number of alternative derivatives including option contracts or $\$ 300$ cap products that will not be considered in this study.

Like in almost every electricity exchange, futures contracts traded in the SFE refer to the average electricity price during a delivery period. Thus, for a base period futures contract the contract unit is one Megawatt of electricity per hour (MWH) for each hour from 00:00 hours to 24:00 hours over the duration of the contract. For a quarterly base load contract, the size (in MWH) will vary depending on the number of days within the quarter. For example, for a quarter with 90 days, a contract refers to 2,160 MWH during the delivery period while for a quarter with 92 days, a contract refers to 2,208 MWH. In addition to base load futures contracts, peak period contracts are also traded. Given that electricity prices show strong intra-day variation and are heavily affected by demand in every precise moment (Lucia and Schwartz, 2002), the distinction between the whole day and the peak delivery period is important for market participants. In Australia, the peak period refers to the hours from 07:00 to 22:00 on weekdays (excluding public holidays) over the duration of the contract quarter. This implies that the off peak period includes the hours from 22:00 to 07:00 on weekdays and 
all hours on Saturday and Sunday. Therefore, the size of a quarterly peak period futures contract will vary depending on the number of days and peak-load hours within the quarter: for example a contract with 62 weekdays during a quarter (a so-called 62 day contract quarter) will equate to $930 \mathrm{MWH}$.

The contracts do not require physical delivery of electricity, but rather are settled financially. Therefore, market participants can participate in electricity futures markets and increase market liquidity without owning physical generation assets. The cash settlement price of a base (peak) period contract is calculated by taking the arithmetic average of the NEM final base (peak) load spot prices on a half hourly basis, rounded to two decimal places over the contract quarter. A provisional cash settlement price is declared on the first business day after expiry of the contract, while the final cash settlement takes place on the fourth business day after expiry of the contract.

\subsection{Ex-Post Risk Premiums in Electricity Markets}

The difference between the forward price and the expected spot price can be interpreted as a compensation for bearing the spot price risk (Bessembinder and Lemmon, 2002; Longstaff and Wang, 2004). However, as the ex-ante premium is basically unobservable, empirical analysis often concentrates on the ex-post or realized futures or forward premium in these markets:

$$
\mathrm{RP}_{t,\left[\mathrm{~T}_{1}, \mathrm{~T}_{2}\right]}=\mathrm{F}_{\mathrm{t},\left[\mathrm{T}_{1}, \mathrm{~T}_{2}\right]}-\overline{\mathrm{S}}_{\left[\mathrm{T}_{1}, \mathrm{~T}_{2}\right]}
$$

Hereby, $\mathrm{RP}_{t,\left[\mathrm{~T}_{1}, \mathrm{~T}_{2}\right]}$ denotes the realized risk premium measured as the difference between the quote for a futures base or peak load contract, $\mathrm{F}_{\mathrm{t},\left[\mathrm{T}_{1}, \mathrm{~T}_{2}\right]}$, referring to delivery period $\left[\mathrm{T} 1, \mathrm{~T}_{2}\right]$ at time $t$ and the actual average base or peak load spot price, $\bar{S}_{\left[\mathrm{T}_{1}, \mathrm{~T}_{2}\right]}$, during the delivery period.

However, none of these studies investigate futures premiums at different time instances. We argue that investigating dynamic futures premiums is essential, since Deaves and Krinsky (1995) note that risk premiums may be time varying. Therefore, this paper presents a thorough analysis on ex-post futures premiums at different time intervals ranging from 12 months up to the last trading day before the beginning of the delivery period of the contract. 
Empirical studies have generally found significant positive premiums in electricity forward markets. Longstaff and Wang (2004) find positive risk premiums of up to 14 percent for the PJM day ahead market while Redl et al. (2009) find positive premiums for monthahead forward contracts in the Nordpool and EEX market. They report premiums ranging from 8 percent for baseload forward contracts in the Nordpool market and 9 percent for baseload up to 13 percent for peak load contracts in the EEX market. Botterud et al. (2010) report premiums ranging from 1.3 to 4.4 percent for the Nord Pool market when considering forward contracts with a delivery period from one week up to six weeks ahead. A number of other studies also confirm the significance of forward premiums in various electricity markets. Significant premiums are reported, for example, by Hadsell and Shawky (2006) for the New York Independent System Operator (NYISO), by Diko et al. (2006) for the Netherland APX, Bierbrauer et al. (2007) for the EEX, by Weron (2008) for the Scandinavian Nordpool market, Kolos and Ronn (2008) and by Daskalakis and Markellos (2009) for the EEX, Nordpool and Powernext markets. Interestingly, the studies provide quite different results on the actual sign of the risk premium even for the same markets: while Redl et al. (2009) find significant positive premiums for monthly baseload and peakload futures contracts in the EEX, Kolos and Ronn (2008) find a negative forward premium for monthly, quarterly and yearly contractsint the EEX during the 2002-2003 trading period. Bierbrauer et al. (2007) find positive ex-ante risk premiums for short-term futures contracts, while for contracts with maturities more than six months ahead the observed premiums are negative. Diko et al. (2006), investigating EEX peak load contracts, find that forward premiums decrease as time to maturity increases. Overall, the majority of authors seem to find rather positive risk premiums in electricity futures markets.

In a first step, we analyse the sign and behaviour of realized risk premiums with respect to the time-to-delivery of the contracts. Note that for this part of the analysis we decided to pool the observations on realized risk premiums into different time-to-delivery intervals in order to make our results more robust. Thus, each interval involves one month, such that we have 12 intervals, i.e. 12 refers to observations during the period from 12 to 11 months before beginning of the delivery period, 11 refers to the period 11 to 10 months before the delivery period, and so on. Finally, the last interval refers to observations during the last month prior 
to the beginning of the delivery period of a contract. ${ }^{4}$ Note that given the results by Handika and Trück (2013) indicating strong differences between observed risk premiums for different quarters and markets, we analyse each quarter, i.e. Q1, Q2, Q3 and Q4, and region separately.

In a second step, using regression analysis, we try to relate the observed risk premiums to explanatory variables. Given our interest in the behaviour of futures risk premiums with respect to the maturity of the contracts, a key variable will be the remaining time to the beginning of the delivery period of the futures contract. However, as mentioned above the literature also suggests a variety of other variables that may have an impact on the magnitude and behaviour of risk premiums. Therefore, we also include spot prices levels, volatility in the spot market, and an additional risk measure, i.e. the number of price spikes, as explanatory variables for observed futures premiums in the examined markets. Given the substantial differences for the observed risk premiums in the markets and quarters, we estimate the models for each region and quarter separately. While it would be beneficial to have a model for all observations, we believe that the observed dynamics of the futures risk premiums would not justify such an approach.

\subsection{Descriptive Analysis of Risk Premiums}

\subsubsection{The Data}

Our sample includes electricity spot and futures prices in four Australian regions: New South Wales (NSW), Queensland (QLD), South Australia (SA) and Victoria (VIC). We choose these because they exhibit the highest demand for electricity in Australia (Higgs, 2009) and data on futures are available only for these regions. In order to obtain the daily spot price we average the half-hourly electricity prices quoted from AEMO to calculate daily spot prices. We consider spot prices from 1 January 2005 to 30 June $2012^{5}$ in our analysis, including weekends and holidays. Based on this sample, average spot prices can be calculated for base and peak periods. We quote the settlement price from the year prior to the last trading day for the first quarter (Q1), second quarter (Q2), third quarter (Q3) and fourth

\footnotetext{
${ }^{4}$ While pooling the data will lead to more robust results with respect to observed risk premiums, it also has a disadvantage with respect to the violation of the assumption of independent observations. When testing for significance of the realized premiums, we, therefore, have to use an adjusted t-test, see e.g. Wilks (1997).

${ }^{5}$ We exclude data from July 1, 2012 onward since on July 1, 2012 a carbon tax of \$23 per ton of CO2 emission became effective, significantly increasing spot electricity prices.
} 
quarter (Q4) from 2005 to 2012. Data on electricity futures prices areobtained from d-cypha trade. Both the spot and futures prices are quoted in Australian dollars per Megawatt hour $(\$ / \mathrm{MWh})$.

Table 1 shows a statistical summary of electricity spot prices for base and peak periods in the four Australian regions considered. ${ }^{6}$ Recall that peak period prices refer to the hours from 07:00 to 22:00 on weekdays only, excluding public holidays. We find that there are clear differences between the regions and quarters. The considered markets tend to be most volatile in Q1, as indicated by the highest volatility and the highest number of price spikes during these quarters. Q2, Q3 and Q4 tend to be less volatile, while also the number of price spikes seems to be lower for these periods. Average daily electricity spot prices range from \$28.51/MWh (VIC region Quarter 4) to \$68.33/MWh (SA region Quarter 1) for base period contracts and from \$35.97/MWh (QLD region Quarter 3) to \$119.99/MWh (SA region Quarter 1) for peak contracts. These stylized facts confirm the strong seasonality in Australian electricity markets. Therefore, it might be more beneficial to conduct the analysis of risk premiums in Australian electricity markets separately for different quarters.

\subsubsection{Risk Premiums}

Figure 1 provides a plot of observed average futures premiums for Q1, Q2, Q3 and Q4 base load futures contracts in all regions (NSW, QLD, SA and VIC) at different time intervals. Premiums are calculated based on the pooled data for a monthly period ranging from 12 months up to the last month before the beginning of the delivery period of the contracts. Figure 2 provides the same plot for peak load contracts. From both figures, we see the changing dynamics of futures premiums in Australian electricity markets. We also observe that realized risk premiums depend heavily not only on the considered regional markets and contracts (base or peak load), but possibly even more on the quarter the futures contract refers to.

\footnotetext{
${ }^{6}$ According to Table 1, there are some negative prices that can be explained the following way: generators may be willing to accept negative prices for a number of hours when it is cheaper for them to keep the electricity production turned on instead of a costly shut-down of the generation facility (AEMO Information Centre, 2011). $\mathrm{Hu}$ et al. (2005) note that generation units (used to produce electricity) cannot be switched on and off in a short time for reasons of efficiency and safety. Therefore, producers may be better off paying a negative price to consumers rather than suddenly shutting down their production. Another view by Thomas et al. (2006) suggests that is a tactical bidding strategy to ensure that the generators are dispatched.
} 
The upper left panel of Figure 1 provides results for average realized risk premiums referring to Q1 base load contracts. For NSW, we find that Q1 premiums on average are around $\$ 13$, while they range from approximately $\$ 10$ approximately 10 months before the beginning of the delivery period, up to a level of more than $\$ 16$ approximately 8 months before the beginning of the delivery period. Interestingly, after an initial increase, observed premiums decline to a level between $\$ 10$ and $\$ 14$ during the last 6 months before the beginning of the delivery period. For QLD observed premiums range from approximately $\$ 7$ (12 months before beginning of the delivery period) up to almost $\$ 20$ (5 months before the beginning of the delivery period). Similar to the NSW market, there is a steep increase in the premiums between 12 and 7 months before the beginning of the delivery period, while premiums stay at this comparably high level for several months. Only during the last two months before the beginning of the delivery periods, futures prices on average drop such that the realized premiums are around $\$ 17$ two months, and $\$ 13$ during the last month before the beginning of the delivery period. A similar behaviour can also be observed for VIC, where risk premiums show an increase from approximately $\$ 8$ to more than $\$ 12$, before dropping again to a level of approximately $\$ 7$. Interestingly, for SA we observe a strong continuous increase in realized risk premiums for Q1 base load contracts from $-\$ 4$ (12 months) up to approximately $\$ 6$ during the last two months prior to the delivery period of the contract.

Results are very different when risk premiums for Q2 base load contracts are considered. Observed premiums are negative for all markets and exhibit a pattern that is very different to what can be observed for Q1 contracts. Recall that Q2 typically refers to periods lower prices and a significantly smaller number of price spikes as illustrated by Table 1 . Therefore, the demand for taking long positions in the futures market may be significantly lower. The negative premiums even points towards a higher demand for short positions in the futures markets indicating that producers may be willing to even pay a premium to consumers or speculators for taking a long position.

Also premiums for contracts referring to Q3 are characterized by a different behaviour through time. There is tendency for premiums to decline during the first 8 months of trading during, i.e. for the period ranging from 12 up to four months before the delivery period. However, during the last three months before the beginning of the delivery period, we observe a steep increase in realized premiums up to approximately \$12 for QLD and \$13 for NSW. Interestingly, we also observe that for Q3 the all markets seem to behave very similar with respect to the dynamics of futures prices. The steep increase in risk premiums closer to 


\begin{tabular}{|c|c|c|c|c|}
\hline \multicolumn{5}{|c|}{ Quarter 1 } \\
\hline Descriptive Statistics & NSW Base & QLD Base & SA Base & VIC Base \\
\hline Mean & 40.66 & 42.54 & 68.33 & 43.10 \\
\hline Standard Deviation & 88.95 & 104.05 & 222.76 & 121.89 \\
\hline Skewness & 10.91 & 9.97 & 7.36 & 13.70 \\
\hline Number of Price Spikes & 160 & 169 & 267 & 160 \\
\hline Descriptive Statistics & NSW Peak & QLD Peak & SA Peak & VIC Peak \\
\hline Mean & 59.62 & 62.68 & 119.99 & 67.21 \\
\hline Standard Deviation & 163.31 & 169.62 & 411.54 & 224.10 \\
\hline Skewness & 9.30 & 8.83 & 6.10 & 11.55 \\
\hline Number of Price Spikes & 143 & 144 & 242 & 146 \\
\hline \multicolumn{5}{|c|}{ Quarter 2} \\
\hline Descriptive Statistics & NSW Base & QLD Base & SA Base & VIC Base \\
\hline Mean & 42.33 & 37.25 & 39.20 & 41.17 \\
\hline Standard Deviation & 61.86 & 50.50 & 23.00 & 56.19 \\
\hline Skewness & 8.82 & 8.20 & 2.33 & 15.78 \\
\hline Number of Price Spikes & 152 & 110 & 40 & 68 \\
\hline Descriptive Statistics & NSW Peak & QLD Peak & SA Peak & VIC Peak \\
\hline Mean & 55.88 & 48.81 & 48.35 & 54.03 \\
\hline Standard Deviation & 106.32 & 84.36 & 30.00 & 100.37 \\
\hline Skewness & 8.00 & 7.54 & 3.04 & 15.02 \\
\hline Number of Price Spikes & 125 & 100 & 31 & 60 \\
\hline \multicolumn{5}{|c|}{ Quarter 3} \\
\hline Descriptive Statistics & NSW Base & QLD Base & SA Base & VIC Base \\
\hline Mean & 34.61 & 29.65 & 36.39 & 34.46 \\
\hline Standard Deviation & 23.29 & 18.39 & 20.83 & 21.10 \\
\hline Skewness & 6.57 & 5.80 & 4.70 & 5.72 \\
\hline Number of Price Spikes & 52 & 25 & 30 & 33 \\
\hline Descriptive Statistics & NSW Peak & QLD Peak & SA Peak & VIC Peak \\
\hline Mean & 42.63 & 35.97 & 45.22 & 43.32 \\
\hline Standard Deviation & 38.83 & 28.95 & 30.47 & 32.72 \\
\hline Skewness & 6.63 & 6.53 & 5.74 & 6.56 \\
\hline Number of Price Spikes & 47 & 23 & 26 & 31 \\
\hline \multicolumn{5}{|c|}{ Quarter 4} \\
\hline Descriptive Statistics & NSW Base & QLD Base & SA Base & VIC Base \\
\hline Mean & 42.81 & 34.38 & 39.95 & 28.51 \\
\hline Standard Deviation & 109.68 & 55.96 & 96.51 & 20.30 \\
\hline Skewness & 8.88 & 9.75 & 12.34 & 7.65 \\
\hline Number of Price Spikes & 150 & 94 & 106 & 52 \\
\hline Descriptive Statistics & NSW Peak & QLD Peak & SA Peak & VIC Peak \\
\hline Mean & 67.08 & 48.51 & 60.81 & 36.97 \\
\hline Standard Deviation & 204.18 & 94.00 & 178.70 & 33.62 \\
\hline Skewness & 7.32 & 9.06 & 10.45 & 8.16 \\
\hline Number of Price Spikes & 141 & 79 & 93 & 43 \\
\hline
\end{tabular}

Table 1: Descriptive statistics of daily base and peak load electricity spot prices from January 1, 2005 to June 30, 2012 for different quarters and markets. The table provides the mean, standard deviation, skewness as well as the number of price spikes for the considered NSW, QLD, SA and VIC regions during base and peak load periods. 
the delivery period is even more surprising as Q3 is usually characterized the lowest average electricity prices, low volatility in prices and a very small number of price spikes.

Finally, for Q4 we observe mainly positive risk premiums, in particular for QLD, SA and VIC markets. Interestingly, for the NSW market, we also observe negative risk premiums during the time period between nine and six months prior to the beginning of the delivery period of the contracts. For all markets, after an initial decline, premiums increase significantly between eight and four months prior to the delivery period and then decline again during the last three months. The negative premiums for NSW are surprising, since on average NSW exhibits the highest number of price spikes during Q4.
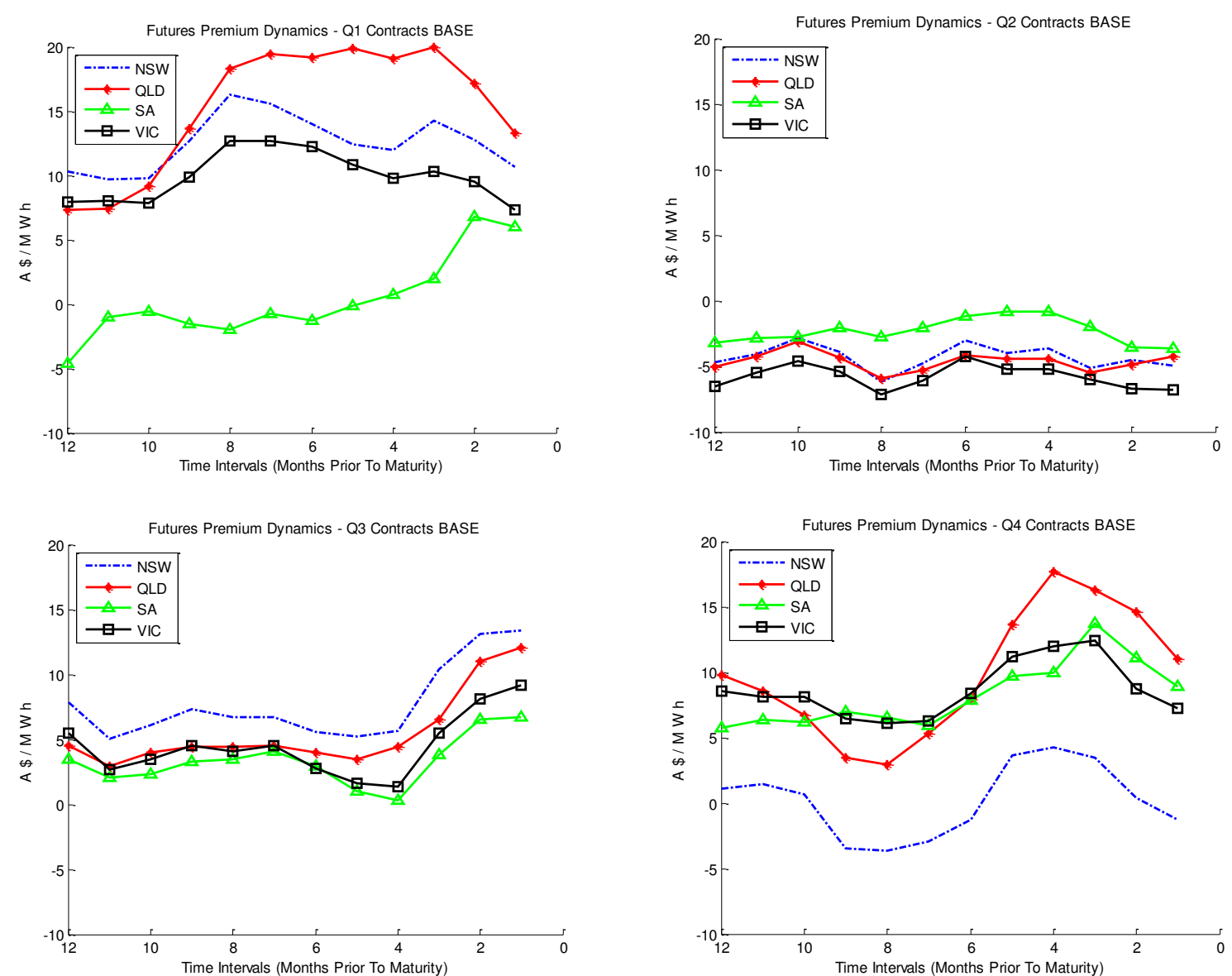

Figure 1: Average of realized futures premiums for Q1, Q2, Q3 and Q4 Futures Contracts in all regions at different time intervals (from 12 months up to 1 month prior to the beginning of the delivery period of the contract) for quarterly base load futures contracts. 

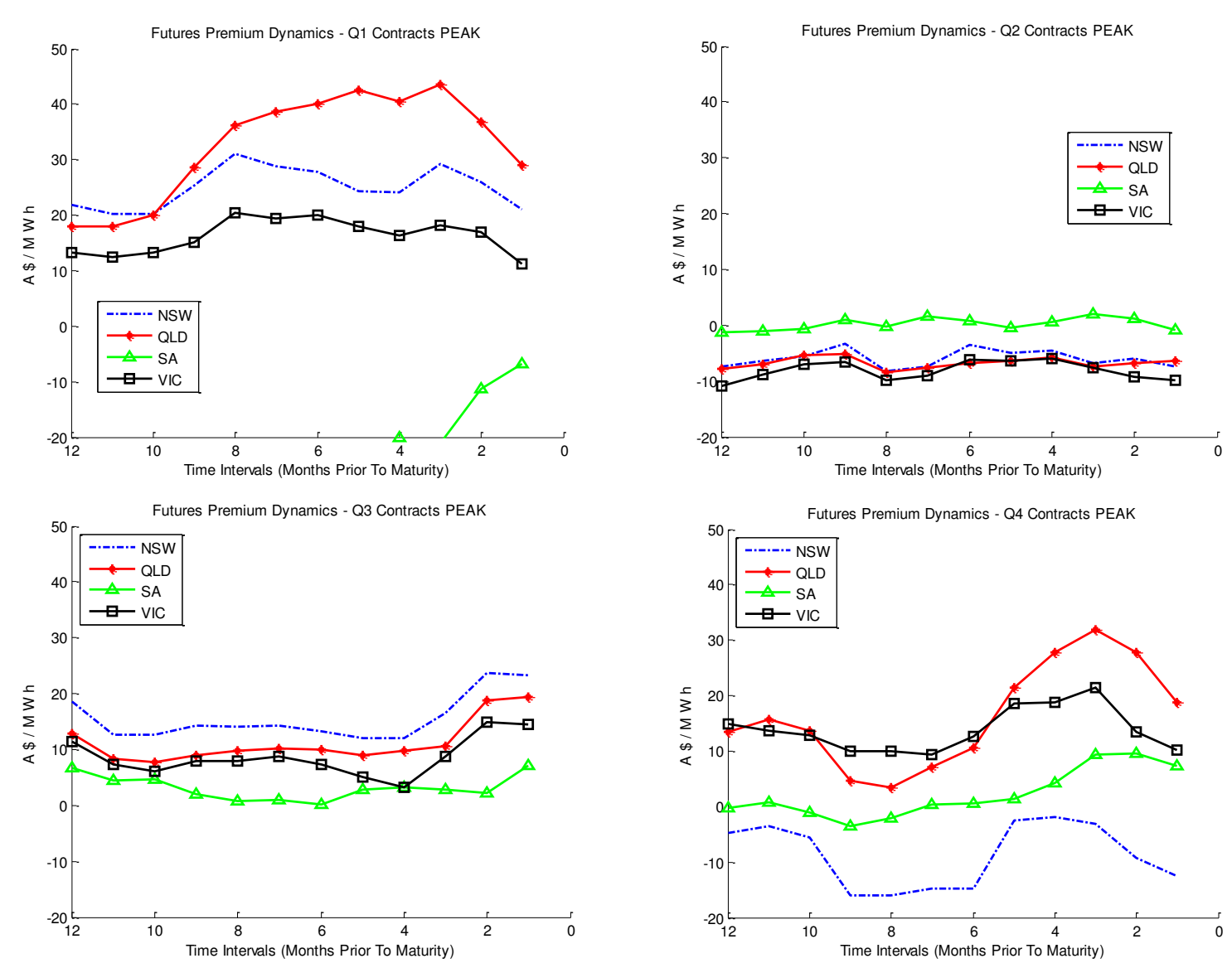

Figure 2: Average of realized futures premiums for Q1, Q2, Q3 and Q4 Futures Contracts in all regions at different time intervals (from 12 months up to 1 month prior to the beginning of the delivery period of the contract) for quarterly peak load futures contracts.

As indicated by Figure 2, we find similar patterns for the dynamics of risk premiums referring to peak period futures contracts. However, the magnitude of the premiums is even higher. For example, for Q1 peak contracts average risk premiums are between $\$ 20$ and $\$ 31$ for NSW, between \$18 and \$44 for QLD and between \$11 and \$20 for VIC. Again, the SA market shows a very different behaviour with average risk premiums increasing from approximately $-\$ 47$ to $-\$ 7$ during the year prior to the beginning of the delivery period. Again we find that for Q2 contracts observed premiums are predominantly negative, while they are usually positive for contracts referring to Q3 and Q4. Again for Q4, risk premiums are negative for the NSW markets despite the high price levels, volatility and comparably large number of price spikes. One could argue that for Q4, during the considered period from 2005 to 2012 realized spot prices were even higher than what had been anticipated by market participants. 
Overall, the descriptive analysis shows that there are quite substantial differences between observed premiums for different markets and delivery quarters. While realized premiums are predominantly positive for most markets and quarters, we also find negative premiums for Q2 contracts in all markets and for NSW in Q4. It also becomes obvious that futures prices do generally not provide an accurate estimate of realized average spot prices during the delivery period. In a next step we will now analyse the significance of observed premiums for the considered intervals ranging from 12 months up to the last month prior to the beginning of the delivery period.

Table 2 and Table 3 report realized risk premiums for base and peak load futures contracts as well as results on the significance of the premiums for NSW, QLD, SA and VIC. Recall that due to the pooled data, realized risk premiums exhibit relatively high levels of autocorrelation for each contract. Therefore, it may be critical to apply a standard t-test in order to test for significance of the premiums. A solution to this problem is to adjust the variance, i.e. use the so-called variance inflation factor (VIF), before applying a t-test (Wilks, 1997). Therefore, according to Wilks (1997), we adjust the sample variance of the data by the variance inflation factor (VIF) using

$$
\operatorname{var}(\mathrm{x})=\mathrm{V} \frac{\mathrm{s}_{\mathrm{x}}^{2}}{\mathrm{n}},
$$

where $\mathrm{s}_{\mathrm{x}}{ }^{2}$ denotes the sample variance of the realized risk premiums, $\mathrm{n}$ denotes the number of observations, and $\mathrm{V}$ is the variance inflation factor. The variance inflation factor can be calculated as

$$
\mathrm{V}=1+2 \sum_{\mathrm{k}=1}^{20}\left(1-\frac{\mathrm{k}}{\mathrm{n}}\right) \mathrm{r}_{\mathrm{k}},
$$

where $r_{k}$ denotes estimates of the autocorrelation at lag $k$. Note that in order to estimate $r_{k}$ we use up to 20 lags since in each monthly interval we usually have 20 days of trading.

We find that futures risk premiums tend to be more significant as contracts are closer to the beginning of the delivery period. On the other hand, we observe large differences also with respect to the significance of the premiums depending on the considered market and delivery quarter of the contract. For Q1 base load contracts, observed risk premiums are positive and highly significant in all regions except SA. For Q2 base load contracts, the observed futures premiums are negative, but they are not statistically significant for any of the considered regions. For Q3 base load contracts, the observe futures premiums are positive 


\begin{tabular}{|c|c|c|c|c|c|c|c|c|c|c|c|c|}
\hline \multicolumn{13}{|c|}{ NSW BASE LOAD CONTRACTS } \\
\hline INTERVALS & 12 & 11 & 10 & 9 & 8 & 7 & 6 & 5 & 4 & 3 & 2 & 1 \\
\hline Q1 Premium & 10.32 & 9.69 & 9.77 & 12.65 & 16.27 & 15.56 & 14.02 & 12.40 & 12.01 & 14.28 & 12.79 & 10.66 \\
\hline t-Stat & 2.37 & 2.54 & 2.00 & 2.33 & 2.09 & 1.94 & 1.92 & 1.93 & 1.86 & 1.81 & 1.95 & 1.79 \\
\hline $\mathrm{p}$-value & 0.02 & 0.01 & 0.05 & 0.02 & 0.04 & 0.05 & 0.06 & 0.06 & 0.06 & 0.07 & 0.05 & 0.07 \\
\hline Number of Observations & 142 & 141 & 154 & 135 & 154 & 148 & 151 & 156 & 151 & 153 & 151 & 141 \\
\hline Q2 Premium & -4.67 & -4.09 & -2.84 & -3.88 & -6.16 & -4.77 & -3.03 & -4.01 & -3.67 & -5.16 & -4.56 & -4.95 \\
\hline $\mathrm{t}-\mathrm{Stat}$ & -0.43 & -0.33 & -0.23 & -0.36 & -0.53 & -0.43 & -0.26 & -0.35 & -0.36 & -0.49 & -0.50 & -0.58 \\
\hline $\mathrm{p}$-value & 0.67 & 0.74 & 0.82 & 0.72 & 0.60 & 0.67 & 0.79 & 0.73 & 0.72 & 0.62 & 0.62 & 0.56 \\
\hline Number of Observations & 135 & 154 & 148 & 151 & 156 & 151 & 153 & 151 & 141 & 162 & 162 & 176 \\
\hline Q3 Premium & 7.86 & 5.04 & 6.12 & 7.32 & 6.74 & 6.70 & 5.59 & 5.24 & 5.69 & 10.36 & 13.12 & 13.39 \\
\hline $\mathrm{t}$-Stat & 1.56 & 1.10 & 1.28 & 1.41 & 1.27 & 1.35 & 1.39 & 1.52 & 2.14 & 4.99 & 3.31 & 2.90 \\
\hline p-value & 0.12 & 0.28 & 0.20 & 0.16 & 0.20 & 0.18 & 0.17 & 0.13 & 0.03 & 0.00 & 0.00 & 0.00 \\
\hline Number of Observations & 130 & 133 & 129 & 132 & 129 & 121 & 142 & 141 & 154 & 135 & 154 & 148 \\
\hline Q4 Premium & 1.12 & 1.40 & 0.62 & -3.49 & -3.68 & -2.91 & -1.27 & 3.63 & 4.29 & 3.45 & 0.41 & -1.26 \\
\hline t-Stat & 0.19 & 0.27 & 0.11 & -0.67 & -0.67 & -0.50 & -0.19 & 0.46 & 0.50 & 0.34 & 0.05 & -0.17 \\
\hline $\mathrm{p}$-value & 0.85 & 0.79 & 0.91 & 0.50 & 0.50 & 0.62 & 0.85 & 0.65 & 0.62 & 0.74 & 0.96 & 0.87 \\
\hline Number of Observations & 132 & 129 & 121 & 142 & 141 & 154 & 135 & 154 & 148 & 151 & 156 & 151 \\
\hline \multicolumn{13}{|c|}{ QLD BASE LOAD CONTRACTS } \\
\hline INTERVALS & 12 & 11 & 10 & 9 & 8 & 7 & 6 & 5 & 4 & 3 & 2 & 1 \\
\hline Q1 Premium & 7.35 & 7.38 & 9.19 & 13.64 & 18.27 & 19.40 & 19.16 & 19.91 & 19.07 & 19.99 & 17.18 & 13.30 \\
\hline t-Stat & 1.23 & 1.47 & 1.90 & 2.71 & 2.43 & 2.18 & 2.28 & 2.05 & 1.92 & 1.95 & 1.94 & 1.73 \\
\hline p-value & 0.22 & 0.14 & 0.06 & 0.01 & 0.02 & 0.03 & 0.02 & 0.04 & 0.06 & 0.05 & 0.05 & 0.09 \\
\hline Number of Observations & 142 & 141 & 154 & 135 & 154 & 148 & 151 & 156 & 151 & 153 & 151 & 141 \\
\hline Q2 Premium & -5.02 & -4.23 & -3.11 & -4.31 & -5.91 & -5.28 & -4.20 & -4.42 & -4.47 & -5.46 & -4.90 & -4.25 \\
\hline $\mathrm{t}-\mathrm{S}$ tat & -0.54 & -0.40 & -0.29 & -0.45 & -0.58 & -0.54 & -0.41 & -0.44 & -0.50 & -0.58 & -0.59 & -0.59 \\
\hline p-value & 0.59 & 0.69 & 0.77 & 0.65 & 0.57 & 0.59 & 0.68 & 0.66 & 0.62 & 0.56 & 0.55 & 0.56 \\
\hline Number of Observations & 135 & 154 & 148 & 151 & 156 & 151 & 153 & 151 & 141 & 162 & 162 & 176 \\
\hline Q3 Premium & 4.48 & 2.91 & 3.99 & 4.46 & 4.46 & 4.55 & 4.00 & 3.47 & 4.43 & 6.57 & 10.99 & 12.03 \\
\hline t-Stat & 1.06 & 0.63 & 0.85 & 0.87 & 0.86 & 0.99 & 0.98 & 1.04 & 1.99 & 5.14 & 2.59 & 2.43 \\
\hline $\mathrm{p}$-value & 0.29 & 0.53 & 0.40 & 0.39 & 0.39 & 0.32 & 0.33 & 0.30 & 0.05 & 0.00 & 0.01 & 0.02 \\
\hline Number of Observations & 130 & 133 & 129 & 132 & 129 & 121 & 142 & 141 & 154 & 135 & 154 & 148 \\
\hline Q4 Premium & 9.78 & 8.55 & 6.69 & 3.46 & 2.96 & 5.32 & 7.95 & 13.68 & 17.66 & 16.23 & 14.61 & 11.00 \\
\hline $\mathrm{t}-\mathrm{Stat}$ & 1.85 & 1.97 & 2.49 & 1.36 & 1.37 & 3.78 & 2.99 & 2.54 & 2.14 & 1.81 & 1.89 & 1.63 \\
\hline $\mathrm{p}$-value & 0.07 & 0.05 & 0.01 & 0.18 & 0.17 & 0.00 & 0.00 & 0.01 & 0.03 & 0.07 & 0.06 & 0.11 \\
\hline Number of Observations & 132 & 129 & 121 & 142 & 141 & 154 & 135 & 154 & 148 & 151 & 156 & 151 \\
\hline \multicolumn{13}{|c|}{ SA BASE LOAD CONTRACTS } \\
\hline INTERVALS & 12 & 11 & 10 & 9 & 8 & 7 & 6 & 5 & 4 & 3 & 2 & 1 \\
\hline Q1 Premium & -4.58 & -1.05 & -0.60 & -1.57 & -1.94 & -0.74 & -1.27 & -0.16 & 0.75 & 2.02 & 6.84 & 5.97 \\
\hline t-Stat & -0.31 & -0.06 & -0.04 & -0.13 & -0.16 & -0.07 & -0.11 & -0.01 & 0.07 & 0.20 & 0.74 & 0.68 \\
\hline p-value & 0.76 & 0.95 & 0.97 & 0.89 & 0.87 & 0.95 & 0.91 & 0.99 & 0.94 & 0.84 & 0.46 & 0.50 \\
\hline Number of Observations & 142 & 141 & 154 & 135 & 154 & 148 & 151 & 156 & 151 & 153 & 151 & 141 \\
\hline Q2 Premium & -3.23 & -2.85 & -2.75 & -2.02 & -2.77 & -2.10 & -1.16 & -0.84 & -0.79 & -1.98 & -3.52 & -3.64 \\
\hline $\mathrm{t}-\mathrm{Stat}$ & -0.51 & -0.44 & -0.43 & -0.34 & -0.47 & -0.38 & -0.19 & -0.14 & -0.14 & -0.39 & -0.86 & -1.03 \\
\hline $\mathrm{p}$-value & 0.61 & 0.66 & 0.67 & 0.74 & 0.64 & 0.71 & 0.85 & 0.89 & 0.89 & 0.69 & 0.39 & 0.31 \\
\hline Number of Observations & 135 & 154 & 148 & 151 & 156 & 151 & 153 & 151 & 141 & 162 & 162 & 176 \\
\hline Q3 Premium & 3.44 & 2.10 & 2.33 & 3.31 & 3.49 & 4.12 & 2.97 & 0.97 & 0.29 & 3.85 & 6.50 & 6.71 \\
\hline t-Stat & 0.54 & 0.36 & 0.42 & 0.56 & 0.56 & 0.64 & 0.55 & 0.22 & 0.07 & 1.13 & 1.61 & 1.69 \\
\hline $\mathrm{p}$-value & 0.59 & 0.72 & 0.68 & 0.57 & 0.58 & 0.52 & 0.58 & 0.83 & 0.94 & 0.26 & 0.11 & 0.09 \\
\hline Number of Observations & 130 & 133 & 129 & 132 & 129 & 121 & 142 & 141 & 154 & 135 & 154 & 148 \\
\hline Q4 Premium & 5.70 & 6.40 & 6.19 & 6.96 & 6.55 & 5.93 & 7.83 & 9.71 & 9.94 & 13.70 & 11.08 & 8.93 \\
\hline t-Stat & 1.14 & 1.53 & 1.55 & 1.58 & 1.61 & 1.38 & 1.37 & 1.47 & 1.54 & 1.54 & 1.80 & 1.52 \\
\hline $\mathrm{p}$-value & 0.26 & 0.13 & 0.12 & 0.12 & 0.11 & 0.17 & 0.17 & 0.14 & 0.12 & 0.13 & 0.07 & 0.13 \\
\hline Number of Observations & 132 & 129 & 121 & 142 & 141 & 154 & 135 & 154 & 148 & 151 & 156 & 151 \\
\hline \multicolumn{13}{|c|}{ VIC BASE LOAD CONTRACTS } \\
\hline INTERVALS & 12 & 11 & 10 & 9 & 8 & 7 & 6 & 5 & 4 & 3 & 2 & 1 \\
\hline Q1 Premium & 7.96 & 8.07 & 7.87 & 9.86 & 12.67 & 12.67 & 12.27 & 10.82 & 9.78 & 10.34 & 9.52 & 7.36 \\
\hline t-Stat & 1.20 & 1.23 & 1.39 & 1.85 & 1.90 & 1.93 & 2.01 & 2.14 & 2.09 & 1.91 & 2.09 & 1.69 \\
\hline $\mathrm{p}$-value & 0.23 & 0.22 & 0.17 & 0.07 & 0.06 & 0.06 & 0.05 & 0.03 & 0.04 & 0.06 & 0.04 & 0.09 \\
\hline Number of Observations & 142 & 141 & 154 & 135 & 154 & 148 & 151 & 156 & 151 & 153 & 151 & 141 \\
\hline Q2 Premium & -6.56 & -5.46 & -4.57 & -5.38 & -7.18 & -6.14 & -4.22 & -5.21 & -5.20 & -5.99 & -6.70 & -6.81 \\
\hline t-Stat & -0.92 & -0.66 & -0.53 & -0.75 & -0.97 & -0.87 & -0.56 & -0.74 & -0.82 & -0.97 & -1.28 & -1.47 \\
\hline $\mathrm{p}$-value & 0.36 & 0.51 & 0.59 & 0.46 & 0.33 & 0.39 & 0.58 & 0.46 & 0.41 & 0.33 & 0.20 & 0.14 \\
\hline Number of Observations & 135 & 154 & 148 & 151 & 156 & 151 & 153 & 151 & 141 & 162 & 162 & 176 \\
\hline Q3 Premium & 5.50 & 2.69 & 3.48 & 4.50 & 4.11 & 4.52 & 2.80 & 1.58 & 1.37 & 5.46 & 8.10 & 9.15 \\
\hline $\mathrm{t}-\mathrm{Stat}$ & 0.84 & 0.45 & 0.58 & 0.73 & 0.66 & 0.73 & 0.56 & 0.37 & 0.35 & 1.75 & 2.04 & 1.90 \\
\hline $\mathrm{p}$-value & 0.40 & 0.65 & 0.56 & 0.47 & 0.51 & 0.47 & 0.57 & 0.71 & 0.72 & 0.08 & 0.04 & 0.06 \\
\hline Number of Observations & 130 & 133 & 129 & 132 & 129 & 121 & 142 & 141 & 154 & 135 & 154 & 148 \\
\hline Q4 Premium & 8.56 & 8.11 & 8.15 & 6.44 & 6.11 & 6.25 & 8.39 & 11.18 & 11.99 & 12.42 & 8.76 & 7.21 \\
\hline t-Stat & 2.48 & 2.28 & 2.21 & 1.89 & 1.99 & 2.31 & 3.21 & 3.25 & 2.80 & 2.43 & 3.39 & 4.16 \\
\hline $\mathrm{p}$-value & 0.01 & 0.02 & 0.03 & 0.06 & 0.05 & 0.02 & 0.00 & 0.00 & 0.01 & 0.02 & 0.00 & 0.00 \\
\hline Number of Observations & 132 & 129 & 121 & 142 & 141 & 154 & 135 & 154 & 148 & 151 & 156 & 151 \\
\hline
\end{tabular}

Table 2: Realized risk premiums, $\mathrm{t}$-stats and $\mathrm{p}$-values for significance of the premium for quarterly base load futures contracts with time to delivery ranging from approximately twelve months up to the last month before the beginning of the delivery period. 
and quite substantial for all regions. Nevertheless, they are only statistically significant during the last three months prior to the beginning of the delivery period in NSW, QLD and VIC. For Q4 base load contracts, the observed futures premiums are positive and statistically significant for the QLD, SA and VIC market. On the other hand premiums are negative, but not significantly different from zero for NSW.

For Q1 peak load contracts, observed futures risk premiums are positive and statistically significant for NSW and QLD, while they are positive but no significantly different from zero for VIC. For the SA market, Q1 risk premiums are negative and despite being of high magnitude, they are not significantly different from zero due to the high standard deviation of observed premiums. For Q2 peak load contracts, observed risk premiums tend to be negative and quite large. However, they are not statistically significant for any region. For Q3 peak load contracts, risk premiums are significant only for the NSW and QLD region, while they are still positive but not significantly different from zero for SA and VIC. Finally, for Q4 peak load contracts, observed risk premiums are positive and statistically significant in QLD and VIC. For NSW and SA, Q4 risk premiums are negative, but not statistically significant.

Overall, we find that realized risk premiums for the considered contracts, usually tend to be positive and of high magnitude. However, they are not always significantly different, in particular for the SA and VIC market. Further, the huge difference in results with respect to the quarter a contract is referring to, suggests strong seasonal effects not only in electricity spot and futures prices, but also in the behaviour of realized risk premiums. Different results for different time intervals also respond to the question of whether observed risk premiums are positive or negative. The generally increasing pattern for the observed premiums also support economic intuition of short term positive risk premiums due to increased hedging demand by retailers or consumers, see e.g. Benth et al. (2008).

While the analysis of this section has been limited to the behavior of premiums with respect to delivery quarter, region and time to maturity of the contracts, in the following we will further investigate the determinants of the observed risk premiums. In particular we examine how spot price level and volatility as well as the number of price spikes impact on realized risk premiums in the considered markets. 


\begin{tabular}{|c|c|c|c|c|c|c|c|c|c|c|c|c|}
\hline \multicolumn{13}{|c|}{ NSW PEAK LOAD CONTRACTS } \\
\hline INTERVALS & 12 & 11 & 10 & 9 & 8 & 7 & 6 & 5 & 4 & 3 & 2 & 1 \\
\hline Q1 Premium & 21.83 & 20.14 & 20.29 & 25.38 & 31.10 & 28.87 & 27.77 & 24.39 & 24.03 & 29.26 & 25.99 & 21.01 \\
\hline t-Stat & 2.27 & 2.41 & 1.94 & 2.18 & 2.10 & 1.92 & 1.91 & 1.90 & 1.87 & 1.82 & 2.00 & 1.77 \\
\hline $\mathrm{p}$-value & 0.02 & 0.02 & 0.05 & 0.03 & 0.04 & 0.06 & 0.06 & 0.06 & 0.06 & 0.07 & 0.05 & 0.08 \\
\hline Number of Observations & 142 & 141 & 154 & 135 & 154 & 148 & 151 & 156 & 151 & 153 & 151 & 141 \\
\hline Q2 Premium & -7.41 & -6.37 & -5.48 & -3.34 & -8.27 & -7.37 & -3.57 & -4.89 & -4.55 & -6.85 & -6.06 & -7.38 \\
\hline $\mathrm{t}-\mathrm{Stat}$ & -0.36 & -0.28 & -0.24 & -0.16 & -0.38 & -0.35 & -0.17 & -0.23 & -0.24 & -0.36 & -0.36 & -0.45 \\
\hline $\mathrm{p}$-value & 0.72 & 0.78 & 0.81 & 0.87 & 0.70 & 0.72 & 0.87 & 0.82 & 0.81 & 0.72 & 0.72 & 0.65 \\
\hline Number of Observations & 135 & 154 & 148 & 151 & 156 & 151 & 153 & 151 & 141 & 162 & 162 & 176 \\
\hline Q3 Premium & 18.52 & 12.65 & 12.65 & 14.19 & 13.99 & 14.21 & 13.21 & 12.10 & 12.09 & 16.60 & 23.66 & 23.30 \\
\hline t-Stat & 2.13 & 1.76 & 1.72 & 1.80 & 1.74 & 1.81 & 2.02 & 2.34 & 2.76 & 7.70 & 3.90 & 3.38 \\
\hline $\mathrm{p}$-value & 0.04 & 0.08 & 0.09 & 0.07 & 0.09 & 0.07 & 0.05 & 0.02 & 0.01 & 0.00 & 0.00 & 0.00 \\
\hline Number of Observations & 130 & 133 & 129 & 132 & 129 & 121 & 142 & 141 & 154 & 135 & 154 & 148 \\
\hline Q4 Premium & -4.78 & -3.57 & -5.56 & -15.99 & -16.01 & -14.78 & -14.75 & -2.44 & -1.88 & -3.12 & -9.30 & -12.56 \\
\hline $\mathrm{t}-\mathrm{Stat}$ & -0.29 & -0.23 & -0.32 & -1.03 & -1.01 & -0.90 & -0.89 & -0.13 & -0.09 & -0.13 & -0.49 & -0.68 \\
\hline $\mathrm{p}$-value & 0.78 & 0.82 & 0.75 & 0.30 & 0.32 & 0.37 & 0.37 & 0.90 & 0.93 & 0.89 & 0.63 & 0.50 \\
\hline Number of Observations & 132 & 129 & 121 & 142 & 141 & 154 & 135 & 154 & 148 & 151 & 156 & 151 \\
\hline \multicolumn{13}{|c|}{ QLD PEAK LOAD CONTRACTS } \\
\hline INTERVALS & 12 & 11 & 10 & 9 & 8 & 7 & 6 & 5 & 4 & 3 & 2 & 1 \\
\hline Q1 Premium & 17.99 & 17.90 & 20.09 & 28.55 & 36.15 & 38.55 & 40.12 & 42.60 & 40.53 & 43.61 & 36.82 & 29.00 \\
\hline t-Stat & 1.64 & 2.14 & 2.27 & 2.92 & 2.51 & 2.22 & 2.28 & 2.06 & 1.96 & 1.92 & 2.00 & 1.76 \\
\hline p-value & 0.10 & 0.03 & 0.02 & 0.00 & 0.01 & 0.03 & 0.02 & 0.04 & 0.05 & 0.06 & 0.05 & 0.08 \\
\hline Number of Observations & 142 & 141 & 154 & 135 & 154 & 148 & 151 & 156 & 151 & 153 & 151 & 141 \\
\hline Q2 Premium & -7.82 & -6.93 & -5.41 & -5.13 & -8.41 & -7.62 & -6.77 & -6.33 & -5.85 & -7.41 & -6.76 & -6.30 \\
\hline $\mathrm{t}-$ Stat & -0.47 & -0.37 & -0.29 & -0.30 & -0.46 & -0.46 & -0.37 & -0.35 & -0.37 & -0.45 & -0.47 & -0.48 \\
\hline p-value & 0.64 & 0.71 & 0.77 & 0.76 & 0.64 & 0.65 & 0.71 & 0.72 & 0.71 & 0.65 & 0.64 & 0.63 \\
\hline Number of Observations & 135 & 154 & 148 & 151 & 156 & 151 & 153 & 151 & 141 & 162 & 162 & 176 \\
\hline Q3 Premium & 12.82 & 8.44 & 7.75 & 8.97 & 9.83 & 10.28 & 9.93 & 9.06 & 9.74 & 10.64 & 18.87 & 19.37 \\
\hline $\mathrm{t}-\mathrm{Stat}$ & 1.87 & 1.34 & 1.29 & 1.23 & 1.31 & 1.50 & 1.63 & 2.10 & 3.16 & 6.16 & 2.98 & 2.89 \\
\hline $\mathrm{p}$-value & 0.06 & 0.18 & 0.20 & 0.22 & 0.19 & 0.14 & 0.11 & 0.04 & 0.00 & 0.00 & 0.00 & 0.00 \\
\hline Number of Observations & 130 & 133 & 129 & 132 & 129 & 121 & 142 & 141 & 154 & 135 & 154 & 148 \\
\hline Q4 Premium & 13.41 & 15.69 & 13.73 & 4.71 & 3.38 & 7.15 & 10.60 & 21.39 & 27.69 & 31.82 & 27.85 & 18.75 \\
\hline $\mathrm{t}$-Stat & 2.11 & 2.27 & 3.16 & 0.95 & 0.71 & 1.50 & 1.76 & 2.18 & 1.92 & 1.55 & 1.56 & 1.23 \\
\hline $\mathrm{p}$-value & 0.04 & 0.03 & 0.00 & 0.35 & 0.48 & 0.13 & 0.08 & 0.03 & 0.06 & 0.12 & 0.12 & 0.22 \\
\hline Number of Observations & 132 & 129 & 121 & 142 & 141 & 154 & 135 & 154 & 148 & 151 & 156 & 151 \\
\hline \multicolumn{13}{|c|}{ SA PEAK LOAD CONTRACTS } \\
\hline INTERVALS & 12 & 11 & 10 & 9 & 8 & 7 & 6 & 5 & 4 & 3 & 2 & 1 \\
\hline Q1 Premium & -46.60 & -43.35 & -41.61 & -43.28 & -43.42 & -39.05 & -38.53 & -31.33 & -20.19 & -21.13 & -11.26 & -6.77 \\
\hline $\mathrm{t}-\mathrm{Stat}$ & -1.12 & -1.10 & -1.07 & -1.17 & -1.13 & -1.04 & -1.03 & -0.86 & -0.61 & -0.61 & -0.35 & -0.24 \\
\hline p-value & 0.26 & 0.27 & 0.29 & 0.25 & 0.26 & 0.30 & 0.30 & 0.39 & 0.54 & 0.54 & 0.72 & 0.81 \\
\hline Number of Observations & 142 & 141 & 154 & 135 & 154 & 148 & 151 & 156 & 151 & 153 & 151 & 141 \\
\hline Q2 Premium & -1.23 & -0.97 & -0.62 & 0.89 & -0.18 & 1.65 & 0.79 & -0.36 & 0.50 & 1.91 & 1.11 & -0.79 \\
\hline $\mathrm{t}-\mathrm{Stat}$ & -0.12 & -0.09 & -0.06 & 0.09 & -0.02 & 0.17 & 0.08 & -0.04 & 0.05 & 0.21 & 0.16 & -0.14 \\
\hline p-value & 0.90 & 0.93 & 0.95 & 0.93 & 0.99 & 0.86 & 0.94 & 0.97 & 0.96 & 0.84 & 0.87 & 0.89 \\
\hline Number of Observations & 135 & 154 & 148 & 151 & 156 & 151 & 153 & 151 & 141 & 162 & 162 & 176 \\
\hline Q3 Premium & 6.73 & 4.46 & 4.71 & 2.07 & 0.85 & 0.98 & 0.19 & 2.75 & 3.21 & 2.78 & 2.23 & 7.03 \\
\hline $\mathrm{t}-$ Stat & 0.71 & 0.51 & 0.53 & 0.26 & 0.11 & 0.13 & 0.03 & 0.46 & 0.64 & 0.60 & 0.48 & 1.48 \\
\hline $\mathrm{p}$-value & 0.48 & 0.61 & 0.60 & 0.79 & 0.91 & 0.90 & 0.98 & 0.65 & 0.53 & 0.55 & 0.63 & 0.14 \\
\hline Number of Observations & 130 & 133 & 129 & 132 & 129 & 121 & 142 & 141 & 154 & 135 & 154 & 148 \\
\hline Q4 Premium & -0.28 & 0.69 & -1.13 & -3.55 & -2.07 & 0.27 & 0.47 & 1.37 & 4.19 & 9.31 & 9.48 & 7.27 \\
\hline $\mathrm{t}-$ Stat & -0.02 & 0.05 & -0.08 & -0.32 & -0.19 & 0.02 & 0.04 & 0.12 & 0.31 & 0.57 & 0.72 & 0.54 \\
\hline $\mathrm{p}$-value & 0.99 & 0.96 & 0.94 & 0.75 & 0.85 & 0.98 & 0.97 & 0.91 & 0.75 & 0.57 & 0.47 & 0.59 \\
\hline Number of Observations & 132 & 129 & 121 & 142 & 141 & 154 & 135 & 154 & 148 & 151 & 156 & 151 \\
\hline \multicolumn{13}{|c|}{ VIC PEAK LOAD CONTRACTS } \\
\hline INTERVALS & 12 & 11 & 10 & 9 & 8 & 7 & 6 & 5 & 4 & 3 & 2 & 1 \\
\hline Q1 Premium & 13.32 & 12.44 & 13.36 & 15.01 & 20.41 & 19.49 & 19.94 & 17.88 & 16.24 & 18.25 & 16.85 & 11.23 \\
\hline $\mathrm{t}-\mathrm{Stat}$ & 0.87 & 0.87 & 1.08 & 1.29 & 1.49 & 1.48 & 1.53 & 1.65 & 1.62 & 1.51 & 1.66 & 1.12 \\
\hline $\mathrm{p}$-value & 0.38 & 0.39 & 0.28 & 0.20 & 0.14 & 0.14 & 0.13 & 0.10 & 0.11 & 0.13 & 0.10 & 0.27 \\
\hline Number of Observations & 142 & 141 & 154 & 135 & 154 & 148 & 151 & 156 & 151 & 153 & 151 & 141 \\
\hline Q2 Premium & -10.83 & -8.81 & -7.04 & -6.50 & -9.88 & -9.10 & -6.23 & -6.37 & -6.08 & -7.70 & -9.19 & -9.96 \\
\hline $\mathrm{t}-\mathrm{Stat}$ & -1.02 & -0.67 & -0.52 & -0.55 & -0.84 & -0.83 & -0.51 & -0.54 & -0.59 & -0.82 & -1.17 & -1.34 \\
\hline $\mathrm{p}$-value & 0.31 & 0.50 & 0.60 & 0.59 & 0.40 & 0.41 & 0.61 & 0.59 & 0.55 & 0.42 & 0.24 & 0.18 \\
\hline Number of Observations & 135 & 154 & 148 & 151 & 156 & 151 & 153 & 151 & 141 & 162 & 162 & 176 \\
\hline Q3 Premium & 11.37 & 7.37 & 6.06 & 7.88 & 7.91 & 8.68 & 7.36 & 5.06 & 3.18 & 8.77 & 14.85 & 14.55 \\
\hline $\mathrm{t}$-Stat & 1.09 & 0.84 & 0.70 & 0.90 & 0.86 & 0.92 & 0.91 & 0.77 & 0.52 & 1.66 & 1.97 & 1.91 \\
\hline $\mathrm{p}$-value & 0.28 & 0.40 & 0.48 & 0.37 & 0.39 & 0.36 & 0.36 & 0.44 & 0.61 & 0.10 & 0.05 & 0.06 \\
\hline Number of Observations & 130 & 133 & 129 & 132 & 129 & 121 & 142 & 141 & 154 & 135 & 154 & 148 \\
\hline Q4 Premium & 14.91 & 13.74 & 12.75 & 10.04 & 10.04 & 9.34 & 12.70 & 18.54 & 18.86 & 21.44 & 13.43 & 10.16 \\
\hline $\mathrm{t}$-Stat & 2.54 & 2.46 & 2.22 & 1.66 & 1.71 & 1.80 & 2.39 & 2.55 & 2.31 & 2.10 & 2.69 & 3.23 \\
\hline $\mathrm{p}$-value & 0.01 & 0.02 & 0.03 & 0.10 & 0.09 & 0.07 & 0.02 & 0.01 & 0.02 & 0.04 & 0.01 & 0.00 \\
\hline Number of Observations & 132 & 129 & 121 & 142 & 141 & 154 & 135 & 154 & 148 & 151 & 156 & 151 \\
\hline
\end{tabular}

Table 3: Realized risk premiums, $t$-stats and $p$-values for significance of the premium for quarterly peak load futures contracts with time to delivery ranging from approximately twelve months up to the last month before the beginning of the delivery period. 


\subsection{Determinants of Realized Futures Premiums}

Modeling the dynamics of risk premiums implied in electricity futures contracts can be considered as one of the most challenging tasks in these markets. As pointed out by Huisman and Kilic (2012), forward models for electricity markets with imperfect indirect storability should depend heavily on price expectations, and are required to include time-varying risk premiums. Their findings also imply that it will be difficult to rely on a one-size fits all model for various futures contracts in different regional electricity markets. Haugom and Ulrich (2012) conclude that they are unable to find support for the equilibrium forward pricing model suggested by Bessembinder and Lemmon (2002). Considering short-term electricity forward contracts, they report highly unstable parameter values when a using rolling and recursive estimations of the model. This implies that modeling electricity futures premiums is challenging because electricity markets tend to be very dynamic. Despite these complexities, we try to develop a model that can identify determinants of dynamic risk premiums in electricity futures markets.

Bailey and Ng (1991) emphasize the importance of time-varying risk premiums for both theoretical and empirical research on forward and futures markets. Bessembinder and Chan (1992) document non-random price movements, implying evidence of time-varying risk premiums in 12 different futures markets. Wilkens and Wimschulte (2007) find that the bias of futures prices depends on the remaining time to maturity of futures contracts in the European Energy Exchange (EEX) markets. This also implies that time to maturity is an essential factor in explaining electricity futures premiums. Another study by Bhar and Lee (2011) shows that the timing of hedging mismatches could raise risk premiums, implying that an the time to maturity of a contract is essential for hedging and determining risk premiums. Gorton et al. (2012) also identify time-varying risk premiums in various commodity markets. Their findings suggest that risk premiums could vary at different times and therefore, time to maturity could be an important factor for the risk premium. Given our results in the previous section, we also suggest that the remaining time to the beginning of the delivery period of a contract is a key factor for explaining dynamic risk premiums. However, the results also indicate that the impact is quite different, depending on the delivery quarter and region of a considered contract.

Raynauld and Tessier (1984) propose two elements explaining ex-post futures premiums: rational agents and co-movement. For both elements, spot price behavior may 
play an important role in determining the premiums. As suggested by Chevillon and Rifflart (2009), observed premiums could also depend on the deviation of nominal spot prices from their long-term price levels. Furthermore, Wilkens and Wimschulte (2007) find that electricity spot price levels could explain the bias in electricity futures prices. Therefore, in our analysis we include recent information on spot price levels and volatility as possible determinants of futures risk premiums. We also include an additional factor, namely the number of price spikes in the spot market as a proxy for the risk of extreme outcomes in the considered market.

In particular, we include the moving average of the spot price as an explanatory variable for the risk premium. We use historical daily data up to one year prior to $t<\mathrm{T}_{1}$ when the quote of a futures price referring to delivery period $\left[\mathrm{T}_{1}, \mathrm{~T}_{2}\right]$ is observed. Seminal work on the electricity premiums modeling (Bessembinder and Lemmon, 2002; Douglas and Popova, 2008; Lucia and Toro, 2008, Redl et al. 2009) also suggest volatility in the spot market or electricity demand as one of the key determinants of the risk premium. Todorov (2010) concludes that investors tend to be sensitive to recent jump activity and that their willingness to pay for protection against potential jumps in prices increases significantly immediately after the occurrence of jumps. These findings suggest that large market movements may also drive time-varying risk aversion and, therefore, realized risk premiums. This leads to two important points: (i) large market movements affect investors' willingness to pay for protection, and, (ii) investors are sensitive to recent jump activity. Therefore, we suggest that spot market volatility, a reflection of market movement, plays an essential role in explaining dynamic risk premiums. We estimate the current level of volatility in the spot market, using an Exponentially Weighted Moving Average (EWMA) model to capture the sensitivity to recent changes in volatility. Given the convex relationship between electricity volatility and risk premiums in electricity futures markets, see e.g. Bessembinder and Lemmon (2002), Handika and Trück (2013), we might also include recent estimates of both volatility and variance of electricity spot prices into our model.

Recent research by Benth et al. (2013) models time-varying electricity risk premiums in the EEX market, using different information sets in the spot and forward market. Their findings confirm the existence of risk premiums in electricity derivatives markets. They also suggest that information about the future, for example information referring to the delivery period of a derivatives contract may be incorporated in the pricing. A more detailed multifactor model by Redl and Bunn (2013) suggests that the occurrence of spikes in the spot 
market increases the electricity forward premium. Therefore, it is sensible to argue that price spikes are also an essential component of the relationship between spot and futures prices, next to other statistical properties including the mean, volatility and variance of electricity demand or prices. This implies that price spikes may also determine the magnitude of electricity futures premiums. Another detailed argument can be found in Coulon et al. (2013) where it is suggested that the electricity stack reflects the key features of load and price dynamics. The authors observe that times of high load tend to be related to price spikes. Assuming that electricity market participants are rational, we could argue that recent observations of price spikes, reflecting times of unexpected high loads, can prompt participants to worry about future electricity prices, with the result that they increase the demand for long positions in electricity futures contracts. Therefore, the occurrence of price spikes can be expected to increase risk premiums implied in electricity futures contracts. In summary, we classify current levels of spot prices, the volatility and variance of the spot prices as well as the number of price spikes as highly relevant information in electricity spot markets that might determine the sign and magnitude of electricity futures premiums.

Based on this reasoning, we suggest the following model to examine the dynamics of realized risk premiums in Australian electricity futures markets using the following model:

$$
\mathrm{RP}_{\mathrm{t},\left[\mathrm{T}_{1}, \mathrm{~T}_{2}\right]}=\beta_{0}+\beta_{1}\left(\mathrm{~T}_{1}-\mathrm{t}\right)+\beta_{2} \overline{\mathrm{S}}_{\mathrm{t}}+\beta_{3} \sigma_{\mathrm{t}}+\beta_{4} \sigma_{\mathrm{t}}^{2}+\beta_{5} \mathrm{PS}_{\mathrm{t}}+\varepsilon_{\mathrm{t}}
$$

Hereby, $\mathrm{RP}_{t,\left[\mathrm{~T}_{1}, \mathrm{~T}_{2}\right]}$ denotes the realized risk premium measured as the difference between the quote for a futures base or peak load contract referring to delivery period $\left[\mathrm{T}_{1}, \mathrm{~T}_{2}\right]$ at time $\mathrm{t}$ and the actual average base or peak load spot price during the delivery period. Further, $\left(\mathrm{T}_{1}-\mathrm{t}\right)$ denotes the remaining time to the beginning of the delivery period, $\overline{\mathrm{S}_{\mathrm{t}}}$ is the one-year moving average of daily spot price at time $t, \sigma_{t}$ is the volatility estimate for daily spot electricity prices at time $t$ based on an EWMA model with $\lambda=0.94$. Finally, $\sigma_{\mathrm{t}}^{2}$ denotes the variance estimate of daily spot price volatility based on the EWMA model and PS is the number of price spikes exceeding $\$ 300$ during the month prior to t.

Table 4 and Table 5 report results for the regression analysis for model (4) for quarterly base and peak load futures contracts. Note that given the substantial differences between observed risk premiums for different quarters and markets, we decided to analyze each 
quarter and regional market separately. Therefore, both for base load and peak load contracts a total of 16 models, referring to four quarters $(\mathrm{Q} 1, \mathrm{Q} 2, \mathrm{Q} 3, \mathrm{Q} 4)$ and four markets (NSW, QLD, SA, VIC) are estimated. Overall, we find that the observed futures risk premiums tend to increase based on (i) a reduction in time to maturity, i.e. the beginning of the delivery period of the contract, (ii) the average level of spot prices during the last 12 months, and (iii) the number of price spikes in the most recent month prior to the observation of the futures price at time t. The coefficient of determination for the applied models on average is around 0.27 , with $\mathrm{R}^{2}$ ranging from 0.09 to 0.56 for base load futures contracts and from 0.04 to 0.56 for peak load contracts.

For Q1 base load contracts, the dynamics of observed futures risk premiums generally are significantly influenced by the time to maturity, recent levels of electricity spot prices, and the number of price spikes during the most recent month. For NSW, QLD and SA, time to maturity yields a negative coefficient, indicating that the closer a Q1 contract is to the beginning of the delivery period, the higher will on average be the risk premium. Observed premiums for NSW, QLD and VIC are also positively related to average spot price levels during the last year and the number of price spikes during the last month. Interestingly, for SA, the results for spot price levels and the number of price spikes are counter-intuitive, but for this market the model also yields the lowest explanatory power with a coefficient of determination equal to 0.09 . Note that estimated coefficients for the volatility and variance of electricity spot prices do not provide clear-cut results. Only for the VIC region, the results support the convexity, i.e. an estimated negative coefficient for volatility and a positive coefficient for the variance, as it has been initially suggested by Bessembinder and Lemmon (2002).

For Q2 base load contracts, we find that dynamics of futures risk premiums generally are significantly influenced by the time to maturity, recent levels of electricity spot prices, and the number of price spikes. For all regions, time to maturity yields a negative coefficient, while the premiums are positively related to average spot price levels during the last year prior to t. Note that for NSW, QLD and VIC the coefficient for the number of price spikes is positive, while it is negative for the SA market. In all regions we obtain negative coefficients for the volatility and positive coefficient for the variance. This indicates that for Q2, the convex relationship between observed risk premiums and volatility in the spot market suggested by Bessembinder and Lemmon (2002) seems to hold. 
Also for Q3 and Q4 base load contracts, the dynamics of observed futures risk premiums generally are significantly influenced by the time to maturity, recent levels of electricity spot prices, and the number of price spikes. For all regions, time to maturity yields a negative coefficient, while premiums are positively related to spot price levels and the number of price spikes. Similar to the results for Q1, the estimated coefficients for the volatility and variance of electricity spot prices do not provide clear-cut results. Only for SA and VIC (for Q3) and NSW and VIC (for Q4), our results support the convexity assumption.

We obtain similar results for the analysis of risk premiums referring to peak load futures contracts. For Q1 contracts, the dynamics of observed futures risk premiums generally are significantly influenced by the time to maturity, spot price levels, and the number of price spikes. For QLD and SA, time to maturity yields a negative coefficient, indicating that the closer a Q1 contract is to the beginning of the delivery period, the higher will on average be the risk premium. Interestingly, for NSW and VIC the estimated coefficients are positive what can be explained by the relatively low risk premiums during the last month prior to delivery of the contract. Estimated coefficients for spot price level and the number of price spikes are positive and significant for all markets, except SA, where the results for spot price levels and the number of price spikes are counter-intuitive. However, similar to the results for base load contracts, the model yields a relatively low explanatory power for this market. Again, estimated coefficients for the volatility and variance do not provide clear-cut results. Only for the VIC region, the results support the convex relationship between risk premiums and volatility levels. Also for Q2, Q3 and Q4 peak load contracts, the dynamics of observed futures risk premiums in most cases are significantly influenced by time to maturity, spot price levels, and the number of price spikes. The coefficient for time to maturity is negative for all equations and significant for 10 out of 12 estimated models. Also the coefficient for the level of spot prices is positive and significant for all markets, except for Q4 peak load contracts in SA. Results are not that clear-cut for the impact of price spikes on realized risk premiums. While the variable is significant for 10 of the estimated 12 models, the estimated coefficient is negative for Q2, Q3 and Q4 contracts in SA. However, for all other markets estimated coefficients are positive. We also find support for the assumed convex relationship between spot market volatility and realized futures risk premiums for peak load contracts in Q2 and Q4. 


\begin{tabular}{|c|c|c|c|c|c|c|c|}
\hline \multicolumn{8}{|c|}{ BASE PERIOD } \\
\hline \multicolumn{8}{|c|}{ QUARTER 1} \\
\hline REGION & Intercept & Time to Maturity & Spot Price Level & Volatility & Variance \# & $\#$ of Price Spikes & Adj - $R^{2}$ \\
\hline \multirow[t]{2}{*}{ NSW } & -10.95 & $-3.38 * *)$ & $0.62 * * *)$ & -0.01 & $-13.38 * * *)$ & $0.37 * * *)$ & 0.20 \\
\hline & $(-4.96)$ & $(-2.36)$ & $(13.37)$ & $(0.00)$ & $(-3.05)$ & $(12.61)$ & \\
\hline \multirow[t]{2}{*}{ QLD } & -24.46 & $-11.56 * * *)$ & $1.25 * * *)$ & 7.01 & $-23.35 * * *)$ & $0.39 * * *)$ & 0.56 \\
\hline & $(-16.70)$ & $(-9.70)$ & ( 43.01$)$ & $(1.59)$ & $(-6.44)$ & $(10.78)$ & \\
\hline \multirow[t]{2}{*}{ SA } & 19.68 & $-12.11 * * *)$ & $-0.43 * * *)$ & $16.85 *)$ & $17.34 * *)$ & $-0.80 * * *)$ & 0.09 \\
\hline & $(4.61)$ & $(-4.61)$ & $(-7.50)$ & $(1.69)$ & $(2.43)$ & $(-7.37)$ & \\
\hline \multirow[t]{2}{*}{ VIC } & 5.71 & 1.06 & $0.56 * * *)$ & $-90.57 * * *)$ & $59.88 * * *)$ & $0.89 * * *)$ & 0.25 \\
\hline & $(3.20)$ & $(0.81)$ & $(15.62)$ & $(-13.35)$ & $(9.52)$ & $(14.80)$ & \\
\hline \multicolumn{8}{|c|}{ QUARTER 2} \\
\hline REGION & Intercept & Time to Maturity & Spot Price Level & Volatility & Variance \# & \# of Price Spikes & Adj - $R^{2}$ \\
\hline \multirow[t]{2}{*}{ NSW } & -55.05 & -0.25 & $1.36 * * *)$ & $-42.93 * * *)$ & $46.21 * * *)$ & 0.07 & 0.14 \\
\hline & $(-13.25)$ & $(-0.09)$ & $(16.19)$ & $(-4.55)$ & $(5.86)$ & $(1.25)$ & \\
\hline \multirow[t]{2}{*}{ QLD } & -35.87 & -1.45 & $0.95 * * *)$ & $-18.54 * *)$ & $15.35 * *)$ & $0.18 * *)$ & 0.15 \\
\hline & $(-10.61)$ & $(-0.53)$ & $(16.40)$ & $(-1.99)$ & $(2.12)$ & $(2.52)$ & \\
\hline \multirow[t]{2}{*}{ SA } & -20.99 & $-4.21 * * *)$ & $0.56 * * *)$ & $-19.71 * * *)$ & $12.71 * * *)$ & $-0.13 * *)$ & 0.22 \\
\hline & $(-10.55)$ & $(-3.27)$ & $(21.37)$ & $(-4.22)$ & $(3.87)$ & $(-2.51)$ & \\
\hline \multirow[t]{2}{*}{ VIC } & -14.74 & $-6.45 * * *)$ & $0.81 * * *)$ & $-89.84 * * *)$ & $63.73 * * *)$ & $0.34 * * *)$ & 0.16 \\
\hline & $(-5.81)$ & $(-3.72)$ & $(16.51)$ & $(-9.54)$ & $(7.38)$ & $(4.18)$ & \\
\hline \multicolumn{8}{|c|}{ QUARTER 3} \\
\hline REGION & Intercept & Time to Maturity & Spot Price Level & Volatility & Variance \# & \# of Price Spikes & Adj $-R^{2}$ \\
\hline \multirow[t]{2}{*}{ NSW } & -10.22 & $-7.84 * * *)$ & $0.47 * * *)$ & $5.94 *)$ & $-8.12 * * *)$ & $0.19 * * *)$ & 0.24 \\
\hline & $(-6.90)$ & $(-8.60)$ & $(16.05)$ & $(1.72)$ & $(-2.86)$ & $(10.33)$ & \\
\hline \multirow[t]{2}{*}{ QLD } & -8.15 & $-8.36 * * *)$ & $0.42 * * *)$ & 5.98 & $-5.31 *)$ & $0.21 * * *)$ & 0.24 \\
\hline & $(-6.52)$ & $(-8.67)$ & $(17.89)$ & $(1.62)$ & $(-1.80)$ & $(7.07)$ & \\
\hline \multirow[t]{2}{*}{ SA } & -17.07 & $-5.88 * * *)$ & $0.65 * * *)$ & $-29.84 * * *)$ & $14.67 * * *)$ & $0.10 * * *)$ & 0.46 \\
\hline & $(-12.63)$ & $(-7.21)$ & $(34.50)$ & $(-9.40)$ & $(6.46)$ & $(3.02)$ & \\
\hline \multirow[t]{2}{*}{ VIC } & -15.59 & $-6.92 * * *)$ & $0.79 * * *)$ & $-33.44 * * *)$ & $17.93 * * *)$ & $0.31 * * *)$ & 0.39 \\
\hline & $(-11.12)$ & $(-7.76)$ & $(29.54)$ & $(-6.74)$ & $(3.94)$ & $(7.25)$ & \\
\hline \multicolumn{8}{|c|}{ QUARTER 4} \\
\hline REGION & Intercept & Time to Maturity & Spot Price Level & Volatility & Variance \# & \# of Price Spikes & Adj $-R^{2}$ \\
\hline \multirow[t]{2}{*}{ NSW } & -7.15 & -1.73 & $0.31 * * *)$ & $-38.67 * * *)$ & $28.98 * * *)$ & $0.54 * * *)$ & 0.19 \\
\hline & $(-2.86)$ & $(-1.04)$ & ( 6.06 ) & $(-6.75)$ & $(6.00)$ & $(16.31)$ & \\
\hline \multirow[t]{2}{*}{ QLD } & -10.80 & $-12.33 * * *)$ & $0.60 * * *)$ & $9.62 * *)$ & $-7.18 * *)$ & $0.47 * * *)$ & 0.39 \\
\hline & $(-8.03)$ & $(-9.90)$ & $(22.44)$ & $(2.29)$ & $(-2.17)$ & $(13.87)$ & \\
\hline \multirow[t]{2}{*}{ SA } & -13.72 & $-10.65 * * *)$ & $0.46 * * *)$ & $10.85 *)$ & -2.46 & $0.11 *)$ & 0.14 \\
\hline & $(-5.32)$ & $(-6.41)$ & $(12.98)$ & $(1.73)$ & $(-0.55)$ & $(1.72)$ & \\
\hline \multirow[t]{2}{*}{ VIC } & -7.03 & $-2.63 * * *)$ & $0.48 * * *)$ & $-11.64 * * *)$ & 1.64 & $0.51 * * *)$ & 0.48 \\
\hline & $(-8.69)$ & $(-4.56)$ & $(29.13)$ & $(-3.70)$ & $(0.57)$ & $(18.56)$ & \\
\hline
\end{tabular}

Table 4: Results of regression analysis (4) for realized futures risk premium for each quarter during base load period in NSW, QLD, SA and VIC. Explanatory variables are based on the time to maturity, average spot price, volatility and variance estimates of the daily change of spot prices and the number of price spikes in the recent month. The asterisk indicates a significant risk premium at the *) $10 \%$ significance level, $* *$ ) $5 \%$ significance level, and $* * *$ ) $1 \%$ significance level. 


\begin{tabular}{|c|c|c|c|c|c|c|c|}
\hline \multicolumn{8}{|c|}{ PEAK PERIOD } \\
\hline \multicolumn{8}{|c|}{ QUARTER 1} \\
\hline REGION & Intercept & Time to Maturity & pot Price Level & Volatility & Variance & \# of Price Spikes & Adj - $R^{2}$ \\
\hline NSW & 17.92 & 0.63 & $0.27 * * *)$ & $-19.04 * *)$ & $-17.60 * * *)$ & $1.18 * * *)$ & 0.20 \\
\hline & $(4.43)$ & $(0.23)$ & $(4.74)$ & $(-2.34)$ & $(-3.27)$ & $(17.39)$ & \\
\hline QLD & -59.54 & $-20.75 * * *)$ & $1.68 * * *)$ & $81.48 * * *)$ & $-82.56 * * *)$ & $0.88 * * *)$ & 0.56 \\
\hline & $(-20.28)$ & $(-8.19)$ & $(40.46)$ & $(9.75)$ & $(-13.15)$ & ( 10.81$)$ & \\
\hline SA & 37.83 & $-62.25 * * *)$ & $-0.94 * * *)$ & $74.83 * * *)$ & 27.12 & $-3.91 * * *)$ & 0.14 \\
\hline & $(3.76)$ & $(-7.77)$ & $(-11.17)$ & $(3.07)$ & $(1.63)$ & $(-9.57)$ & \\
\hline VIC & 25.30 & $6.59 * *)$ & $0.50 * * *)$ & $-174.91 * * *)$ & $106.51 * * *)$ & $2.19 * * *)$ & 0.21 \\
\hline & $(7.03)$ & $(2.19)$ & $(9.17)$ & $(-14.90)$ & $(10.75)$ & $(14.37)$ & \\
\hline \multicolumn{8}{|c|}{ QUARTER 2} \\
\hline REGION & Intercept & Time to Maturity & pot Price Level & Volatility & Variance & \# of Price Spikes & Adj - $R^{2}$ \\
\hline NSW & -52.85 & -3.71 & $1.20 * * *)$ & $-103.81 * * *)$ & $71.55 * * *)$ & $0.30 * *)$ & 0.10 \\
\hline & $(-7.37)$ & $(-0.72)$ & $(12.06)$ & $(-7.29)$ & $(7.54)$ & $(2.42)$ & \\
\hline QLD & -28.76 & $-12.72 * * *)$ & $1.14 * * *)$ & $-114.40 * * *)$ & $71.19 * * *)$ & $0.60 * * *)$ & 0.15 \\
\hline & $(-5.23)$ & $(-2.85)$ & $(16.53)$ & $(-8.12)$ & $(6.80)$ & $(4.45)$ & \\
\hline SA & -18.80 & $-7.25 * * *)$ & $0.51 * * *)$ & $-47.27 * * *)$ & $35.84 * * *)$ & $-0.73 * * *)$ & 0.36 \\
\hline & $(-9.0$ & $(-4.27)$ & $(29.09)$ & $(-9.66)$ & $(10.59)$ & $(-8.55)$ & \\
\hline VIC & -16.70 & $-10.46 * * *)$ & $0.86 * * *)$ & $-127.71 * * *)$ & $72.45 * * *)$ & $0.76 * * *)$ & 0.19 \\
\hline & $(-4.80)$ & $(-3.90)$ & $(16.23)$ & $(-11.45)$ & $(7.55)$ & $(5.11)$ & \\
\hline \multicolumn{8}{|c|}{ QUARTER 3} \\
\hline REGION & Intercept & Time to Maturity & pot Price Level & Volatility & Variance & \# of Price Spikes & Adj - $R^{2}$ \\
\hline NSW & 6.93 & $-8.75 * * *)$ & $0.25 * * *)$ & -6.73 & $-4.96 *)$ & $0.50 * * *)$ & 0.18 \\
\hline & $(3.09)$ & $(-6.30)$ & $(8.59)$ & $(-1.52)$ & $(-1.73)$ & $(14.71)$ & \\
\hline QLD & -7.72 & $-10.28 * * *)$ & $0.43 * * *)$ & 5.43 & $-8.42 * *)$ & $0.46 * * *)$ & 0.26 \\
\hline & $(-4.39)$ & $(-7.68)$ & $(18.87)$ & $(1.15)$ & $(-2.39)$ & $(10.28)$ & \\
\hline SA & -17.04 & $-4.42 * * *)$ & $0.41 * * *)$ & $-25.65 * * *)$ & $14.45 * * *)$ & -0.08 & 0.45 \\
\hline & $(-10.77)$ & $(-4.10)$ & $(34.45)$ & $(-7.23)$ & $(6.04)$ & $(-1.43)$ & \\
\hline VIC & -20.08 & $-10.77 * * *)$ & $0.84 * * *)$ & $-44.99 * * *)$ & $21.34 * * *)$ & $0.46 * * *)$ & 0.43 \\
\hline & $(-9.56)$ & $(-8.06)$ & $(30.67)$ & $(-7.58)$ & $(4.36)$ & $(6.24)$ & \\
\hline \multicolumn{8}{|c|}{ QUARTER 4} \\
\hline REGION & Intercept & Time to Mat & pot Price Level & Volatility & Variance \# & \# of Price Spikes & Adj $-R^{2}$ \\
\hline NSW & -9.37 & -2.02 & $0.38 * * *)$ & $-104.77 * * *)$ & $65.25 * * *)$ & $1.30 * * *)$ & 0.14 \\
\hline & $(-1.47)$ & $(-0.48)$ & $(4.46)$ & $(-8.56)$ & $(8.01)$ & $(12.88)$ & \\
\hline QLD & -16.04 & $-18.71 * * *)$ & $0.84 * * *)$ & $-17.91 * * *)$ & 4.50 & $1.37 * * *)$ & 0.39 \\
\hline & $(-5.94)$ & $(-8.11)$ & $(22.40)$ & $(-2.37)$ & $(0.79)$ & $(18.61)$ & \\
\hline SA & -14.67 & $-22.52 * * *)$ & 0.06 & $68.52 * * *)$ & $-28.47 * * *)$ & -0.14 & 0.04 \\
\hline & $(-2.95)$ & $(-5.60)$ & $(1.44)$ & $(5.57)$ & $(-3.41)$ & $(-0.67)$ & \\
\hline VIC & -14.63 & $-3.77 * * *)$ & $0.61 * * *)$ & $-14.09 * * *)$ & 0.21 & $1.01 * * *)$ & 0.49 \\
\hline & $(-10.22)$ & $(-3.61)$ & $(29.18)$ & $(-3.15)$ & $(0.06)$ & $(17.82)$ & \\
\hline
\end{tabular}

Table 5: Results of regression analysis (4) for realized futures risk premium for each quarter during peak load period in NSW, QLD, SA and VIC. Explanatory variables are based on the time to maturity, average spot price, volatility and variance estimates of daily change of spot prices and the number of price spikes in the recent month. The asterisks indicate a significant risk premium at the *) $10 \%$ significance level, **) $5 \%$ significance level, and ***) $1 \%$ significance level. 
Overall, our analysis strongly supports the assumption that the dynamics of observed futures risk premiums are significantly influenced by the time to maturity, recent levels of electricity spot prices, and the number of price spikes during the most recent month. The negative coefficient for time to maturity points towards increasing risk premiums as futures contracts get closer to the beginning of the delivery period. Furthermore, observed premiums are almost unanimously positively related to average spot price levels and the number of price spikes in the spot market. Finally, while results on the relationship between spot price volatility and realized risk premiums are not clear-cut, we find some support for the convex relationship between these variables that has been suggested by Bessembinder and Lemmon (2002). However, the explanatory power of the models, as well as the significance and sign of estimated coefficients show strong variations for considered markets and delivery quarters. In particular, the substantial differences in the estimated coefficients support results by earlier studies such as Huisman and Kilic (2012) and Haugom and Ullrich (2012), who find timevarying risk premiums and unstable parameter estimates. Our results also emphasize the difficulties one may face in finding a single model for the determinants of risk premiums that is valid for various electricity futures markets.

\subsection{Summary and Conclusions}

This paper investigates the dynamics of realized futures risk premiums in the four major Australian electricity markets NSW, QLD, SA and VIC. We analyze futures risk premiums for quarterly contracts at different time instances. In particular we focus on the relationship between realized risk premiums and the remaining time until the beginning of the delivery period of a contract. We provide a new perspective on risk premiums in electricity markets, by examining the dynamics and determinants of risk premiums across several electricity markets in Australia that are considered to be among the most volatile markets in the world.

Using data from 2005 to mid-2012, we find that futures premiums are statistically significant and are generally higher as a contract is to the beginning of the delivery period. The magnitude and significance of the observed premiums, however, varies significantly for different regions and even more for contracts referring to different delivery periods, i.e. the first, second, third or fourth quarter of the year. Based on these findings, we suggest that there 
are strong seasonal effects and time-variation in futures risk premiums for regional Australian electricity markets.

In a second step we also investigate the determinants of the observed risk premiums. We develop a model for the dynamics of realized risk premiums and suggest time to maturity, spot price levels, volatility and variance of spot prices, as well as the number of price spikes in the most recent month as explanatory variables. Overall, we find that futures premiums tend to increase with (i) a reduction in the time to the beginning of the delivery period of the contract, (ii) recent spot price levels, and (iii) the frequency of price spikes in the spot market. Furthermore, we find some support for the convex relationship between risk premiums and volatility in the spot market that has been initially suggested by Bessembinder and Lemmon (2002). However, we find that our results vary quite significantly across the examined quarters and regions. Therefore, we confirm results by previous studies pointing towards the difficulties one may face in finding a general model for the dynamics and determinants of risk premiums in electricity futures markets. It remains a very challenging task to find such a model that is valid not only for different electricity markets with unique features but also at different points in time. In particular the latter is particularly demanding due to strong seasonal effects in the relationship between electricity spot and futures prices.

Our results also suggest several areas for future work. In our study we investigate realized, or ex-post, futures premiums only. An analysis of ex-ante premiums in the considered Australian markets should also be of significant interest to market participants and would complement our analysis using a different perspective. Another possible area of research might be to apply robust regression analysis using panel data. However, integrating contracts referring to different markets and quarters into a panel framework needs to be carried out very carefully, due to the seasonal behaviour of electricity spot and futures markets and the time-varying relationship between these markets. The time-varying and seasonal dynamics of electricity spot and futures prices also distinguishes these markets clearly from other financial markets. 


\section{Bibliography}

Anderson, EJ, Hu, X \& Winchester, D 2007, 'Forward Contract In Electricity Markets: The Australian Experience', Energy Policy, no. 35, pp. 3089 - 3103.

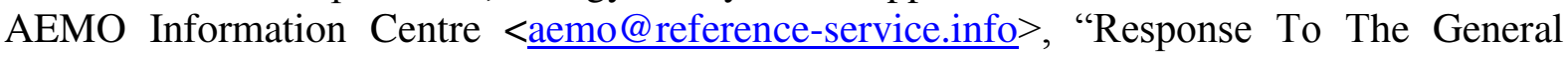
Information Query Question Q22582”, 13 May 2011.

Australian Energy Market Operator 2010, An Introduction To Australian's National Electricity Markets, July 2010.

Australian Energy Market Operator 2010, About AEMO - Overview, http://www.aemo.com.au/corporate/aboutaemo.html, viewed 29 December 2010.

Bailey, W \& Ng, E 1991, 'Default Premium In Commodity Markets: Theory And Evidence', The Journal of Finance, vol. 46 no. 3, pp. 1071 - 1093.

Baxter, J, Conine, TE \& Tamarkin, M 1985, 'On Commodity Market Risk Premiums: Additional Evidence', The Journal of Futures Markets, vol. 5, no. 1, pp. 121 - 125.

Benth, F, Benth, S \& Koekebakker, S 2008, Stochastic Modelling of Electricity and Related Markets, $2^{\text {nd }}$ edition, World Scientific. Advanced Series on Statistical Science and Applied Probability.

Benth, FE, König, RB \& Kiesel, R 2013, ‘An Empirical Study Of The Information Premium On Electricity Markets', Energy Economics, no. 36, pp. 55 - 77

Bessembinder, H \& Chan, K 1992, 'Time Varying Risk Premia And Forecastable Returns In Futures Markets', Journal of Financial Economics, no. 32, pp. 169 - 193.

Bessembinder, H \& Lemmon, ML 2002, 'Equilibrium Pricing And Optimal Hedging In Electricity Forward Markets', The Journal of Finance, vol. 57 no. 3, pp. 1347 - 1381.

Bhar, D \& Lee, D 2011, 'Time-Varying Market Price Of Risk In The Crude Oil Futures Market', The Journal of Futures Markets, vol. 31, no. 8, pp. 779 - 807.

Bierbrauer, M, Menn, C, Rachev, ST \& Trück, S 2007, 'Spot And Derivative Pricing In The EEX Power Market', The Journal of Banking \& Finance, no. 31, pp. 3462 - 3485.

Botterud, A, Bhattacharyya, AK \& Ilic, M 2002, 'Futures And Spot Prices - An Analysis Of The Scandinavian Electricity Market', Working Paper, pp. $1-8$.

Botterud, A, Kristiansen, T \& Ilic, M 2010, 'The Relationship Between Spot And Futures Prices In The Nord Pool Electricity Market', Energy Economics, no. 32, pp. $967-978$.

Bowden, N \& Pane, JE 2008, 'Short Term Forecasting Of Electricity Prices For MISO Hubs: Evidence From ARIMA-EGARCH Models', Energy Economics, no. 30, pp. 31863197.

Burger, M, Klar, B, Müller, A \& Schindlmayr, G 2004, 'A Spot Market Model For Pricing Derivatives In Electricity Markets', Quantitative Finance, vol. 4, pp. 109 - 122.

Chevillon, G \& Rifflart, C 2009, 'Physical Market Determinants Of The Price Of Crude Oil And The Market Premium', Energy Economics, no. 31, pp. 537 - 549.

Cootner, PH 1960, 'Returns To Speculators: Telser Versus Keynes', The Journal of Political Economy, vol. 68 , no. 4 , pp. $396-404$.

Coulon, M, Powell, WB \& Sircar R 2013, 'A Model For Hedging Load And Price Risk In The Texas Electricity Market', Energy Economics, http://dx.doi.org/10.1016/j.eneco.2013.05.020

d-cyphaTrade, http://d-cyphatrade.com.au/products/overview_of_the_australian_el, viewed 29 December 2010

Daskalakis, G \& Markellos, RN 2009, 'Are Electricity Risk Premia Affected By Emission Allowance Prices? Evidence From The EEX, Nord Pool And Powernext', Energy Policy, no. 3, pp. 2594 - 2604. 
Deaves, R \& Krinsky, I 1995, 'Do Futures Prices For Commodities Embody Risks Premiums', The Journal of Futures Markets, vol. 15, no. 6, pp. 637 - 648.

Diko, P, Lawford, S \& Limpens, V 2006, 'Risk Premia In Electricity Forward Markets', Studies in Nonlinear Dynamics \& Econometrics, vol. 10 no. 3, pp. $1-22$.

Douglas, S \& Popova, J 2008, 'Storage And The Electricity Forward Premium', Energy Economics, no. 30, pp. 1712 - 1727.

Dusak, K 1973, 'Futures Trading And Investor Returns: An Investigation Of Commodity Market Risk Premiums', The Journal of Political Economy, vol. 81, no. 6, pp. 1387 1406.

Furio, D \& Meneu, V 2010, 'Expectations And Forward Risk Premium In The Spanish Deregulated Power Market', Energy Policy, no. 38, pp. 784 - 793.

Gorton, GB, Hayashi, F \& Rouwenhorst, KG 2012, 'The Fundamentals Of Commodity Futures Returns', Review of Finance, no. 17, pp. 35 - 105.

Hadsell, L \& Shawky, HA 2006, 'Electricity Price Volatility And The Marginal Cost Of Congestion: An Empirical Study Of Peak Hours In The NYISO Market 2001-2004', The Energy Journal, vol. 27 no. 2, pp. 157 - 179.

Handika, R, \& Trück, S 2013, 'Risk Premiums In Interconnected Australian Electricity Futures Markets', Working Paper.

Haugom, E \& Ullrich, CJ 2012, 'Market Efficiency And Risk Premia In Short-Term Forward Prices', Energy Economics, no. 34, pp. 1931 - 1941.

Higgs, H 2009, 'Modeling Price And Volatility Inter-Relationship In The Australia Wholesale Spot Electricity Markets', Energy Economics, no. 31, pp. 748 - 756.

Huisman, R, Huurman, C \& Mahieu, R 2007, 'Hourly Electricity Prices In Day-Ahead Markets', Energy Economics, no. 29, pp. 240 - 248.

Huisman, R \& Kilic, M 2012, 'Electricity Futures Prices: Indirect Storability, Expectations, And Risk Premiums', Energy Economics, no. 34, pp. 892 - 898.

$\mathrm{Hu}, \mathrm{X}$, Grozev, G \& Battern, D 2005, 'Empirical Observations Of Bidding Patterns In Australia's National Electricity Market', Energy Policy, no. 33, pp. 2075 - 2086.

Kaldor, N 1939. 'Speculation And Economic Stability', The Review of Economic Studies, vol. 7, no. 1 , pp. $1-27$.

Kanamura, T \& Ohashi, K 2008, 'On Transition Probabilities Of Regime Switching In Electricity Prices', Energy Economics, no. 30, pp. 1158 - 1172.

Karakatsani, NV \& Bunn, DW 2008, 'Intra-Day And Regime-Switching Dynamics In Electricity Price Formation', Energy Economics, no. 30, pp. 1176 - 1797.

Keynes, JM 1930. A Treatise On Money, Macmillan, London.

Kho, BC 1996, 'Time-varying Risk Premia, Volatility, And Technical Trading Rule Profits: Evidence From Foreign Currency Futures Markets', Journal of Financial Economics, no. 41 , pp. $249-290$.

Kolos, SP \& Ronn, EI 2008, 'Estimating The Commodity Market Price Of Risk For Energy Prices', Energy Economics, no. 30, pp. 621 - 641.

Kvam, PH \& Vidakovic, B 2007, Nonparametric Statistics With Applications To Science And Engineering, John Wiley \& Sons Inc., New Jersey USA.

Longstaff, FA \& Wang, AW 2004, 'Electricity Forward Prices: A High Frequency Empirical Analysis', The Journal of Finance, vol. 59, no. 4, pp. 1877 - 1900.

Lucia, JJ \& Schwartz, ES 2002, 'Electricity Prices And Power Derivatives: Evidence From The Nordic Power Exchange', Review of Derivatives Research, no. 5, pp. 5 - 50.

Lucia, JJ \& Torro, H, 2008, 'Short-Term Electricity Futures Prices: Evidence On The TimeVarying Risk Premium', Working Paper, pp. 1 - 34. 
Raynauld, J \& Tessier, J 1984, 'Risk Premiums In Futures Markets: An Empirical Investigation', The Journal of Futures Markets, vol. 4, no. 2, pp. $189-211$.

Redl, C, Haas, R, Huber, C \& Böhm, B 2009, 'Price Formation In Electricity Forward Markets And The Relevance Of Systematic Forecast Errors', Energy Economics, no. 31, pp. $356-364$.

Redl, C \& Bunn, DW 2013, 'Determinants of the Premium in Forward Contracts', Journal of Regulatory Economics, vol. 43, no. 1, pp. 90 - 111.

Shawky, AH, Marathe, A \& Barrett, CL 2003, 'A First Look At The Empirical Relation Between Spot And Futures Electricity Prices In The Unites States', The Journal of Futures Markets, vol. 23, no. 10, pp. 931 - 955.

So, JC 1987, 'Commodity Futures Risk Premium And Unstable Systematic Risk', The Journal of Futures Markets, vol. 7, no. 3, pp. $311-326$.

Thomas, S, Ramiah, V, Mitchell, H \& Heaney, R 2006, 'Seasonal Factors And Outlier Effects In Returns On Electricity Spot Prices In Australia's National Electricity Market', Working Paper - School of Economics, Finance and Marketing, RMIT University, pp. $1-32$.

Todorov, V 2010, 'Variance Risk-Premium Dynamics: The Role of Jumps', Review of Financial Studies, vol. 23, no. 1, pp. $345-383$.

Weron, R 2006, Modeling And Forecasting Loads And Prices In Deregulated Electricity Markets, Agencja Rynku Energii S A, Warszawa Poland.

Weron, R 2008. 'Market Price Of Risk Implied By Asian-style Electricity Options And Futures', Energy Economics, no. 30, pp. 1098 - 1115.

Wilkens, S \& Wimschulte, J 2007, 'The Pricing Of Electricity Futures: Evidence From The European Exchange', The Journal of Futures Markets, vol. 27, no. 4, pp. 387 - 410.

Wilks, DS 1997. 'Resampling Hypothesis Tests For Autocorrelated Fields', Journal of Climate, vol. 10, pp. 65 - 82.

Worthington, A, Kay-Spratley, A \& Higgs, H 2005, 'Transmission Of Prices And Price Volatility In Australian Electricity Markets', Energy Economics, no. 27, pp. 337 - 350. 


\title{
4. Modelling Price Spikes in Electricity Markets - the Impact of Load, Weather and Capacity
}

\begin{abstract}
We examine the impact of explanatory variables such as load, weather and capacity constraints on the occurrence and magnitude of price spikes in regional Australian electricity markets. We apply the so-called Heckman correction, a two-stage estimation procedure that allows us to investigate the impact of the considered variables on extreme price observations only, while correcting for a selection bias due to non-random sampling in the analysis. The framework is applied to four regional electricity markets in Australia and it is found that for these markets, load, relative air temperature and reserve margins are significant variables for the occurrence of price spikes, while electricity loads and relative air temperature are significant variables to impact on the magnitude of a price spike. The Heckman selection model is also found to outperform standard OLS regression models with respect to forecasting the magnitude of electricity price spikes.
\end{abstract}




\subsection{Introduction}

In recent decades, many countries have transformed the electricity power sector from monopolistic, government controlled systems into deregulated, competitive markets. Like other commodities, electricity is now traded under competitive rules using spot and derivative contracts (Harris, 2006). Electricity prices are far more volatile than other commodity prices, as pointed out by e.g. Eydeland and Wolyniec (2012), Huisman (2009) or Weron (2006). The volatility of electricity, measured by daily standard deviation of returns, can be as high as 50 percent, while the maximum volatilities of stocks are usually lower than 4 percent (Weron 2000). Therefore, the risk of extreme outcomes in electricity spot markets is of significant concern to market participants.

Electricity prices often exhibit unique behaviour compared to other commodity markets. Typical features include mean-reversion, seasonality, extreme volatility and socalled price spikes (Bierbrauer et al., 2007; Higgs and Worthington, 2008; Huisman et al., 2007; Janczura and Weron, 2010; Kanamura and Ohashi, 2008; Lucia and Schwartz, 2002). The latter usually describe abrupt, short-lived and generally unanticipated extreme changes in the spot price and can be considered as one of the most pronounced features of electricity spot markets. Despite their rarity, spikes account for a large part of the total variation of changes in the spot price and are therefore an important component of the risk faced by market participants. Spikes are also a key reason for designing derivatives contracts such as futures and options that have been introduced to allow electricity buyers and sellers to hedge against extreme price movements in the spot market (Anderson, 2007; Shawky et al., 2003). For example, in Australia, next to yearly and quarterly futures contracts, also option contracts or so-called '\$300 cap products' are traded in the ASX Australian Electricity Futures and Options Market. For these contracts, the payoff is determined based on both the frequency and magnitude of observed half-hourly price spikes during a calendar quarter. To evaluate these instruments accurately and to facilitate price spike risk management, it is necessary to understand the impacts of different factors on the occurrence and magnitude of price spikes.

From a modelling perspective, price spikes are one of the most serious reasons for including discontinuous components in econometric models of electricity price dynamics. The literature suggests a variety of approaches how to achieve this, including, for example, autoregressive time-series models with thresholds (Misiorek et al., 2006), mean reverting jump-diffusion models (Cartea and Figueroa 2005, Clewlow and Strickland, 2000; Geman 
and Roncoroni, 2006, Knittel and Roberts, 2005) or Markov-switching models incorporating spikes by proposing different price regimes (Becker et al., 2007; Bierbrauer et al., 2007; de Jong, 2006; Huisman and Mahieu, 2003; Kanamura and Ohashi, 2008; Kosater, 2008; Weron et al., 2004).

Factors explaining the large variation of electricity prices in general, and the occurrence of price spikes in particular, have also been analysed in a number of studies, see, for example, Escribano et al. (2002), Huisman (2008), Kanamura and Ohashi (2007, 2008), Knittel and Roberts (2005), Kosater (2008), Mount et al. (2006).

Escribano et al., (2002) and Knittel and Roberts (2005) suggest a jump-diffusion model with time-varying intensity parameter, where the intensity of the jump process is modelled as being dependent on deterministic seasonal and diurnal factors. Kanamura and Ohashi (2007) provide a structural model for electricity prices taking into account the nonlinear relationship between supply and demand in the market and spot electricity prices. In particular they focus on modelling the relationship between demand and occurring price spikes by formulating the supply function as a hockey-stick shaped curve and by incorporating the demand seasonality explicitly. Mount et al. (2006) confirm the hockey stick shape of the electricity supply curve and argue that supply is elastic when demand is lower than a certain threshold, but when demand exceeds this threshold, supply is virtually infinitely inelastic, what leads to price spikes. Due to the different phases of price behaviour for electricity prices, the authors suggest to use a regime-switching model with two different states where the price process itself as well as the transition probabilities between the regimes are dependent on explanatory variables such as demand and the reserve margin. Kanamura and Ohashi (2008) follow a similar approach and employ a regime-switching model with a non-spike and a spike regime. Transition probabilities are then dependent on the relationship between demand levels and the threshold of supply capacity, changes in demand as well a trend caused by the deviation of temporary demand fluctuation from its long-term mean. Huisman (2008) introduces a temperature dependent regime-switching model, where either price levels or both price levels and the probability for a transition to the spike regime are dependent on the temperature deviation from its mean level. Kosater (2008) particularly focuses on the impact of weather on the price behaviour in different regimes while Cartea et al. (2009) relate the occurrence and magnitude of price spikes to forward looking capacity constraints.

Generally, the literature agrees that electricity spot prices behave quite differently in the spike regime compared to the normal regime, see e.g. Huisman (2009) and Janczura and 
Weron (2010). Also, studies by, e.g., Cartea et al. (2009), Kanamura and Ohashi (2007, 2008), Mount et al. (2006), seem to provide evidence that also the relationship between determinants of electricity spot prices and the price itself is quite different when prices are extreme than under a normal regime. Therefore, when modelling the relationship between explanatory variables such as load, weather or capacity constraints and the magnitude of price spikes, a model that focuses on spike observations only and not the entire sample of spot electricity prices may be more appropriate. This idea motivated us to conduct this study.

The contribution of this paper is twofold. First, this is one of the few studies to concentrate in particular on explaining and modelling the magnitude of price spikes in electricity spot markets. Many models that have been suggested in the literature for the behaviour of spot electricity prices feature components that have been designed to include price spikes, such as e.g. a jump-diffusion component or a separate regime for price spikes. However, often the suggested models do not include additional explanatory variables besides the price process itself (Bierbrauer et al., 2007; de Jong, 2006; Huisman and Mahieu, 2003) or the relationship between exogenous variables and electricity prices is modelled using the entire sample (Kanamura and Ohashi, 2007; Kosater, 2008; Mount et al., 2006). Given the changing nature in the relationship between exogenous variables and electricity prices, it may well be that a model that attaches all weight to spike observations and zero weight to nonspike observations may perform better in modelling and forecasting the spikes. In a similar line of thought, Christensen et al. $(2009,2012)$ suggest that the intensity of the occurrence of price spikes is not homogenous, but is also driven by additional exogenous variables. Building on this fact, the authors suggest to focus more on forecasting extreme price events only instead of modelling the entire price trajectory. Note, however, that these authors are only concerned with modelling the occurrence of price spikes and not with modelling the actual magnitude of the extreme prices what is the focus of our study. Clearly, market participants will not only be interested in the occurrence of a price spike, but would also like to obtain an estimate for the size or magnitude of the extreme observation.

Second, to our best knowledge, in this paper we provide the first application of the Heckman selection model to electricity markets in order to determine appropriate models for the occurrence and magnitude of price spikes. Following Hill et al. (2008), the application of this technique can be used to appropriately estimate the relationship between exogenous and a dependent variable for a non-random subset of the observations. For our application of modelling electricity price spikes this means that we are able to estimate the relationship 
between the considered explanatory variables and the subsample of observed electricity prices spikes only while controlling for potential selection bias. Note that a similar approach has been applied to modelling losses from operational risk in a recent paper by Dahen and Dione (2010). However, to our best knowledge this study presents the first application of the technique to electricity spot markets.

The remainder of the paper is organized as follows In Section 2 we present a brief overview of regional Australian electricity markets, focusing on market price caps and products available to hedge the risk of occurring price spikes. Section 3 describes the theoretical basis for the inclusion of the considered explanatory variables. Section 4 reviews the Heckman selection method and illustrates how it can be applied to model the magnitude of electricity price spikes. Section 5 reports the estimation results for the Heckman selection model, different OLS models and evaluates their performance. Finally, in Section 6 we conclude and discuss future work.

\subsection{The Australian National Electricity Market}

Since the late 1990s the Australian electricity market has experienced significant changes. At that point in time, to promote energy efficiency and reduce the costs of electricity production, the Australian government commenced a significant structural reform. Key objectives of this reform were the separation of transmission from electricity generation, the merge of twenty-five electricity distributors into a smaller number of distributors, and the functional separation of electricity distribution from the retail supply of electricity. Also retail competition was introduced through the reform such that state's electricity purchases could be made through a competitive retail market and customers were now free to choose their retail supplier.

As a wholesale market, the National Electricity Market (NEM) in Australia began operating in December 1998. It is now an interconnected grid comprising several regional networks which provide supply of electricity to retailers and end-users. The NEM includes the states of Queensland (QLD), New South Wales (NSW), Victoria (VIC) and South Australia (SA), while Tasmania (TAS) is connected to VIC via an undersea inter-connector. The link between electricity producers and electricity consumers is established through a pool which is used to aggregate the output from all generators in order to meet the forecasted 
demand. The pool is managed by the Australian Energy Market Operator (AEMO). Unlike many other markets, the Australian spot electricity market is not a day-ahead market but electricity is traded in a constrained real-time spot market where prices are set each 5 minutes by AEMO. Therefore, generators are able to submit their offers every five minutes. This information is used to select generators to produce electricity in the most cost-efficient way. The final price is determined in half-hour intervals for each of the regions as an average over the 5-minute spot prices for each trading interval. AEMO determines the half-hourly spot prices for each of the regional markets separately. Note that for Australian electricity markets until June 30, 2010 the market price cap was $\mathrm{A} \$ 10,000 / \mathrm{MWh}$. The market price cap determines the maximum possible bidding price and therefore, also the highest possible outcome for a half-hourly price. On July 1, 2010 the bid-cap was increased to A \$12,500/MWh, while it was further increased to A \$12,900/MWh on July 1, 2012 and to A $\$ 13,100 / M W h$ on July 1, 2013. Price spikes play an important role in hedging decisions for NEM market participants, since Australian electricity markets can be considered as being significantly more volatile and spike-prone than other comparable markets (Higgs and Worthington, 2008). There have been several occasions in the regional markets, when the determined half-hourly price was close to or even reached the determined market price cap. Therefore, research on the determinants of the occurrence and magnitude of price spikes is of significant importance for market participants.

In recent years, also the market for electricity derivatives has developed rapidly including electricity forward, futures and option contracts being traded at the Sydney Futures Exchange (SFE). Next to the futures contracts that are priced with respect to average electricity spot prices during a delivery period, the SFE also offers a number of alternative derivative contracts. These include, for example, option contracts or so-called ' $\$ 300$ cap products' for a calendar quarter. For these contracts, the payoff is determined by the sum of all base load half hourly spot prices for the region in the calendar quarter greater than $\$ 300$ (i.e. the severity of the spikes) and the total number of half hourly spot prices for the region in the calendar quarter greater than $\$ 300$ (i.e. the frequency of the spikes). While in this study we do not price these products, our results will be of great interest in particular with respect to modeling the payoff distribution of these contracts in future work.

Note that for electricity markets derivative contracts typically do not require physical delivery of electricity but are settled financially. Therefore, market participants can 
participate in electricity derivatives markets and increase market liquidity without owning physical generation assets.

\subsection{Explanatory Variables}

Generally, the reasons for the occurrence of a price spike can be manifold and may include the unexpected outage or shut-down of power plants, problems with the network transmission grid, extreme temperature events, unanticipated high loads, or they may be a result of the bidding behaviour of market participants, see, e.g., Eydeland and Wolyniec (2012), Harris (2006), Weron (2006). Therefore, as pointed out by Misiorek et al. (2006) the spot electricity price can be considered as the outcome of a vast number of variables including fundamentals (like loads and network constraints) but also unquantifiable psychoand sociological factors that can cause an unexpected and irrational buyout of certain contracts leading to price spikes.

The empirical literature suggests a number of variables that may have a significant impact on the occurrence and magnitude of price spikes, see e.g. Becker et al. (2007), Cartea et al. (2009), Huisman (2008), Kosater (2008), Lu et al. (2005), Mount et al. (2006), Weron and Misiorek (2008). Generally, these variables can be grouped into three classes: (i) factors related to electricity demand and load, (ii) factors related to weather conditions, and, (iii) factors related to the capacity of the system and the reserve margin.

The load measures electricity demand and given that electricity supply is constrained in the short run, the load usually has a significant impact on wholesale electricity prices. Load patterns typically exhibit seasonality throughout the day, week and the year. The load has been determined as one of the key factors determining spot electricity prices in many studies. For example, Lu et al. (2005) suggest that electricity load is a significant variable in determining the probability of the occurrence of a price spike. Misiorek et al. (2006) conclude that day-ahead load forecasts issued by the system operator in California (CAISO) lead to more accurate day-ahead spot price forecasts than the actual load. They explain this phenomenon by the fact that the prices are an outcome of the bids, which in turn are placed with the knowledge of load forecasts but not actual future loads. Indeed, electricity suppliers generally do not know the exact system load by the time they enter their bids. Instead, they 
often have to rely on weather variables and/or past observations of load (Mount et al. 2006, Weron and Misiorek 2008).

Also, weather conditions will have a significant impact on electricity consumption. It can be expected that during a cold winter or a hot summer, electricity consumption will increase due to the use of heating or air-conditioning, respectively. Various weather variables can be considered, but temperature and humidity are the most commonly used load predictors. Hippert et al. (2001) report that of the 22 research publications considered in their electricity load prediction survey, 13 made use of temperature only, three made use of temperature and humidity, three utilized additional weather parameters, and three used only load parameters. Generally, with respect to temperature, electricity demand and hence spot prices depend more on the deviation from the normal temperature, rather than the temperature itself (Huisman 2008). For this reason, in our empirical analysis we will use the absolute or squared deviation of the air temperature from 18 degrees Celsius.

Finally, the reserve margin measures the relationship between the available capacity in the system and peak demand. It provides a measure for the aptitude of the market to maintain reliable operation while meeting unforeseen increases in demand (e.g. extreme weather) and unexpected outages of existing capacity. It has been found to be a significant factor in determining the occurrence of price spikes in previous studies, see e.g. Cartea et al. (2009), Lu et al. (2005), Mount et al. (2006), just to mention a few. For this reason, we also consider the reserve margin as an explanatory variable for the occurrence and magnitude of price spikes in this study.

\subsection{Methodology}

This section discusses the Heckman correction that can be applied in order to overcome a selection bias in the modeling procedure when estimating the relationship between the considered explanatory variables and the magnitude of price spikes. We will also briefly review the so-called Box-Cox transformation technique that is applied to the raw price data in order to obtain approximate normality of the variables that is required by the Heckman selection model. We also provide an overview of measures for comparing the forecast ability of the different models that are applied in this paper. 


\subsubsection{The Heckman Selection Model}

The Heckman selection model is a statistical approach developed by Heckman (1979) to correct for selection bias. Standard econometric literatures (Hill et al., 2008; Greene, 2008; Verbeek, 2008) argue that when the majority of the observations for the dependent variable takes on a value of 0, a standard Ordinary Least Squares (OLS) regression approach is not appropriate, for a detailed proof see, e.g., Kennedy (2003). Under these circumstances an alternative approach for regression analysis is required. In this paper, the dependent variable of interest is the magnitude of observed price spikes in our sample. As argued by several authors, see e.g., Cartea et al. (2009), Kanamura and Ohashi (2007, 2008), Mount et al. (2006), the relationship between explanatory variables such as load, weather or capacity constraints and spot electricity prices may be very different for price spikes than for price observations under a normal price regime. Therefore, one of the motivations of this study is that we believe that a model that focuses on spike observations only and not the entire sample of spot electricity prices may be more appropriate to quantify this relationship for extreme observations. However, including observations of price spikes only into the analysis, is somehow critical due to the bias of pre-selecting data based on whether observations are classifies as a price spike or not. Such a systematic pre-selection violates the random sample principle and, therefore, we need to apply an econometric technique is able to correct estimates for the sample selection bias. In this paper we decide to use the Heckman correction for this task.

The Heckman (1979) selection model is essentially a two-stage procedure and the resulting model can generally be described by a system of two equations. The first equation determines the probability of the occurrence of an event, i.e. a binary choice model, while the second equation estimating the relationship between the explanatory variables and the outcome of the dependent variable. The first step, i.e. the model for the occurrence of an event is typically modeled using a probit equation and estimated using Maximum Likelihood. Then for each observation the so-called Inverse Mills Ratio (IMR) is calculated as the standard normal density function divided by the cumulative standard normal distribution function of the probit model for the occurrence of the event. Then, in a second step, the dependent variable, i.e. the size or magnitude of an event, is regressed on the explanatory variables and the IMR using standard OLS. Then a test to detect the presence of a sample selection bias can be conducted by testing whether the coefficient of the IMR is significantly 
different from zero (Hill et al., 2008). If the coefficient of the IMR is significantly different from zero, a selection bias is present and the Heckman correction is favorable to applying standard OLS to the selected data. Note that the full model, i.e. the selection equation (the binary choice model) and the equation (the standard OLS equation) are typically estimated jointly using maximum likelihood.

\subsubsection{The Lognormal and Box-Cox Transformation}

In the Heckman selection model, it is assumed that error terms are normally distributed such that large deviations of the dependent variable from normality would possibly provide spurious results. Spot electricity prices, however, usually exhibit positive skewness and excess kurtosis, indicating that the empirical distribution is far more heavy-tailed than the normal distribution. Therefore, often a transformation of the observed spot prices is conducted before the estimation of an econometric model, see e.g. Bierbrauer et al. (2007), Huisman (2009), Weron and Misiorek (2008). The most popular transformation in the econometric literature for electricity markets is to use the logarithm of the actually observed prices in order to dampen the extreme volatility, skewness and excess kurtosis. In our empirical analysis, we therefore also consider log-transformed spot electricity prices for estimation of the model instead of the originally observed prices.

An alternative and more general technique for the transformation of heavy-tailed price data is to apply the Box-Cox (1964) transformation in order to obtain approximate normality of the considered variables (Davidson and MacKinnon, 1993). The Box-Cox transformation of a variable $y$ is defined as

$$
y(\lambda)= \begin{cases}\frac{y^{\lambda}-1}{\lambda} & (\lambda \neq 0) \\ \log y & (\lambda=0)\end{cases}
$$

where y denotes the original observation, is the so-called transformation parameter and $\mathrm{y}(\lambda)$ denotes the transformed variable. Clearly, this technique offers a more flexible way of transforming data, depending on the choice of the parameter $\lambda$. Note that for the special case when $\lambda$ is chosen to be zero, the Box-Cox transformation becomes the logarithmic transformation. To estimate the optimal value for $\lambda$ that generates transformed observations being as close as possible to a normal distribution, maximum likelihood estimation is used, 
see, e.g., Davidson and MacKinnon (1993) for further details. Due to the popularity of the log-transformation in the literature on modeling electricity spot prices, in our empirical analysis we will provide the results for models based on the logarithm transformation as well as the Box-Cox transformation with $\lambda \neq 0$.

\subsubsection{Measures to Compare Forecast Accuracy}

In our empirical analysis we will compare the performance of different models with respect to their ability to appropriately model the magnitude of a spike. In particular, we will compare the results for the estimated Heckman correction-based model in comparison to standard OLS regression approaches. Clearly, there has been a variety of measures suggested in the literature in order to compare the performance of econometric models. Given that we are mainly interested in the ability of the models to appropriately quantify or forecast price spikes, we will focus on the following three measures: the Mean Absolute Error (MAE), the Mean Absolute Percentage Error (MAPE) as well as Log likelihood of the estimated models. Note that we decided to rather use the MAE instead of the Mean Squared Error (MSE), since the latter is usually much more dominated by a few large outliers. Since price spikes can be of quite extreme magnitude and for the considered time period take on values up to $\$ 10,000$, it is likely that a comparison of models based on the MSE would be dominated by the few really extreme observations only. The MAE is defined as

$$
\operatorname{MAE}=\frac{1}{\mathrm{~T}} \sum_{\mathrm{t}=1}^{\mathrm{T}}\left|\mathrm{y}_{\mathrm{t}}-\mathrm{f}_{\mathrm{t}}\right|
$$

where $\mathrm{T}$ denotes the number of observations, $\mathrm{y}_{\mathrm{t}}$ the transformed spot price (either using the natural $\log$ or Box-Cox transformation), and $\mathrm{f}_{\mathrm{t}}$ is the model forecast for the transformed price. In a similar manner the MAPE is defined as

$$
\text { MAPE }=\frac{100}{T} \sum_{t=1}^{T}\left|\frac{y_{t}-f_{t}}{y_{t}}\right| .
$$


Clearly, the MAPE focuses more on the relative forecast error and will, therefore, give less weight to extreme spike observations that are also expected to coincide with large model forecast errors.

\subsection{Empirical Results}

\subsubsection{Data and Models}

We consider data on price spikes for four Australian regional markets, namely NSW, QLD, SA and VIC. Note that these are the states with the highest electricity demand in Australia (Higgs, 2009), while SFE offers a variety of derivatives contracts, including futures as well as $\$ 300$ cap options in those states only. Electricity spot prices and system loads at the half-hourly frequency are obtained from AEMO. We use data from the period April 1, 2002 to June 30,2010 , the time period where the market price cap had been set to A $\$ 10,000 / \mathrm{MWh}$ (AEMO, 2012). As mentioned previously, from July 1, 2010 onwards the cap was increased to $\mathrm{A} \$ 12,500 / \mathrm{MWh}$, while it was further increased to A $\$ 12,900 / \mathrm{MWh}$ on July 1, 2012 and to A \$13,100/MWh on July 1, 2013 such that data on price spikes from later periods may exhibit different properties due to the revised market price caps. We therefore decided to exclude all price observations from July 1, 2010 onwards from the conducted analysis.

Half-hourly weather data are obtained from the Bureau of Meteorology (BOM) and includes relative air temperature, wet bulb temperature, dew point temperature, relative humidity and mean sea level pressure (BOM, 2012). We decided to use observations on weather that are measured at airport weather stations in Sydney for NSW, Brisbane for QLD, Adelaide for SA and Melbourne for VIC. Data on the capacity in the system is obtained from AEMO. Based on the information provided on the capacity and load in the market, we define the reserve margin as $r=$ [capacity / load] -1 . Clearly, with this specification values of $r$ close to zero indicate that there is only little reserve capacity available. On the other hand, larger values of $\mathrm{r}$ illustrate more reserve capacity in the market. Note, however, that we have data on the so-called supply capacity only which reflects the installed capacity for each market, rather than the actual operational capacity.

To illustrate the extremely spiky behaviour in the Australian NEM, consider Figure 1. The figure provides a plot of half-hourly electricity prices in QLD for the considered time 
period April 1, 2002 - June 30, 2010 and illustrates that half-hourly electricity prices exhibit extreme variation and a high number of spikes. We also observe that for the QLD market, half-hourly prices reach the bid-cap of $10,000 \mathrm{~A} \$ \mathrm{MWh}$ in a few cases. There are also occasions on which prices are negative. This situation occurs when the cost of turning off electricity generators is high and producers are willing to put negative bids into the system to ensure that they can dispatch the generated electricity.

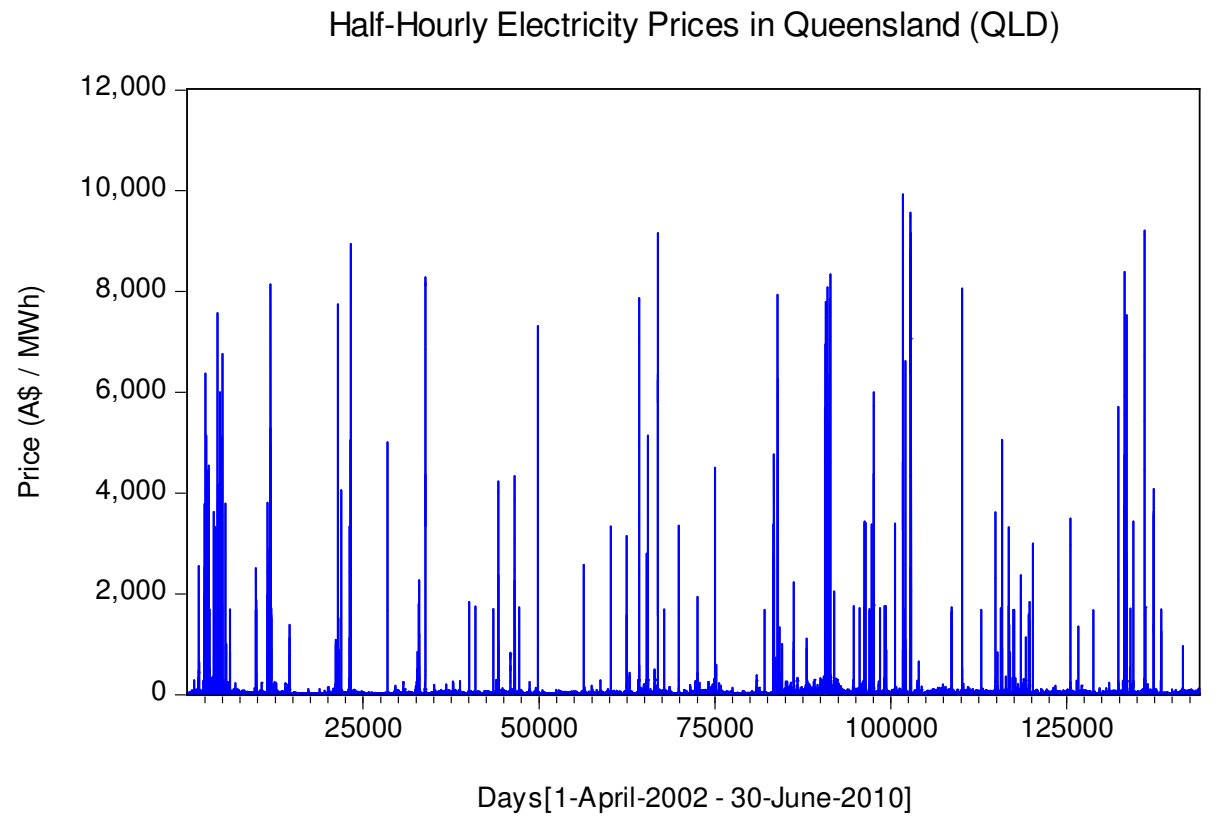

Figure 1: Half-hourly electricity price (A\$/MWh) for the QLD market during the considered time period April 1, 2002 - June 30, 2010.

Table 1 provides detailed descriptive statistics for half-hourly electricity prices in the four states, both for the entire sample as well as for the pre-selected sample that only contains price spikes. Note that in this study we classify all price observation greater than A $\$ 300 / \mathrm{MWh}$ as price spikes. Recall that in Australia, option contracts or so-called A $\$ 300$ cap options are traded in the ASX Australian Electricity derivatives market. The payoff for these products is determined based on both the frequency and magnitude of observed halfhourly prices in excess of $\mathrm{A} \$ 300 / \mathrm{MWh}$ during a calendar quarter. Therefore, given these products available in the market, we believe that the most natural definition of a spike is an observation greater than $\mathrm{A} \$ 300 / \mathrm{MWh}$. 


\begin{tabular}{|c|c|c|c|c|c|c|c|}
\hline State & Obs & Mean & Std Dev & Min & Max & Skewness & Kurtosis \\
\hline \multicolumn{8}{|c|}{ All Prices } \\
\hline NSW & 144,624 & 41.16 & 229.96 & -264.31 & $10,000.00$ & 29.71 & $1,005.33$ \\
\hline QLD & 144,624 & 37.33 & 198.85 & -675.46 & $9,920.99$ & 30.30 & $1,076.61$ \\
\hline SA & 144,624 & 46.29 & 296.32 & $-1,000.00$ & $9,999.92$ & 29.37 & 924.00 \\
\hline VIC & 144,624 & 36.84 & 170.21 & -496.71 & $10,000.00$ & 41.71 & $2,043.70$ \\
\hline \multicolumn{8}{|c|}{ Price Spikes (Prices > A\$ 300 / MWh) Only } \\
\hline NSW & 743 & 2037.29 & 2488.34 & 300.03 & 10000.00 & 1.65 & 4.74 \\
\hline QLD & 590 & 2176.19 & 2228.11 & 300.04 & 9920.99 & 1.52 & 4.56 \\
\hline SA & 549 & 3252.93 & 3556.68 & 300.82 & 9999.92 & 1.04 & 2.45 \\
\hline VIC & 408 & 2057.05 & 2448.91 & 300.13 & 10000.00 & 1.94 & 6.02 \\
\hline
\end{tabular}

Table 1: Descriptive statistics of half-hourly electricity prices for NSW, QLD, SA, VIC for the period April 1, 2002 - June 30, 2010. The upper panel contains descriptive statistics for the entire sample, while the lower panel provides descriptive statistics for the pre-selected sample of spikes, i.e. price observations greater than A $\$ 300 / \mathrm{MWh}$.

For the entire sample we find that the average price is around $\$ 35-45 / \mathrm{MWh}$, while the maximum half-hourly price during the sample period is $\$ 10,000 / \mathrm{MWh}$ or very close to $\$ 10,000 / \mathrm{MWh}$ for each of the four markets. The standard deviation can be as high as $\$ 296 / \mathrm{MWh}$ for SA, but is greater than four times the average spot price for each of the markets. As it is typical for spot electricity prices, data is heavily skewed to the right and exhibits excess kurtosis. For the selected sample of price spikes only, we find that with 408 observations VIC exhibits the lowest number of spikes during the sample period, while in NSW for the same period 743 spikes can be observed. The average magnitude of a spike ranges from $\mathrm{A} \$ 2,037$ in NSW up to $\mathrm{A} \$ 3,253$ in SA. As mentioned before, in each state here are spikes that reach the $\mathrm{A} \$ 10,000$ market price cap during the considered sample period.
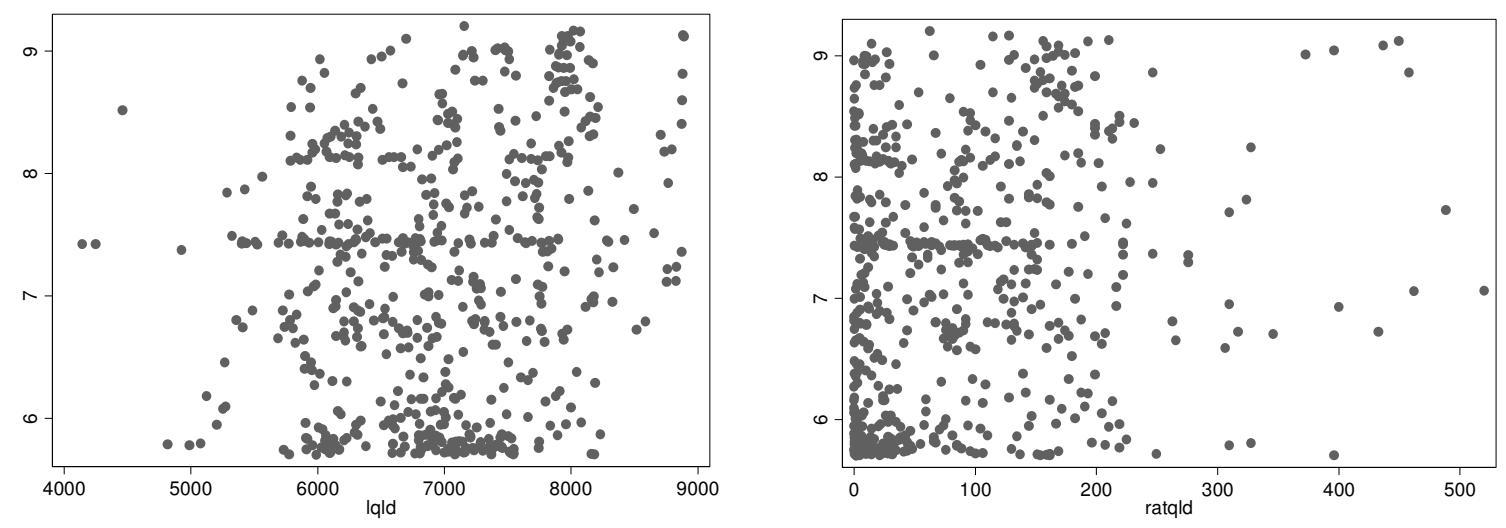

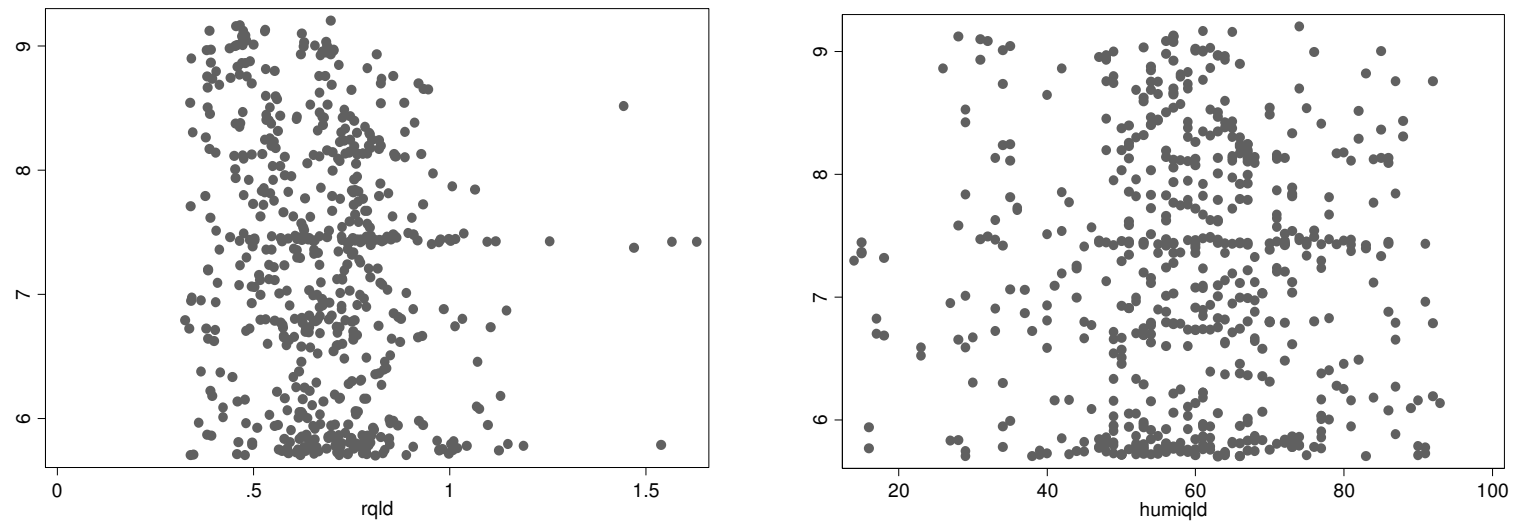

Figure 2: Scatter plot for the relationship between the log transformation of observed price spikes (dependent variable) and the explanatory variables market load (upper left panel), relative air temperature (upper right panel), reserve margin (lower left panel, humidity (lower right panel) for QLD market.

Figure 2 shows the relationship between the log transformed price spikes in the QLD market (i.e. the plot contains only price observations greater than $\mathrm{A} \$ 300 / \mathrm{MWh}$ ) and the explanatory variables market load, relative air temperature, reserve margin and humidity for this market. From a first glance, the plots do not indicate a strong relationship between the explanatory variables and the observed magnitude of price spikes in the QLD market.

We now specify the following model for a more detailed analysis of the relationship between the considered explanatory variables and observed spot electricity prices. For our analysis, the Heckman selection model can be specified by a system containing the two equations (4) and (5). Equation (4) denotes the probit model, i.e. the first stage of the Heckman selection procedure. The probit model is concerned with the determinants of the occurrence of a price spike and, therefore, is estimated using all observations on price data available:

$$
\operatorname{DPS}_{\mathrm{t}}=\gamma_{0}+\gamma_{1} \mathrm{~L}_{\mathrm{t}}+\gamma_{2} \mathrm{r}_{\mathrm{t}}+\gamma_{3} \mathrm{rat}_{\mathrm{t}}+\gamma_{4} \mathrm{webt}_{\mathrm{t}}+\lambda_{5} \mathrm{dwpt}_{\mathrm{t}}+\gamma_{6} \text { humi }_{\mathrm{t}}+\gamma_{7} \operatorname{selp}_{\mathrm{t}}+\varepsilon(4)
$$

$\operatorname{DPS}\left\{\begin{array}{l}1 \\ 0\end{array}\right.$ when a price spike occurs

Hereby, DPS a dummy variable for the occurrence of a price spike, $\mathrm{L}$ is the market load and $\mathrm{r}$ is the reserve margin that is defined as $\mathrm{r}=$ [capacity / load] -1 . Further, rat denotes the relative air temperature that is based on the deviation of the temperature from 18 degrees 
Celcius, i.e. rat $=[\text { air temperature }-18]^{\wedge 2}$, webt denotes the wet bulb temperature measured using a standard mercury-in-glass thermometer, dwpt is the dew point temperature, i.e. a measure of the moisture content of the air and the temperature to which air must be cooled in order for dew to form. Finally, humi denotes the air humidity and selp is the sea level pressure that is affected by changing weather conditions.

Then equation (5) denotes the second stage of the estimation procedure, and, i.e. the model for the magnitude of the occurred price spikes:

$$
\mathrm{LNP}_{\mathrm{t}}=\beta_{0}+\beta_{1} \mathrm{~L}_{\mathrm{t}}+\beta_{2} \mathrm{rat}_{\mathrm{t}}+\beta_{3} \mathrm{r}_{\mathrm{t}}+\beta_{4} \mathrm{IMR}_{\mathrm{t}}+v
$$

Hereby, LNP denotes the log transformation (alternatively, the Box-Cox transform) of the observed electricity price spikes, L is the market load, rat the relative air temperature (as defined earlier), $r=$ [capacity / load] -1 is the reserve margin and IMR denotes the so-called Inverse-Mills-Ratio that is specified as

$$
\mathrm{IMR}=\frac{\phi\left(\gamma_{0}+\gamma_{1} \mathrm{~L}+\gamma_{2} \mathrm{r}+\gamma_{3} \mathrm{rat}+\gamma_{4} \text { webt }+\lambda_{5} \mathrm{dwpt}+\gamma_{6} \text { humi }+\gamma_{7} \text { selp }\right)}{\Phi\left(\gamma_{0}+\gamma_{1} \mathrm{~L}+\gamma_{2} \mathrm{r}+\gamma_{3} \mathrm{rat}+\gamma_{4} \text { webt }+\lambda_{5} \mathrm{dwpt}+\gamma_{6} \text { humi }+\gamma_{7} \text { selp }\right)}
$$

and can be calculated for each observation based on equation (5).

Table 2 shows the number of observations for each market for the original sample and the censored sample that only contains observations of price spikes greater than A \$300/MWh. Obviously, for all markets, the sample size for the probit model is quite large, since all price observations greater than 0 are included, while the sample size for the second step in the Heckman selection model, equation (5), is much smaller but is still reasonable to provide reliable estimation results. Note that we excluded negative and zero prices from the analysis, since both the logarithmic and the Box Cox transformation can only be applied to positive numbers.

\begin{tabular}{|l|c|c|c|c|}
\hline State & NSW & QLD & SA & VIC \\
\hline Observations (No Missing Data) & 141,358 & 143,853 & 142,666 & 140,505 \\
\hline Censored Observations & 140,645 & 143,267 & 142,128 & 140,108 \\
\hline Uncensored Observations & 713 & 586 & 538 & 397 \\
\hline
\end{tabular}

Table 2: Sample sizes (number of observations) details for each state. 


\subsubsection{Estimation Results}

\subsubsection{Heckman Selection Model with Log Transformation}

Table 3 reports the estimation results of the Heckman selection model with logtransformed data for the spot electricity prices. We find that for the estimated probit model the variables load, relative air temperature and reserve margin are significant. As expected, load and relative air temperature have a positive impact on the probability of occurrence of a price spike while the reserve margin has a negative impact, i.e. the closer the system is to full capacity (reserve margin $r$ close to zero), the higher is the probability of a price spike.

\begin{tabular}{|c|c|c|c|c|c|c|c|c|c|c|c|c|}
\hline \multirow{2}{*}{$\begin{array}{c}\text { Region } \\
\text { Variable }\end{array}$} & \multicolumn{3}{|c|}{ NSW } & \multicolumn{3}{|c|}{ QLD } & \multicolumn{3}{|c|}{ SA } & \multicolumn{3}{|c|}{ VIC } \\
\hline & Coef & t-Stat & Sign & Coef & t-Stat & Sign & Coef & t-Stat & Sign & Coef & t-Stat & Sign \\
\hline \multicolumn{13}{|c|}{ Dependent Variable: LNP } \\
\hline Cons & 1.0252 & 0.50 & & 4.8838 & 5.13 & $* * *)$ & -3.3654 & -1.26 & & 5.0556 & 2.95 & $* * *)$ \\
\hline $\mathbf{L}$ & 0.0004 & 3.10 & $* * *)$ & 0.0002 & 2.58 & $* * *)$ & 0.0029 & 4.33 & $* * *)$ & 0.0002 & 1.46 & \\
\hline rat & 0.0026 & 2.99 & $* * *)$ & 0.0015 & 2.50 & $* *)$ & 0.0025 & 3.22 & $* * *)$ & 0.0007 & 1.26 & \\
\hline $\mathbf{r}$ & 0.4989 & 1.22 & & -0.6766 & -1.54 & & 0.3381 & 0.44 & & 2.7471 & 4.01 & $* * *)$ \\
\hline IMR & 0.3958 & 1.53 & & 0.3838 & 2.98 & $* * *)$ & 1.5296 & 2.10 & $* *)$ & -0.1988 & -0.61 & \\
\hline \multicolumn{13}{|c|}{ Dependent Variable: DPS } \\
\hline Cons & 14.2095 & 4.78 & $* * *)$ & 38.9371 & 10.28 & $* * *)$ & 2.8418 & 0.80 & $* * *)$ & -7.7089 & -2.29 & $* *)$ \\
\hline $\mathbf{L}$ & 0.0006 & 26.24 & $* * *)$ & 0.0003 & 7.41 & $* * *)$ & 0.0012 & 10.32 & $* * *)$ & 0.0005 & 12.82 & $* * *)$ \\
\hline $\mathbf{r}$ & -1.3859 & -10.33 & $* * *)$ & -1.4679 & -10.17 & $* * *)$ & -0.9129 & -7.48 & $* * *)$ & -1.7051 & -9.42 & $* * *)$ \\
\hline rat & 0.0033 & 10.14 & $* * *)$ & 0.0031 & 8.88 & $* * *)$ & 0.0012 & 4.07 & $* * *)$ & 0.0031 & 10.46 & $* * *)$ \\
\hline webt & 0.0615 & 3.12 & $* * *)$ & -0.1481 & -5.70 & $* * *)$ & -0.0133 & -0.85 & & -0.0301 & -1.63 & \\
\hline dwpt & -0.0545 & -3.22 & $* * *)$ & 0.0569 & 2.45 & $* *)$ & -0.0070 & -0.63 & & 0.0529 & 3.47 & $* * *)$ \\
\hline humi & 0.0122 & 4.51 & $* * *)$ & -0.0031 & -0.89 & & 0.0028 & 1.13 & & 0.0016 & 0.55 & \\
\hline selp & -0.0231 & -8.05 & $* * *)$ & -0.0397 & -11.11 & $* * *)$ & -0.0065 & -1.89 & $*)$ & 0.0019 & 0.59 & \\
\hline Adj-R2 & & 0.05 & & & 0.06 & & & 0.14 & & & 0.08 & \\
\hline
\end{tabular}

Table 3: Estimation results for Heckman selection method for the log transformation of spot electricity prices. The upper reports results for equation (5) referring to the model for the magnitude of the observed price spikes, while the lower panel provides results for the probit model for the occurrence of a spike specified in equation (4).

In the equation for the magnitude of price spikes, the IMR is significant for the QLD and SA market, while it is almost significant at the 10 percent level for NSW. The Heckman 
correction for sample selection bias is therefore important when examining factors affecting the magnitude of price spikes in electricity spot markets. Also, the variables load L and relative temperature rat are significant and have the expected positive sign in all markets except for VIC. Note, however, that the reserve margin $r$ is only significant in VIC and yields a coefficient with a positive sign for three of the regional markets. This is counterintuitive, since it suggests that price spikes are of greater magnitude with more reserve capacity in the system. These results may be due to the low quality of data on supply capacity which reflects only the installed capacity, rather than the actual operational capacity.

In general, the estimated models do not have a very high explanatory power and yield adjusted $\mathrm{R}^{2}$ coefficients of determination between 0.05 for NSW and 0.14 for SA. This is not surprising since by definition, price spikes are rather unexpected events and can be considered as the outcome of a vast number of variables including fundamentals (like loads and network constraints) but also unquantifiable psycho and sociological factors that can cause an unexpected and irrational buyout of certain contracts (Misiorek et al., 2006). Therefore, for example, an R-squared of 14 percent as it is obtained for the SA market can be considered quite high, since it explains a significant fraction of the variation in the magnitude of the spikes.

\subsubsection{Heckman Selection Model with Box-Cox Transformation}

Table 4 reports the estimation of the Box-Cox transformation parameter $\lambda$, based on Davidson and MacKinnon (1993), for each of the considered states, while Table 5 presents the estimation results for the Heckman selection model after applying the Box-Cox transformation. We obtain results very similar to when the log transformation had been used for the observed spot electricity prices. Note that in the estimated model, the two variables load L, relative air temperature rat are significant for all markets and show the expected sign. Also the reserve margin $r$ is significant for three of the four markets and yields the expected negative coefficient for QLD and SA, while the coefficient is positive and significant for VIC. Also results for the explanatory power of the model are very similar to those obtained for the $\log$ transformation. Interestingly, the explanatory power of the model with the BoxCox transformation is slightly lower than when the log transformation is applied. 


\begin{tabular}{|c|c|}
\hline State & $\lambda$ \\
\hline NSW & -0.6608 \\
\hline QLD & -0.5643 \\
\hline SA & -0.2189 \\
\hline VIC & -0.2405 \\
\hline
\end{tabular}

Table 4: Optimal Box-Cox parameter estimates for each state based on Maximum-Likelihood estimation (Davidson and MacKinnon, 1993).

\begin{tabular}{|c|c|c|c|c|c|c|c|c|c|c|c|c|}
\hline \multirow{2}{*}{$\begin{array}{c}\text { Region } \\
\text { Variable }\end{array}$} & \multicolumn{3}{|c|}{ NSW } & \multicolumn{3}{|c|}{ QLD } & \multicolumn{3}{|c|}{ SA } & \multicolumn{3}{|c|}{ VIC } \\
\hline & Coef & t-Stat & Sign & Coef & t-Stat & Sign & Coef & t-Stat & Sign & Coef & t-Stat & Sign \\
\hline \multicolumn{13}{|c|}{ Dependent Variable: BCP } \\
\hline Cons & 1.4317 & 70.42 & $* * *)$ & 1.6943 & 92.68 & $* * *)$ & 1.3069 & 2.32 & $* *)$ & 3.0458 & 9.85 & $* * *)$ \\
\hline $\mathbf{L}$ & 0.0000 & 3.22 & $* * *)$ & 0.0000 & 2.09 & $* *)$ & 0.0006 & 4.26 & $* * *)$ & 0.0000 & 1.28 & \\
\hline rat & 0.0000 & 3.08 & $* * *)$ & 0.0000 & 3.00 & $* * *)$ & 0.0006 & 3.53 & $* * *)$ & 0.0001 & 1.23 & \\
\hline $\mathbf{r}$ & 0.0067 & 1.65 & $*)$ & -0.0172 & -2.03 & $* *)$ & -0.0407 & -0.25 & & 0.4687 & 3.79 & $* * *)$ \\
\hline IMR & 0.0044 & 1.72 & *) & 0.0098 & 3.95 & $* * *)$ & 0.3916 & 2.53 & $* *)$ & -0.0316 & -0.54 & \\
\hline \multicolumn{13}{|c|}{ Dependent Variable: DPS } \\
\hline Cons & 14.2095 & 4.78 & $* * *)$ & 38.9371 & 10.28 & $* * *)$ & 2.8418 & 0.80 & & -7.7089 & -2.29 & $* *)$ \\
\hline $\mathbf{L}$ & 0.0006 & 26.24 & $* * *)$ & 0.0003 & 7.41 & $* * *)$ & 0.0012 & 10.32 & $* * *)$ & 0.0005 & 12.82 & $* * *)$ \\
\hline $\mathbf{r}$ & -1.3859 & -10.33 & $* * *)$ & -1.4679 & -10.17 & $* * *)$ & -0.9129 & -7.48 & $* * *)$ & -1.7051 & -9.42 & $* * *)$ \\
\hline rat & 0.0033 & 10.14 & $* * *)$ & 0.0031 & 8.88 & $* * *)$ & 0.0012 & 4.07 & $* * *)$ & 0.0031 & 10.46 & $* * *)$ \\
\hline webt & 0.0615 & 3.12 & $* * *)$ & -0.1481 & -5.70 & $* * *)$ & -0.0133 & -0.85 & & -0.0301 & -1.63 & \\
\hline dwpt & -0.0545 & -3.22 & $* * *)$ & 0.0569 & 2.45 & $* *)$ & -0.0070 & -0.63 & & 0.0529 & 3.47 & $* * *)$ \\
\hline humi & 0.0122 & 4.51 & $* * *)$ & -0.0031 & -0.89 & & 0.0028 & 1.13 & & 0.0016 & 0.55 & \\
\hline selp & -0.0231 & 0.00 & $* * *)$ & -0.0397 & -11.11 & $* * *)$ & -0.0065 & -1.89 & $*)$ & 0.0019 & 0.59 & \\
\hline Adj-R2 & & 0.06 & & & 0.06 & & & 0.11 & & & 0.07 & \\
\hline
\end{tabular}

Table 5: Estimation results for Heckman selection method for the Box-Cox transformation of spot electricity prices. The upper reports results for equation (5) referring to the model for the magnitude of the observed price spikes, while the lower panel provides results for the probit model for the occurrence of a spike specified in equation (4).

\subsubsection{OLS Model Estimated with All Electricity Prices}

Table 6 reports the estimation results for a standard OLS regression model when all transformed electricity prices are regressed on the explanatory variables (load, reserve margin, relative air temperature). Results are presented both for the log transformation (upper 
panel) as well as for the Box-Cox transformation (lower panel). The results indicate that all three explanatory variables are significant for each of the considered markets and for both transformations. The coefficient for load always has the expected sign while relative air temperature yields a negative sign for QLD when the log transformation is used and for QLD and SA when the Box-Cox transformation is employed. Surprisingly, also the coefficient for the reserve margin is positive for QLD for both types of transformation. The explanatory power of the models measured by the adjusted R-square is quite high, indicating that the considered variables provide significant explanatory power for the level of spot electricity prices. However, since all price observations are considered in this model, results for the coefficient of determination are not really comparable to the Heckman selection model that is applied to observed price spikes in excess of A $\$ 300 / \mathrm{MWh}$ only.

\begin{tabular}{|c|c|c|c|c|c|c|c|c|c|c|c|c|}
\hline \multirow{2}{*}{$\begin{array}{c}\text { Region } \\
\text { Variable } \\
\end{array}$} & \multicolumn{3}{|c|}{ NSW } & \multicolumn{3}{|c|}{ QLD } & \multicolumn{3}{|c|}{$\mathbf{S A}$} & \multicolumn{3}{|c|}{ VIC } \\
\hline & Coef & t-Stat & Sign & Coef & t-Stat & Sign & Coef & t-Stat & Sign & Coef & t-Stat & Sign \\
\hline \multicolumn{13}{|c|}{ Dependent Variable: LNP, All Prices } \\
\hline Cons & 1.3997 & 107.74 & $* * *)$ & 0.9257 & 36.47 & $* * *)$ & 1.6226 & 89.14 & $* * *)$ & 0.6716 & 49.19 & $* * *)$ \\
\hline $\mathbf{L}$ & 0.0002 & 183.77 & $* * *)$ & 0.0004 & 121.33 & $* * *)$ & 0.0012 & 154.19 & $* * *)$ & 0.0005 & 238.43 & $* * *)$ \\
\hline rat & 0.0016 & 53.96 & $* * *)$ & -0.0001 & -4.09 & $* * *)$ & 0.0002 & 7.47 & $* * *)$ & 0.0004 & 20.88 & $* * *)$ \\
\hline $\mathbf{r}$ & -0.1278 & -26.37 & $* * *)$ & 0.1253 & 15.57 & $* * *)$ & -0.0525 & -12.94 & $* * *)$ & -0.0920 & -18.04 & $* * *)$ \\
\hline Adj-R2 & \multicolumn{3}{|c|}{0.44} & \multicolumn{3}{|c|}{0.28} & \multicolumn{3}{|c|}{0.48} & \multicolumn{3}{|c|}{0.49} \\
\hline Region & \multicolumn{3}{|c|}{ NSW } & \multicolumn{3}{|c|}{ QLD } & \multicolumn{3}{|c|}{ SA } & \multicolumn{3}{|c|}{ VIC } \\
\hline Variable & Coef & t-Stat & Sign & Coef & t-Stat & Sign & Coef & t-Stat & Sign & Coef & t-Stat & Sign \\
\hline \multicolumn{13}{|c|}{ Dependent Variable: BCP, All Prices } \\
\hline Cons & 1.1393 & 988.33 & $* * *)$ & 1.1416 & 338.17 & $* * *)$ & 1.7190 & 212.00 & $* * *)$ & 1.1080 & 189.88 & $* * *)$ \\
\hline $\mathbf{L}$ & 0.0000 & 215.73 & $* * *)$ & 0.0001 & 136.07 & $* * *)$ & 0.0005 & 143.08 & $* * *)$ & 0.0002 & 246.87 & $* * *)$ \\
\hline rat & 0.0001 & 21.15 & $* * *)$ & -0.0001 & -20.84 & $* * *)$ & -0.0001 & -10.98 & $* * *)$ & 0.0000 & 4.80 & $* * *)$ \\
\hline $\mathbf{r}$ & -0.0154 & -35.72 & $* * *)$ & 0.0095 & 8.91 & $* * *)$ & -0.0596 & -33.00 & $* * *)$ & -0.0462 & -21.21 & $* * *)$ \\
\hline Adj-R2 & & 0.50 & & & 0.34 & & & 0.48 & & & 0.50 & \\
\hline
\end{tabular}

Table 6: Estimation results using OLS for the entire sample of electricity spot prices from April 1, 2002 to June 30, 2010. Note that the results on the explanatory power of the model cannot be compared to Table 3 and 5, since the estimation refers to a much larger data set that contains mainly price observations from a 'normal' price regime. 


\subsubsection{Standard OLS Results For Price Spike Sub-sample}

Table 7 presents the estimation results of for the transformed price spikes on the considered explanatory variables ignoring the selection bias. Results are quite similar to those for the Heckman selection procedure with significant and positive coefficients for the variables load $\mathrm{L}$ and relative air temperature rat for most of the regional markets. Interestingly, load is not significant for the QLD market anymore. However, reserve margin $r$ is significant for three of the four markets (NSW, SA, VIC) but in each case yields a counterintuitive positive sign. As indicated by the results for the Heckman selection model where the IMR was significant for several of the considered markets, estimation results of a simple OLS model are not reliable because they are biased. However, results on adjusted $\mathrm{R}^{2}$ are very similar to the results we obtain for the Heckman selection model.

\begin{tabular}{|c|c|c|c|c|c|c|c|c|c|c|c|c|}
\hline \multirow{2}{*}{$\begin{array}{l}\text { Region } \\
\text { Variable }\end{array}$} & \multicolumn{3}{|c|}{ NSW } & \multicolumn{3}{|c|}{ QLD } & \multicolumn{3}{|c|}{ SA } & \multicolumn{3}{|c|}{ VIC } \\
\hline & Coef & t-Stat & Sign & Coef & t-Stat & Sign & Coef & t-Stat & Sign & Coef & t-Stat & Sign \\
\hline \multicolumn{13}{|c|}{ Dependent Variable: LNP, Price Spikes only (Prices > A \$ 300 / MWh) } \\
\hline Cons & 4.0378 & 7.91 & $* * *)$ & 6.2360 & 7.43 & $* * *)$ & 1.9256 & 2.57 & $* *)$ & 4.0665 & 7.35 & $* * *)$ \\
\hline $\mathbf{L}$ & 0.0002 & 5.16 & $* * *)$ & 0.0001 & 1.58 & & 0.0016 & 6.79 & $* * *)$ & 0.0003 & 4.10 & $* * *)$ \\
\hline rat & 0.0014 & 4.12 & $* * *)$ & 0.0014 & 2.37 & $* *)$ & 0.0013 & 3.04 & $* * *)$ & 0.0010 & 2.67 & $* * *)$ \\
\hline $\mathbf{r}$ & 0.9574 & 3.44 & $* * *)$ & -0.2017 & -0.49 & & 1.7630 & 5.52 & $* * *)$ & 2.4064 & 6.06 & $* * *)$ \\
\hline Adj-R2 & \multicolumn{3}{|c|}{0.07} & \multicolumn{3}{|c|}{0.05} & \multicolumn{3}{|c|}{0.17} & \multicolumn{3}{|c|}{0.12} \\
\hline Region & \multicolumn{3}{|c|}{ NSW } & \multicolumn{3}{|c|}{ QLD } & \multicolumn{3}{|c|}{ SA } & \multicolumn{3}{|c|}{ VIC } \\
\hline Variable & Coef & t-Stat & Sign & Coef & t-Stat & Sign & Coef & t-Stat & Sign & Coef & t-Stat & Sign \\
\hline \multicolumn{13}{|c|}{ Dependent Variable: BCP, Price Spikes only (Prices > A\$ 300 / MWh) } \\
\hline Cons & 1.4654 & 287.26 & $* * *)$ & 1.7288 & 107.47 & $* * *)$ & 2.6651 & 17.57 & $* * *)$ & 2.8885 & 28.91 & $* * *)$ \\
\hline $\mathbf{L}$ & 0.0000 & 5.01 & $* * *)$ & 0.0000 & 0.67 & & 0.0003 & 5.77 & $* * *)$ & 0.0000 & 3.59 & $* * *)$ \\
\hline rat & 0.0000 & 3.91 & $* * *)$ & 0.0000 & 2.85 & $* * *)$ & 0.0003 & 3.19 & $* * *)$ & 0.0002 & 2.53 & $* *)$ \\
\hline $\mathbf{r}$ & 0.0119 & 4.29 & $* * *)$ & -0.0051 & -0.64 & & 0.3223 & 4.99 & $* * *)$ & 0.4145 & 5.78 & $* * *)$ \\
\hline Adj-R2 & & 0.07 & & & 0.04 & & & 0.14 & & & 0.11 & \\
\hline
\end{tabular}

Table 7: Estimation results using OLS for the sub-sample of price spikes, i.e. prices greater than $\mathrm{A} \$ 300 / \mathrm{MWh}$ only.

\subsubsection{Comparing the forecasting ability of the models}

In the following, we compare the forecasting ability of the three estimated models (Heckman selection model, OLS model using all prices, OLS model using price spikes only) 
for the observed price spikes in the sample. Hereby, as pointed out in Section 4.3, we focus on the following three performance measures: MAE, MAPE and log likelihood of the estimated models. Results for all three models and performance criteria are shown in Table 8. We find that for each of the considered measures and markets, the Heckman selection model yields the best performance. This is true both for the logarithmic and the Box-Cox transformation of the price data. For all markets, the estimated OLS model that uses price spikes only performs second best, while the OLS model using all prices performs significantly worse.

The poor performance of the standard OLS model that is estimated using all prices can be explained by the fact that the model is calibrated using mainly non-spike observations and only gives a small weight to actual price spikes. It also points towards the non-linear relationship between wholesale prices and the considered explanatory variables as it has been suggested e.g. by Kanamura and Ohashi (2008), Mount et al. (2006) or Weron (2006). These studies also suggest that the relationship between load or demand and electricity wholesale prices can be characterized by a hockey stick shape. Overall, the weaker performance of a standard OLS model for quantifying the magnitude of price spikes is not very surprising.

More interestingly, the estimated Heckman selection model also outperforms an OLS model that is estimated using price spikes only. This indicates that a correction for the selection bias in the estimation as well as the inclusion of the Inverse Mills Ratio into the model plays an important role and should be further examined in future studies.

\begin{tabular}{|c|c|c|c|}
\hline \multicolumn{5}{|c|}{ Natural Log Transformation for Price } \\
\hline METHOD & 1) OLS - All Prices & 2) OLS - Price Spikes & 3) Heckman Selection \\
\hline \multicolumn{4}{|c|}{ NSW } \\
\hline MAE & 2.75 & 0.94 & 0.94 \\
\hline MAPE & 38.20 & 13.57 & 13.54 \\
\hline Log Likelihood & $-1,784.76$ & $-1,067.90$ & $-1,067.05$ \\
\hline \multicolumn{5}{|c|}{ QLD } \\
\hline MAE & 3.57 & 0.87 & 0.86 \\
\hline MAPE & 48.81 & 12.39 & 12.26 \\
\hline Log Likelihood & $-1,600.50$ & -833.97 & -829.90 \\
\hline \multicolumn{5}{|c|}{ SA } \\
\hline MAE & 2.81 & 0.95 & 0.94 \\
\hline MAPE & 36.80 & 13.43 & -814.70 \\
\hline Log Likelihood & $-1,362.85$ & -820.71 & \\
\hline
\end{tabular}




\begin{tabular}{|c|c|c|c|}
\multicolumn{5}{|c|}{ VIC } \\
\hline MAE & 2.75 & 0.84 & 0.84 \\
\hline MAPE & 37.92 & 12.03 & 12.08 \\
\hline Log Likelihood & -993.98 & -557.55 & -557.21 \\
\hline
\end{tabular}

\begin{tabular}{|c|c|c|c|}
\hline \multicolumn{4}{|c|}{ Box Cox Transformation for Price } \\
\hline METHOD & 1) OLS - All Prices & 2) OLS - Price Spikes & 3) Heckman Selection \\
\hline \multicolumn{4}{|c|}{ NSW } \\
\hline MAE & 0.08 & 0.01 & 0.01 \\
\hline MAPE & 5.25 & 0.65 & 0.65 \\
\hline Log Likelihood & 764.57 & $2,217.11$ & $2,217.85$ \\
\hline \multicolumn{4}{|c|}{ QLD } \\
\hline MAE & 0.21 & 0.02 & 0.02 \\
\hline MAPE & 11.96 & 0.96 & 0.95 \\
\hline Log Likelihood & 77.47 & $1,483.25$ & $1,490.47$ \\
\hline \multicolumn{4}{|c|}{$\mathbf{S A}$} \\
\hline MAE & 0.76 & 0.19 & 0.19 \\
\hline MAPE & 20.64 & 5.40 & 5.33 \\
\hline Log Likelihood & -651.99 & 38.92 & 46.39 \\
\hline \multicolumn{4}{|c|}{ VIC } \\
\hline MAE & 0.69 & 0.15 & 0.15 \\
\hline MAPE & 20.31 & 4.54 & 4.54 \\
\hline Log Likelihood & -443.89 & 121.95 & 122.29 \\
\hline
\end{tabular}

Table 8: MAE, MAPE and log likelihood of the estimated models for the OLS using the entire sample, OLS applied to price spikes only and the Heckman selection model. Note that results are reported for log transformation and Box-Cox transformation of the original prices.

\subsection{Summary and Conclusions}

In this paper, we propose the Heckman selection model framework to examine factors driving the frequency and magnitude of price spikes. Using this framework, estimation results are not influenced by low (or normal) electricity prices while the selection bias due to nonrandom sampling is overcome. The literature suggests that electricity spot prices behave quite differently in the spike regime compared to the normal regime, see e.g. Huisman (2009) and Janczura and Weron (2010). Studies by, e.g., Cartea et al. (2009), Kanamura and Ohashi (2007, 2008), Mount et al. (2006), seem to provide further evidence that also the relationship 
between determinants of electricity spot prices and the price itself is quite different when prices are extreme than under a normal regime. Therefore, when modelling the relationship between explanatory variables such as load, weather or capacity constraints and the magnitude of price spikes, a model that focuses on spike observations only and not the entire sample of spot electricity prices may be more appropriate.

The Heckman procedure is applied to four regional electricity markets in Australia and it is found that for each of these markets, load, relative air temperature and reserve margins are significant variables for the occurrence of price spikes, while load and relative air temperature are have a significant impact on the magnitude of a price spike. It is also found that the Inverse Mills Ratio is significant for several of the considered markets, what indicates that estimation results of a standard OLS model to pre-selected data of price spikes will generally lead to biased results. The performance of the Heckman selection model for the quantification of price spikes is also compared with the performance of an OLS model using all prices and an OLS model using price spikes only. We find for all of the considered measures that the Heckman selection model performs best in each of the considered markets. Our results encourage further application of the Heckman selection model to electricity markets. 


\section{Bibliography}

AEMO 2012, 'AEMO Submission to the Review of the Reliability and Emergency Reserve Trader (RERT) Issues Paper', AEMO.

Anderson, EJ, Hu, X \& Winchester, D 2007, 'Forward Contracts in Electricity Markets: The Australian Experience', Energy Policy, vol. 65, pp. 329 - 344.

Australia Government Bureau of Meteorology (BOM), http://www.bom.gov.au/climate/glossary/, viewed 26 June 2012.

Becker, R, Hurn, S \& Pavlov, V 2007, 'Modelling Spikes in Electricity Prices', The Economic Record, vol. 35, pp. 371 - 382.

Bierbrauer, M, Menn, C, Rachev, ST \& Trück, S 2007, 'Spot and Derivative Pricing in the EEX Power Market', The Journal of Banking \& Finance, no. 31, pp. 3462 - 3485.

Box, GEP \& Cox, DR 1964, 'An Analysis of Transformations', Journal of the Royal Statistical Society Series B (Methodological), vol. 26 no. 2, pp. $211-252$.

Brooks, C 2008, Introductory Econometric for Finance $2^{\text {nd }}$ Edition, Cambridge University Press, Cambridge.

Cartea, A, Figueroa, EG, \& Geman,HS 2000, 'Modelling Electricity Prices with Forward Looking Capacity Constraints', Applied Mathematical Finance, vol. 16 no. 2, pp. 103 122.

Cartea, A \& Figueroa, MG 2005, 'Pricing in Electricity Markets: A Mean Reverting Jump Diffusion Model with Seasonality', Applied Mathematical Finance, vol. 12 no. 4, pp. $313-335$.

Christensen, TM, Hurn, AS \& Lindsay, KA 2009, 'It Never Rains but It Pours: Modelling the Persistence of Spikes in Electricity Prices', The Energy Journal, vol. 30 no. 1, pp. 25 48.

Christensen, TM, Hurn, AS \& Lindsay, KA 2012, 'Forecasting Spikes in Electricity Prices', International Journal of Forecasting, vol. 28 no. 2, pp. $400-411$.

Clewlow, L \& Strickland, C 2000, Energy Derivatives - Pricing and Risk Management, Lacima Publications, London UK.

Dahen, H \& Dione, G 2010, 'Scaling Models for the Severity and Frequency of External Operational Loss Data', The Journal of Banking \& Finance, no. 34, pp. 1484 - 1496.

Davidson, R \& MacKinnon, JG 1993, Estimation and Inference in Econometrics, Oxford University Press, Cambridge.

De Jong, C 2006, 'The Nature of Power Spikes: A Regime-Switching Approach', Studies in Nonlinear Dynamics and Econometrics, vol. 10, no. 3, pp. $1-26$.

Escribano, A, Pena, JI \& Villaplana, P 2002, 'Modelling Electricity Prices: International Evidence', Working Paper 02-27, Universidad Carlos III de Madrid.

Eydeland, A \& Wolyniec, K 2012, Energy and Power Risk Management $2^{\text {nd }}$ Edition, Wiley, Hoboken NJ.

Frontier Economic Report 2010, 'Implications for the National Electricity Market from Increases to the Market Price Cap and/or Cumulative Price Threshold', Frontier Economics Pty. Ltd., Australia.

Geman, H \& Roncoroni, A 2006, 'Understanding the Fine Structure of Electricity Prices', Journal of Busines, vol. 79, no. 3, pp. $1225-1261$.

Greene, WH 2008, Econometric Analysis $6^{\text {th }}$ Edition, Pearson Prentice Hall, USA.

Heckman, J 1979, 'Selection Bias as a Specification Error', Econometrica, vol. 47 no. 1, pp. $153-161$.

Harris, C 2006, Electricity Markets: Pricing, Structures and Economics, Wiley, Chichester. 
Higgs, H 2009, 'Modeling Price and Volatility Inter-Relationship in the Australia Wholesale Spot Electricity Markets', Energy Economics, no. 31, pp. 748 - 756.

Higgs, H \& Worthington, A 2008, 'Stochastic Prices Modeling of High Volatility, Mean Reverting, Spike-Prone Commodities: The Australia Wholesale Spot Electricity Market', Energy Economics, no. 30, pp. 3172 - 3185.

Hill, RC, Griffiths, WE \& Lim, GC 2008, Principles of Econometrics $3^{\text {rd }}$ Edition, John Wiley \& Sons Inc., New Jersey USA.

Hippert, HS, Pedreira, CE \& Souza, RC 2001, 'Neural Networks for Short Term Load Forecasting: A Review and Evaluation', IEEE Transactions on Power Systems, vol. 16 no. 1, pp. 44 - 55.

Huisman, R \& Mahieu, R 2003, 'Regime Jumps in Electricity Prices', Energy Economics, no. 25 , pp. $425-434$.

Huisman, R, Huurman, C \& Mahieu, R 2007, 'Hourly Electricity Prices in Day-Ahead Markets', Energy Economics, no. 29, pp. 240 - 248.

Huisman, R, 2008, 'The Influence of Temperature on Spike Probability in Day-Ahead Power Prices', Energy Economics, no. 30, pp. 2697 - 2704.

Huisman, R, 2009, An Introduction to Models for the Energy Markets. Risk Books, London UK.

Janczura, J, \& Weron, R 2010, 'An Empirical Comparison of Alternate Regime-Switching Models for Electricity Spot Prices', Energy Economics, no. 32, pp. 1059 - 1073.

Kanamura, T \& Ohashi, K 2007, 'A Structural Model for Electricity Prices with Spikes Measurement of Spike Risk and Optimal Policies for Hydropower Plant Operation', Energy Economics, no. 29, pp. 1010 - 1032.

Kanamura, T \& Ohashi, K 2008, 'On Transition Probabilities of Regime Switching in Electricity Prices', Energy Economics, no. 30, pp. 1158 - 1172.

Kennedy, P 2003, A Guide to Econometrics $5^{\text {th }}$ Edition, Pearson Prentice Hall, USA.

Knittel, CR \& Roberts, MR 2005, 'An Empirical Examination of Restructured Electricity Prices', Energy Economics, no. 27, pp. $791-817$.

Kosaster, P 2008, 'On the Impact of Weather on German Hourly Power Prices', Energy Economics, no. 30, pp. $2697-2704$.

Lucia, JJ \& Schwartz, ES 2002, 'Electricity Prices and Power Derivatives: Evidence from the Nordic Power Exchange', Review of Derivatives Research, no. 5, pp. 5 - 50.

Lu, X, Dong, ZY \& Li, X, 2005, 'Electricity Market Price Spike Forecast with Data Mining Techniques', Electric Power Systems Research, no. 73, pp. $19-29$.

Misiorek, A, Trück, S \& Weron, R 2006, 'Point and Interval Forecasting of Spot Electricity Prices: Linear vs Non-Linear Time Series Models', Studies in Nonlinear Dynamics \& Econometrics, vol. 10 no. 3, Article 2.

Mount, TD, Ning, Y \& Cai, X 2006, 'Predicting Price Spikes in Electricity Markets Using a Regime-Switching Model with Time-Varying Parameteres', Energy Economics, no. 28, pp. $62-80$.

Shawky, AH, Marathe, A \& Barrett, CL 2003, 'A First Look at the Empirical Relation between Spot and Futures Electricity Prices in the Unites States', The Journal of Futures Markets, vol. 23 no. 10, pp. $931-955$.

Verbeek, M., 2008. A Guide to Modern Econometrics $3^{\text {rd }}$ edition. John Wiley \& Sons Ltd., West Sussex England.

Vuong, QH 1989, 'Likelihood Ratio Tests for Model Selection and Non-Nested Hypotheses', Econometrica, vol. 57 no. 2, pp. 307 - 333.

Weron, R 2000. 'Energy Price Risk Management', Physica A, no. 285, pp. 127 - 134. 
Weron, R, Bierbrauer, M \& Trück, S 2004. 'Modelling Electricity Prices: Jump Diffusion and Regime Switching', Physica A, no. 336, pp. 39 - 48.

Weron, R 2006, Modeling and Forecasting Loads And Prices In Deregulated Electricity Markets, John Wiley \& Sons Inc., New Jersey USA.

Weron, R \& Misiorek, A 2008. 'Forecasting Spot Electricity Prices: A Comparison of Parametric and Semiparametric Time Series Models', International Journal of Forecasting, no. 24, pp. $744-763$. 


\title{
5. Convenience Yield Risk Premiums
}

\begin{abstract}
The convenience yield is an important risk factor for commodity derivatives. However, very little is known about how convenience yield risk is priced. In this paper, we construct portfolios of commodity futures that directly track the convenience yield risk premium. Our empirical results for a variety of different commodities show that convenience yield risk premiums are consistently positive. However, the magnitude of the premium varies strongly between groups of commodities. Our study has important implications for the risk management of commodity positions and shows that convenience yield risk premiums can be very valuable for investors. For grains, a risk-averse investor realizes monetary utility gains over a risk-free investment of up to 11 percent per year from a corresponding trading strategy.
\end{abstract}




\subsection{Introduction}

Commodity futures have long been used by producers and consumers to manage commodity price risk. More recently, they have also received much attention in the context of commodity investment strategies and the growth in commodity investments via futures trading has even led to a controversial debate about the financialization of commodity markets. ${ }^{1}$ Given the importance of commodity futures, a good understanding of the factors behind their risk and return is a crucial issue for producers, consumers and commodity investors alike.

The convenience yield, i.e., the "flow of services which accrues to the owner of a physical inventory but not to the owner of a contract for future delivery", ${ }^{2}$ is an important determinant of commodity futures prices. The literature on convenience yields shows that they can vary strongly over time and should be treated as stochastic. ${ }^{3}$ However, it is astonishing that previous research provides rather limited evidence on convenience yield risk premiums. A better understanding of the risk premiums is important for different reasons. First, the premiums affect firms' risk management and hedging strategies with futures contracts because they are a component of the costs and benefits of hedging. Second, commodity investment strategies with futures require a thorough assessment of the risk-return trade-off and should also consider convenience yield risk premiums. Finally, a better understanding of the premiums could improve pricing models for commodity derivatives via a more adequate specification of the market price of convenience yield risk.

\footnotetext{
${ }^{1}$ See, for example, Stoll and Whaley (2010), Irwin and Sanders (2011), Tang and Xiong (2012), and Basak and Pavlova (2013)

${ }^{2}$ See Brennan (1991), p.33.

${ }^{3}$ Even is one does not follow the economic notion of a convenience yield, there is no doubt that a second stochastic factor besides the commodity spot price is required to explain commodity futures prices. For example, Schwartz and Smith (2000) develop a two-factor model with stochastic long-term and short-term spot price components. They show that this model is observationally equivalent to the stochastic convenience yield model by Gibson and Schwartz (1990).
} 
In this paper, we investigate the convenience yield risk premium for different commodities and make the following two contributions. First, we shows how to extract the premium by means of a trading strategy with commodity futures. This trading strategy is easy to implement because it is based on the knowledge of current futures prices alone. The returns of this strategy are natural estimates of the premium. Second, we perform an extensive empirical study that quantifies the convenience yield risk premium for different commodities and assesses the value of the corresponding trading strategy for investors.

Our empirical results for a variety of different commodities show that convenience yield risk premiums are consistently positive. However, the magnitude of the premium varies strongly between groups of commodities. These results are very robust and do not depend on the subperiod investigated, the specific contracts used and the consideration of additional interest rate risk. Convenience yield risk premiums can be very valuable for investors. For grains, a risk-averse investor realizes monetary utility gains over a risk-free investment of up to $11 \%$ per year from a corresponding trading strategy.

Our work is related to different strands of the literature. There is a natural link to the literature on the convenience yield itself. Starting with the classical contributions by Kaldor (1939) and Working (1949), this literature studies the economic rationale behind the convenience yield, its determinants and empirical properties (See, for example, Brennan (1991), Casassus et al. (2005), Bollinger and Kind (2010), and Prokopczuk and Wu (2013)). However, this literature deals with the convenience yield itself and does not investigate the convenience yield risk premium that we study in our paper.

Some evidence on convenience yield risk premiums is provided by studies that develop and test pricing models for commodity derivatives, because such models often require the estimation 
of the market price of convenience yield risk (see Gibson and Schwartz (1990), Schwartz (1997), Casassus and Collin-Dufresne (2005), and Casassus et al. (2012)). However, such estimates are notoriously imprecise and have to be obtained simultaneously with all other model parameters. In contrast, we follow a more direct approach that exploits the returns of a trading strategy. Our approach is also model based but does not require any knowledge of unknown model parameters.

In terms of methodology, our work is related to some studies of the variance risk premium (see Coval and Shumway (2001), Bakshi and Kapadia (2003), and Carr and Wu (2009)). These papers analyze the similar problem of extracting the risk premium of a stochastic factor (stochastic volatility) that affects derivatives prices (options) and interacts with another factor (spot price). To obtain the premium, these studies also use certain trading strategies. However, we deal with the convenience yield risk premium instead of the variance risk premium. The former is more relevant for commodity futures whereas the latter is more relevant for options.

Finally, our work belongs to the extensive literature on trading strategies and risk premiums in commodity futures markets. (See Basu and Miffre (2009) Bessembinder (1992), Bessembinder and Chan (1992), Chang (1985), Chng (2009), Dusak (1973), Erb and Harvey (2006), Fama and French (1987), Gorton and Rouwenhorst (2006), Miffre and Rallis (2007), de Roon et al. (2000), de Roon et al. (1998), Rouwenhorst and Tang (2012), and Szakmary et al. (2010). Most closely related to our work are the papers by Daskalaki et al. (2012) and Szymanowska et al. (2013). These authors investigate the structure of risk premiums in futures markets and relate it to different risk factors. However, our paper is the first one that explicitly considers the convenience yield risk premium and investigates a futures trading strategy 
derived to track this premium.

The remainder of the paper is organized as follows. In Section 5.2 we show how to extract the convenience yield risk premium via a trading strategy with commodity futures. Section 5.3 provides our empirical study. After introducing our data in Subsection 5.3.1, we present our results on the sign and magnitude of the risk premiums in Subsection 5.3.2. Subsection 5.3.3 deals with the benefits of our futures trading strategy for investors. Section 5.4 concludes.

\subsection{Extracting Convenience Yield Risk Premiums}

To extract convenience yield risk premiums, we study the returns of futures portfolios that are sensitive to convenience yield changes. We insulate the portfolios from spot price risk by choosing appropriate positions in contracts with different maturities. The portfolio construction is based on the two-factor pricing model by Gibson and Schwartz (1990). This model considers a stochastic commodity spot price and a stochastic convenience yield rate. The two state variables follow the stochastic processes

$$
\begin{aligned}
& d S(t)=(\mu(S, t)-\delta) S \cdot d t+\sigma_{1} S \cdot d w_{1}, \\
& d \delta(t)=a(b-\delta) \cdot d t+\sigma_{2} \cdot d w_{2},
\end{aligned}
$$

where $S$ is the spot price and $\delta$ the convenience yield rate. $\mu(S, t)$ denotes a drift component of the spot price process that can depend on $S$ and time $t .{ }^{4}$ The convenience yield rate is mean reverting with stationary mean $b$ and mean-reversion parameter $a . \sigma_{1}$ and $\sigma_{2}$ are volatility parameters and $d w_{1}$ and $d w_{2}$ denote the increments of two correlated Brownian motions

\footnotetext{
${ }^{4}$ As the drift rate can be a function of time, the model allows for seasonality of the spot price process.
} 
with correlation parameter $\rho_{12}$. The model delivers the following closed-form solution for the futures price:

$$
\begin{gathered}
F(t, \tau)=S(t) \exp \left[-\delta(t) \frac{\left(1-e^{-a \tau}\right)}{a}+A(\tau)\right], \text { with } \\
A(\tau)=\left[r-\left(b-\frac{\sigma_{2} \gamma}{a}\right)+\frac{1}{2} \frac{\sigma_{2}^{2}}{a^{2}}-\frac{\sigma_{1} \sigma_{2} \rho_{12}}{a}\right] \tau+\sigma_{2}^{2} \frac{\left(1-e^{-2 a \tau}\right)}{4 a^{3}} \\
+\left[a\left(b-\frac{\sigma_{2} \gamma}{a}\right)+\sigma_{1} \sigma_{2} \rho_{12}-\frac{\sigma_{2}^{2}}{a}\right] \frac{\left(1-e^{-a \tau}\right)}{a^{2}},
\end{gathered}
$$

where $t$ is calender time, $\tau$ the future's time-to-maturity, $r$ the risk-free interest rate, and $\gamma$ the market price of convenience yield risk.

It is our goal to build portfolios that bear some convenience yield risk but are insensitive to spot price changes, i.e., delta-neutral portfolios. From the pricing equation (3), we easily obtain the spot price sensitivity of a futures contract:

$$
\frac{\partial F(t, \tau)}{\partial S(t)}=\frac{F(t, \tau)}{S(t)} .
$$

According to equation (4), a future's delta equals the current futures price divided by the current spot price. This property is very convenient, because delta can be obtained directly from observable prices and does not require any (potentially imprecise) estimates of model parameters.

Now consider a portfolio that consists of positions in two different futures contracts with times to maturity $\tau_{1}$ and $\tau_{2}$, where $\tau_{1}<\tau_{2}$. Denote the number of long positions in the first futures by $x_{1}$ and the number of long positions in the second one by $x_{2}$. Then the futures portfolio has a delta of $\left[x_{1} F\left(t, \tau_{1}\right)+x_{2} F\left(t, \tau_{2}\right)\right] / S(t)$. Therefore, delta-neutrality of 
the portfolio requires

$$
\frac{x_{1}}{x_{2}}=-\frac{F\left(t, \tau_{2}\right)}{F\left(t, \tau_{1}\right)}
$$

In our analysis, we choose the following values for $x_{1}$ and $x_{2}$ :

$$
x_{1}=\frac{1}{F\left(t, \tau_{1}\right)} \quad \text { and } \quad x_{2}=-\frac{1}{F\left(t, \tau_{2}\right)} .
$$

This choice facilitates the comparison between different commodities with different price levels, because profits or losses of the futures positions can be interpreted as price changes per dollar, i.e., relative changes of futures prices. Also note that we don't need any of the model parameters to obtain $x_{1}$ and $x_{2}$. In the setting of the Gibson and Schwartz (1990) model, the resulting portfolio is (instantaneously) free of spot price risk - only convenience yield risk remains. In addition, it does not require any initial investment. Therefore, the portfolio's expected profit is a pure compensation for convenience yield risk, i.e., it is a convenience yield risk premium.

For a better understanding of the portfolio's properties, let us look at the (instantaneous) change in portfolio value. From Itô's lemma, we obtain

$$
\frac{d F\left(t, \tau_{1}\right)}{F\left(t, \tau_{1}\right)}-\frac{d F\left(t, \tau_{2}\right)}{F\left(t, \tau_{2}\right)}=\gamma \frac{\left(e^{-a \tau_{1}}-e^{-a \tau_{2}}\right) \sigma_{2}}{a}+\frac{\left(e^{-a \tau_{1}}-e^{-a \tau_{2}}\right) \sigma_{2}}{a} d w_{2}
$$

Equation (7) confirms that portfolio risk is driven by the innovation $d w_{2}$ of the convenience yield process only. Spot price risk $\left(d w_{1}\right)$ does not appear. The portfolio's profit or loss could nevertheless be correlated with changes in the spot price, because of a correlation between the innovations $d w_{1}$ and $d w_{2}$. Another interesting observation is that the distribution of the 
portfolio's instantaneous profit does not depend on the state variables, i.e., it is not affected by the current commodity price and the current convenience yield.

The volatility of the portfolio's profit equals $\frac{\left(e^{-a \tau_{1}}-e^{-a \tau_{2}}\right) \sigma_{2}}{a}$. It increases with a higher convenience yield volatility $\left(\sigma_{2}\right)$ and decreases with a higher mean-reversion $(a)$ of the convenience yield process. Moreover, the times-to-maturity of the two futures contracts play an important role. The volatility increases with $\tau_{2}$ and decreases with $\tau_{1}$, which means that a growing distance between the maturity dates of the two futures leads to a higher volatility. The portfolio's expected profit equals the market price of convenience yield risk times the portfolio's volatility. Therefore, the expected profit is positive for $\gamma>0$ and negative for $\gamma<0$. Equation (7) also highlights that $\gamma$ provides the risk compensation per unit of risk, as it equals the ratio of the expected portfolio profit and the portfolio volatility. In summary, we can conclude that the portfolio's profits and losses provide useful information on convenience yield risk premiums that we will exploit in our empirical study.

\subsection{Empirical Study}

\subsubsection{Data}

In our empirical analysis, for the investigation of convenience yield risk premiums, we consider data on futures contracts for eight major commodity markets. In particular we examine the following commodities that can be clustered in three groups, namely metals (gold, silver and copper), grains (corn, soybeans and wheat) and energy (oil and gas). For these commodities data on futures prices is supplied by CME Group ${ }^{5}$. The corresponding futures contracts

\footnotetext{
${ }^{5}$ http://www.cmegroup.com/
} 
have high trading volume, high liquidity and can been seen as benchmark contracts for the particular commodity. Unfortunately, we can not retrieve data for the entire sample period from 1975 to 2010 for all commodities such that our sample period differs for some of the commodities depending on when data on futures prices is available in the futures exchange. Sample periods are from January 1, 1975 to October 1, 2010 for gold, silver, corn, soybean and wheat, as well as August 1, 1988 to October 1, 2010 for copper, July 1, 1986 to October 1, 2010 for crude oil and April 1, 1990 to October 1, 2010 for natural gas. Spot and futures prices are quoted in US Dollar (USD) cents per unit of each commodity quantity: USD cents per pound for copper, USD cents per troy ounce for gold and silver, USD cents per bushel for grains (corn, soybean and wheat), USD cents per barrels for crude oil and USD cents per million British thermal units (mmBtu) for natural gas.

We consider both monthly spot and futures prices for all commodities. Note, however, that the 'spot' here refers to the corresponding futures contract that is closest to maturity, as in Schwartz (1997). We use this proxy because for several of the considered commodity markets, spot price data is not very reliable, see e.g. Gibson and Schwartz (1990). Table 1 provides sample periods as well as descriptive statistics for monthly returns for the nearestterm futures contracts for the eight commodities considered in this analysis.

\subsubsection{Estimates of Risk Premiums}

\section{Base Case}

In a first step we examine estimates for convenience yield risk premiums, by studying the returns of the constructed futures portfolios. Recall that the portfolio construction is based on the two-factor pricing model by Gibson and Schwartz (1990) and the created portfolios are 
Table 1: Sample periods and descriptive statistics of monthly spot returns for the considered commodities. We examine eight commodities hat can be clustered in three groups, namely metals (gold, silver and copper), grains (corn, soybeans and wheat) and energy (oil and gas). Note that the term spot here refers to the corresponding futures contract that is closest to maturity, as in Schwartz (1997).

\begin{tabular}{lcccccccc}
\hline \hline & \multicolumn{3}{c}{ Metals } & \multicolumn{3}{c}{ Grains } & \multicolumn{2}{c}{ Energy } \\
\hline & Gold & Silver & Copper & Corn & Soybeans & Wheat & Oil & Gas \\
\hline$\mu$ & $0.50 \%$ & $0.41 \%$ & $0.33 \%$ & $0.14 \%$ & $0.19 \%$ & $0.15 \%$ & $0.69 \%$ & $0.98 \%$ \\
$\sigma$ & $5.50 \%$ & $9.38 \%$ & $8.17 \%$ & $7.64 \%$ & $7.46 \%$ & $8.23 \%$ & $10.95 \%$ & $18.24 \%$ \\
Min & $-23.10 \%$ & $-75.33 \%$ & $-53.54 \%$ & $-28.75 \%$ & $-55.19 \%$ & $-55.19 \%$ & $-53.40 \%$ & $-63.07 \%$ \\
Max & $24.12 \%$ & $44.81 \%$ & $31.22 \%$ & $40.67 \%$ & $25.37 \%$ & $33.19 \%$ & $37.07 \%$ & $56.49 \%$ \\
\hline Start & Jan 75 & Jan 75 & Aug 88 & Jan 75 & Jan 75 & Jan 75 & Jul 86 & Apr 90 \\
End & Oct 10 & Oct 10 & Oct 10 & Oct 10 & Oct 10 & Oct 10 & Oct 10 & Oct 10 \\
Obs & 427 & 427 & 259 & 431 & 431 & 431 & 288 & 224 \\
\hline \hline
\end{tabular}

insulated from spot price risk by choosing appropriate positions in contracts with different maturities. Table 2 provides results for annualized returns for the created portfolios, i.e. for estimated convenience yield risk premiums for the considered time period from January 1, 1975 to October 1, 2010 for gold, silver, corn, soybean and wheat, as well as for August 1, 1988 to October 1, 2010 for copper, July 1, 1986 to October 1, 2010 for crude oil and for April 1, 1990 to October 1, 2010 for natural gas.

As mentioned above, we divide the portfolios into different groups of commodities, namely metals, grains and energy. Observed returns for the created factor portfolios show that similar commodities yield very similar returns. For gold, silver and copper, annualized returns range from $4.49 \%$ for silver to $4.96 \%$ for gold that are significantly positive. For grains we find that annualized returns are in a range from $10.53 \%$ for soybeans up to $11.92 \%$ for corn, while for wheat annualized returns are $11.24 \%$. Finally, for oil we obtain an estimate of the convenience yield risk premium of $1.19 \%$, while for gas we obtain annualized portfolio returns 
Table 2: Estimates for convenience yield risk premiums based on monthly returns obtained from the constructed futures portfolios for different groups of commodities: metals (gold, silver and copper), grains (corn, soybeans and wheat) and energy (oil and gas). Portfolio construction is based on the two-factor pricing model by Gibson and Schwartz (1990) and the portfolios are insulated from spot price risk by choosing appropriate positions in contracts with different maturities. We report annualized figures for average returns, standard deviations, and Sharpe ratios. Note also the different number of observations for the considered commodities based on the different underlying samples.

\begin{tabular}{lcccccccc}
\hline \hline & & Metals & \multicolumn{3}{c}{ Grains } & \multicolumn{2}{c}{ Energy } \\
\hline & Gold & Silver & Copper & Corn & Soybeans & Wheat & Oil & Gas \\
\hline$\mu$ & $4.96 \%$ & $4.49 \%$ & $4.82 \%$ & $11.92 \%$ & $10.53 \%$ & $11.24 \%$ & $1.19 \%$ & $7.26 \%$ \\
& $(0.000)$ & $(0.000)$ & $(0.000)$ & $(0.000)$ & $(0.000)$ & $(0.001)$ & $(0.535)$ & $(0.172)$ \\
$\sigma$ & $1.13 \%$ & $4.52 \%$ & $4.19 \%$ & $6.81 \%$ & $8.87 \%$ & $13.64 \%$ & $9.24 \%$ & $21.04 \%$ \\
$S R$ & $377.65 \%$ & $99.43 \%$ & $115.14 \%$ & $175.17 \%$ & $118.68 \%$ & $82.44 \%$ & $12.83 \%$ & $34.53 \%$ \\
\hline Obs & 429 & 429 & 261 & 108 & 215 & 108 & 291 & 246 \\
\hline \hline
\end{tabular}

of $7.26 \%$.

It becomes obvious that our estimates for the convenience yield risk premiums are positive for all commodities. However, given the relatively high standard deviation of monthly returns for oil and gas, the convenience yield risk premium is only significant for the groups of metals and grains. ${ }^{6}$ Also calculated annualized Sharpe ratios illustrate that values are high for metals and grains, while they are significantly lower for energy commodities. For metals we find Sharpe ratios between $99.43 \%$ for silver up to $377.65 \%$ for gold, while for grains the equivalent figures range from $82.44 \%$ for wheat up to $175.17 \%$ for corn.

Overall, our results suggest that the estimated convenience yield risk premiums are positive for all commodities, while they are quite substantial and significant in particular for metals and grains. We conclude that with respect to the futures portfolios, there exist clear differences between the examined groups of commodities: returns for grain portfolios are the

\footnotetext{
${ }^{6}$ We use robust Newey-West standard errors with 12 lags to asses the significance of the average returns.
} 
highest, while for metals we obtain lower annualized returns but also a much lower standard deviation in the returns such that estimated convenience yield risk premiums are still positively greater than zero. On the other hand for energy commodities, we do not find a significant convenience yield risk premium.

\section{Influence of Sub-periods}

In a next step we examine whether our results on convenience risk premiums still remain valid when considering different sub-periods. Table 3 reports results for three sub-periods, ranging from January 2000 - October 2010 (Panel A, from January 1990 - December 1999 (Panel B and from January 1980 - December 1989 (Panel C. From a first glance we find that for all constructed portfolios, with the exceptions of oil for the sub-period January 1990 December 1999, estimated convenience yield risk premiums remain positive.

For metals, we find that returns for constructed gold and silver futures portfolios were particularly high during the first sub-period January 1980 - December 1989: for this period, estimates of the convenience yield risk premium are $8.65 \%$ for gold and $4.73 \%$ for silver. Note that for this sub-period, we do not report the results for copper, since data was only available from August 1988 onwards. Results for the second sub-period from January 1990 December 1999 are all significantly greater than zero at the $1 \%$ significance level and annualized premiums range from $3.43 \%$ for gold up to $4.64 \%$ for copper. Finally, also for the third sub-period from January 2000 - October 2010 we obtain slightly lower but still significant positive annualized returns for gold $(2.65 \%)$ and silver $(2.45 \%)$, while returns for copper are $5.53 \%$. We conclude that for metals our results on positive convenience yield risk premiums are robust also across the considered sub-periods. 
Also for grains, we find that estimated convenience yield risk premiums are positive throughout all sub-periods for all commodities. For the first sub-period January 1980 - December 1989 annualized returns are $17.81 \%$ for corn, $14.53 \%$ for soybeans and $9.25 \%$ for wheat. For corn and soybeans, estimated convenience yield risk premiums are significantly greater than zero at the $1.5 \%$ and $0.1 \%$ level, respectively, while returns for are still comparably high but not significant for the first sub-period. For the second sub-period annualized returns for the created grain futures portfolios are all significant at the $5 \%$ level and range from $12.06 \%$ for soybeans up to $23.72 \%$ for wheat. Also for the third sub-period from January 2000 - October 2010 we obtain slightly lower but highly significant positive estimates for convenience yield risk premiums for corn $(7.58 \%)$, soybeans $(11.02 \%)$ and wheat $(7.65 \%)$. Overall, we find that also for grains our results on positive and significant returns of the constructed factor portfolios are robust.

Let us now consider the results for the third group of energy commodities. For the first sub-period from January 1980 - December 1989, we only report results for oil, since futures prices for natural gas were only available from April 1990 onwards. Estimated convenience yield risk premiums for oil are positive $(5.88 \%)$, but due to a high standard deviation of the created monthly portfolio returns they are not significant, at least not at the $5 \%$ level. For the second sub-period from January 1990 - December 1999, annualized returns for the created energy futures portfolios are negative for oil $(-0.70 \%)$, while they are positive and relatively high for gas (9.28\%). However, neither for oil nor gas the estimated risk premiums are significant. For the third sub-period we obtain positive estimates for convenience yield risk premiums for oil $(2.08 \%)$ and gas $(5.47 \%)$ but similar to the other sub-periods due to a high standard deviation of the created monthly portfolio returns the premiums are not 
Table 3: Estimates of convenience yield risk premiums for metals (gold, silver and copper), grains (corn, soybeans and wheat), energy (oil and gas) for different sub-periods. Data is divided into three sub-periods, ranging from January 2000 - October 2010 (Panel A), from January 1990 - December 1999 (Panel B) and from January 1980 - December 1989 (Panel $C$ ). We report annualized figures for average returns, standard deviations, and the Sharpe ratios. Note also the different number of observations for the considered commodities based on the different underlying samples for the sub-periods.

\begin{tabular}{|c|c|c|c|c|c|c|c|c|}
\hline \multicolumn{9}{|c|}{ Panel A: Jan 2000 - Oct 2010} \\
\hline & \multicolumn{3}{|c|}{ Metals } & \multicolumn{3}{|c|}{ Grains } & \multicolumn{2}{|c|}{ Energy } \\
\hline & Gold & Silver & Copper & Corn & Soybeans & Wheat & Oil & Gas \\
\hline \multirow[t]{2}{*}{$\mu$} & $2.65 \%$ & $2.45 \%$ & $5.53 \%$ & $7.58 \%$ & $11.02 \%$ & $7.65 \%$ & $2.08 \%$ & $5.47 \%$ \\
\hline & $(0.000)$ & $(0.000)$ & $(0.023)$ & $(0.000)$ & $(0.001)$ & $(0.000)$ & $(0.220)$ & $(0.214)$ \\
\hline$\sigma$ & $0.50 \%$ & $0.54 \%$ & $3.37 \%$ & $4.47 \%$ & $11.70 \%$ & $4.74 \%$ & $8.68 \%$ & $18.17 \%$ \\
\hline$S R$ & $532.37 \%$ & $457.55 \%$ & $164.03 \%$ & $169.81 \%$ & $94.18 \%$ & $161.47 \%$ & $23.93 \%$ & $30.08 \%$ \\
\hline Obs & 130 & 130 & 130 & 33 & 66 & 33 & 130 & 130 \\
\hline \multicolumn{9}{|c|}{ Panel B: Jan 1990 - Dec 1999} \\
\hline & \multicolumn{3}{|c|}{ Metals } & \multicolumn{3}{|c|}{ Grains } & \multicolumn{2}{|c|}{ Energy } \\
\hline & Gold & Silver & Copper & Corn & Soybeans & Wheat & Oil & Gas \\
\hline \multirow[t]{2}{*}{$\mu$} & $3.43 \%$ & $4.25 \%$ & $4.64 \%$ & $12.63 \%$ & $12.06 \%$ & $23.72 \%$ & $-0.70 \%$ & $9.28 \%$ \\
\hline & $(0.000)$ & $(0.000)$ & $(0.009)$ & $(0.0412)$ & $(0.000)$ & $(0.005)$ & $(0.857)$ & $(0.353)$ \\
\hline$\sigma$ & $0.45 \%$ & $0.65 \%$ & $4.84 \%$ & $7.40 \%$ & $6.64 \%$ & $19.54 \%$ & $8.53 \%$ & $23.91 \%$ \\
\hline$S R$ & $765.30 \%$ & $650.63 \%$ & $96.58 \%$ & $170.53 \%$ & $181.45 \%$ & $121.39 \%$ & $-8.18 \%$ & $38.81 \%$ \\
\hline \multirow[t]{4}{*}{ Obs } & 120 & 120 & 120 & 30 & 30 & 30 & 120 & 116 \\
\hline & \multicolumn{8}{|c|}{ Panel C: Jan 1980 - Dec 1989} \\
\hline & \multicolumn{3}{|c|}{ Metals } & \multicolumn{3}{|c|}{ Grains } & \multicolumn{2}{|c|}{ Energy } \\
\hline & Gold & Silver & Copper & Corn & Soybeans & Wheat & Oil & Gas \\
\hline \multirow[t]{2}{*}{$\mu$} & $8.65 \%$ & $4.73 \%$ & - & $17.81 \%$ & $14.53 \%$ & $9.25 \%$ & $5.88 \%$ & - \\
\hline & (0.000) & $(0.112)$ & - & $(0.015)$ & $(0.001)$ & $(0.120)$ & (0.095) & - \\
\hline$\sigma$ & $1.69 \%$ & $8.20 \%$ & - & $8.73 \%$ & $7.85 \%$ & $15.03 \%$ & $12.52 \%$ & - \\
\hline$S R$ & $510.14 \%$ & $57.64 \%$ & - & $204.01 \%$ & $185.10 \%$ & $61.58 \%$ & $46.95 \%$ & - \\
\hline Obs & 120 & 120 & - & 30 & 60 & 30 & 41 & - \\
\hline
\end{tabular}

significant. So also for energy futures contracts our results for different sub-periods tend to confirm the findings obtained for the entire period.

Overall, results on the sign and significance of convenience yield risk premiums are robust for the considered sub-periods. We obtain positive and significant returns for the constructed 
futures portfolios for metals and grains, while returns from created energy portfolios are predominantly positive but not significant. So we confirm results on the existence of a positive convenience yield risk premium for metals and grains while for energy commodities, we do not find significant convenience yield risk premiums.

\section{Influence of Maturity Choice}

In a next step we examine the robustness of the estimated convenience yield risk premiums with respect to the choice of futures contracts. Recall that for our base case analysis, for metals and energy commodities, the factor portfolios are constructed by taking a long position in one-month futures contracts and a short position in two-month futures contacts, while the weights for each position were chosen according to equation (6). For grains, the constructed portfolios are based on a long position in the one-month futures contract and a short position in the three-month futures contacts. In the following, we analyze whether our results on estimated convenience yield risk premiums are robust also with respect to the contract choice, i.e. we examine whether the maturity of the contracts being used to create the portfolios has an impact on the convenience yield risk premium. To do this, we construct our portfolios now by also using futures contracts with longer maturities. Table 4 provides results on estimated convenience yield risk premiums when portfolios are created by taking a long position with weight $x_{1}=\frac{1}{F\left(t, \tau_{1}\right)}$ in the nearest term futures contracts, and a short position with weight $x_{2}=\frac{1}{F\left(t, \tau_{2}\right)}$ in the third nearest term futures contract. For metals and energy this refers to a long position in the one-month futures and a short position in the three-month futures contract, while for grains we use a long position in the one-monh futures contract and a short position in the five-month futures contract. Note that returns for the constructed portfolios 
Table 4: Estimates of convenience yield risk premiums for metals (gold, silver and copper), grains (corn, soybeans and wheat), energy (oil and gas) for alternative contract choice. Portfolios are constructed by taking a long position with weight $x_{1}=\frac{1}{F\left(t, \tau_{1}\right)}$ in the nearest term futures contracts, and a short position with weight $x_{2}=\frac{1}{F\left(t, \tau_{2}\right)}$ in the third nearest term futures contract.

\begin{tabular}{lcccccccc}
\hline \hline & & Metals & & \multicolumn{3}{c}{ Grains } & \multicolumn{2}{c}{ Energy } \\
\hline & Gold & Silver & Copper & Corn & Soybeans & Wheat & Oil & Gas \\
\hline$\mu$ & $5.42 \%$ & $4.98 \%$ & $4.00 \%$ & $12.58 \%$ & $10.49 \%$ & $13.01 \%$ & $1.12 \%$ & $1.80 \%$ \\
& $(0.000)$ & $(0.000)$ & $(0.013)$ & $(0.000)$ & $(0.000)$ & $(0.063)$ & $(0.681)$ & $(0.814)$ \\
$\sigma$ & $1.37 \%$ & $5.09 \%$ & $5.65 \%$ & $6.99 \%$ & $9.77 \%$ & $18.31 \%$ & $11.91 \%$ & $28.93 \%$ \\
$S R$ & $394.10 \%$ & $97.81 \%$ & $70.84 \%$ & $180.03 \%$ & $107.31 \%$ & $71.05 \%$ & $9.38 \%$ & $6.21 \%$ \\
\hline Obs & 215 & 214 & 258 & 72 & 215 & 72 & 291 & 246 \\
\hline \hline
\end{tabular}

are still calculated on a monthly basis, i.e. each month existing positions in the futures contracts are being closed out and new factor portfolios are constructed.

We find that our results on the sign and significance of estimated convenience yield risk premiums as presented in Table 4 are robust also with respect to the choice of contracts. This means that also for futures contracts with longer maturities we obtain significant positive convenience yield risk premiums for metals and grains, while the premiums are positive but insignificant for energy commodities. We find that also the magnitude of the premiums is similar to the base case: annualized returns for the constructed portfolios range from $4.00 \%$ for copper to $5.42 \%$ for gold and are all significant, even at the $1 \%$ level. As for the base case, for grains we find that annualized returns are higher with $12.58 \%$ for corn, $10.49 \%$ for soybeans and $13.01 \%$ for wheat. For corn and soybeans we find estimated convenience yield risk premiums to be significant at any reasonable level, while for wheat they are only significant at the 10\% level. Finally, for energy commodities, annualized returns for the constructed futures portfolios are rather low $(1.12 \%$ for oil and $1.80 \%$ for gas) and not 
significant. Note that we also considered other combinations of futures contracts with even longer maturities and obtained similar results with respect to the sign and significance of estimated convenience yield risk premiums. These results are not reported here, but are available upon request to the authors.

Overall, we conclude that also when alternative futures contracts with longer maturities are used to create the factor portfolios, our results on convenience yield risk premiums for different groups of commodities still remain valid.

\section{Influence of Interest Rate Risk}

The portfolio strategy we have studied so far was derived from the Gibson and Schwartz (1990) model, which assumes constant interest rates. The question that we investigate now is whether interest rate risk affects our conclusions about convenience yield risk premiums. Schwartz (1997) develops a three-factor extension of Gibson's and Schwartz's model with stochastic interest rates. The stochastic processes of the commodity spot price and the convenience yield rate are the same as in equations (1) and (2). In addition, Schwartz (1997) uses a one-factor Vasicek interest rate model that is based on the following dynamics of the short rate:

$$
d r(t)=k(m-r) \cdot d t+\sigma_{3} \cdot d w_{3}
$$

with mean-reversion parameter $k$, stationary mean $m$ and volatility $\sigma_{3}$. The model yields the following closed-form solution for the futures price:

$$
F(t, \tau)=S(t) \exp \left[-\delta(t) \frac{\left(1-e^{-a \tau}\right)}{a}+r(t) \frac{\left(1-e^{-k \tau}\right)}{k}+B(\tau)\right]
$$


where $B(\tau)$ is a function of the time-to-maturity and all model parameters, but does not depend on any of the three state variables.

To study convenience yield risk, we need portfolios that are insensitive to changes in the spot price and the interest rate. From the pricing equation (9), we obtain the following spot price sensitivity (delta) and interest rate sensitivity (rho) of a futures:

$$
\frac{\partial F(t, \tau)}{\partial S(t)}=\frac{F(t, \tau)}{S(t)} \quad \text { and } \quad \frac{\partial F(t, \tau)}{\partial r(t)}=F(t, \tau) \frac{1-\exp (-k \tau)}{k} .
$$

Now assume that three different futures with times-to-maturity $\tau_{1}, \tau_{2}$ and $\tau_{3}\left(\tau_{1}<\tau_{2}<\tau_{3}\right)$ exist and denote the number of contracts held in these futures by $x_{1}, x_{2}$ and $x_{3}$, respectively. Then a futures portfolio is delta neutral and rho neutral if $x_{1}, x_{2}$ and $x_{3}$ solve the following system of equations:

$$
\begin{gathered}
x_{1} F\left(t, \tau_{1}\right)+x_{2} F\left(t, \tau_{2}\right)+x_{3} F\left(t, \tau_{3}\right)=0, \\
x_{1} F\left(t, \tau_{1}\right) \exp \left(-k \tau_{1}\right)+x_{2} F\left(t, \tau_{2}\right) \exp \left(-k \tau_{2}\right)+x_{3} F\left(t, \tau_{3}\right) \exp \left(-k \tau_{3}\right)=0 .
\end{gathered}
$$

As in Section 5.2, we choose $x_{1}=1 / F\left(t, \tau_{1}\right)$. With this choice, the solutions for $x_{2}$ and $x_{3}$ are

$$
\begin{aligned}
& x_{2}=\frac{1}{F\left(t, \tau_{2}\right)}\left[\frac{\exp \left(-k \tau_{1}\right)-\exp \left(-k \tau_{3}\right)}{\exp \left(-k \tau_{3}\right)-\exp \left(-k \tau_{2}\right)}\right], \\
& x_{3}=\frac{1}{F\left(t, \tau_{3}\right)}\left[\frac{\exp \left(-k \tau_{2}\right)-\exp \left(-k \tau_{1}\right)}{\exp \left(-k \tau_{3}\right)-\exp \left(-k \tau_{2}\right)}\right] .
\end{aligned}
$$

Because $\tau_{1}<\tau_{2}<\tau_{3}$ and $k>0$, the portfolio consists of a long position in the shortest-term 
futures, a short-position in the intermediate-term futures and a long position in the longestterm futures. Unfortunately, the appropriate futures positions can no longer be obtained from observable prices only. In addition, we need the mean-reversion parameter $k$ of the short-rate process. However, this parameter is easy to estimate. We apply the Maximum Likelihood approach outlined in Schwartz (1997) and estimate $k$ from zero-bond prices. We use ten different maturities between one and ten years and monthly observations over the investigation period from January 1975 to October 2010. Our data source are the Treasury yield curves provided by the Federal Reserve System. ${ }^{7}$ The resulting estimate of $k$ is 0.62 . Based on this value, we build futures portfolios according to equations (13) and (14). For crude oil, gas, gold, silver, and copper, we employ futures with times-to-maturity of one, two, and three months. For corn, wheat and soybeans, we use one-, three- and five-months futures. As a robustness check, we consider two alternative futures portfolios based on $k=0.22$ and $k=1.02$.

Our results are presented in Table 5 . We find that our conclusions on the sign and significance of estimated convenience yield risk premiums generally remain valid when portfolios are constructed based on a three-factor extension of the Gibson and Schwartz (1990) model. We obtain positive and highly significant convenience yield risk premiums for all metals and grains except for silver. For silver, we find that monthly returns from the created futures portfolio are positive, but usually only significant at the $10 \%$ level. On the other hand, we obtain positive but insignificant convenience yield risk premiums for oil. Interestingly, for natural gas futures portfolios based on a three-factor model, estimated convenience yield risk premiums are also comparably large (around 13\%) and highly significant. With respect to the magnitude of the

\footnotetext{
${ }^{7}$ For details on this data set see Gurkaynak et al. (2007).
} 
Table 5: Impact of interest rate risk on estimates for convenience yield risk premiums. Results reported are based on the Schwartz (1997) three-factor extension of the Gibson and Schwartz model with stochastic interest rates. For crude oil, gas, gold, silver, and copper, we employ futures with times-to-maturity of one, two, and three months, for corn, wheat and soybeans, we use one-, three- and five-months futures contracts. The mean-reversion parameter $k$ of the short-rate process is estimated using the Maximum Likelihood approach outlined in Schwartz (1997) and estimates of $k$ are derived from zero-bond prices. Results for the parameter estimate $k=0.62$ are reported in Panel $A$ while for a robustness check, we also consider alternative futures portfolios based on $k=0.22$ (Panel $B$ ) and $k=1.02$ (Panel $C)$.

\begin{tabular}{|c|c|c|c|c|c|c|c|c|}
\hline \multicolumn{9}{|c|}{ Panel $A: k=0.62$} \\
\hline & \multicolumn{3}{|c|}{ Metals } & \multicolumn{3}{|c|}{ Grains } & \multicolumn{2}{|c|}{ Energy } \\
\hline & Gold & Silver & Copper & Corn & Soybeans & Wheat & Oil & Gas \\
\hline \multirow[t]{2}{*}{$\mu$} & $4.56 \%$ & $2.98 \%$ & $5.92 \%$ & $8.56 \%$ & $10.57 \%$ & $18.50 \%$ & $1.26 \%$ & $13.02 \%$ \\
\hline & $(0.000)$ & $(0.088)$ & $(0.000)$ & $(0.000)$ & $(0.000)$ & $(0.000)$ & $(0.428)$ & $(0.000)$ \\
\hline$\sigma$ & $1.71 \%$ & $6.96 \%$ & $3.67 \%$ & $4.94 \%$ & $8.99 \%$ & $16.40 \%$ & $7.51 \%$ & $16.96 \%$ \\
\hline$S R$ & $266.80 \%$ & $42.89 \%$ & $161.02 \%$ & $173.34 \%$ & $117.54 \%$ & $112.77 \%$ & $16.75 \%$ & $76.77 \%$ \\
\hline Obs & 215 & 214 & 258 & 72 & 215 & 72 & 291 & 246 \\
\hline \multicolumn{9}{|c|}{ Panel B: $k=0.22$} \\
\hline & \multicolumn{3}{|c|}{ Metals } & \multicolumn{3}{|c|}{ Grains } & \multicolumn{2}{|c|}{ Energy } \\
\hline & Gold & Silver & Copper & Corn & Soybeans & Wheat & Oil & Gas \\
\hline \multirow[t]{2}{*}{$\mu$} & $4.58 \%$ & $3.02 \%$ & $5.88 \%$ & $8.70 \%$ & $10.57 \%$ & $18.31 \%$ & $1.26 \%$ & $12.83 \%$ \\
\hline & $(0.000)$ & $(0.083)$ & $(0.000)$ & $(0.000)$ & $(0.000)$ & $(0.000)$ & $(0.428)$ & $(0.000)$ \\
\hline$\sigma$ & $1.68 \%$ & $6.91 \%$ & $3.67 \%$ & $4.82 \%$ & $8.95 \%$ & $16.31 \%$ & $7.54 \%$ & $16.99 \%$ \\
\hline$S R$ & $271.94 \%$ & $43.65 \%$ & $160.44 \%$ & $180.54 \%$ & $118.09 \%$ & $112.28 \%$ & $16.65 \%$ & $75.55 \%$ \\
\hline Obs & 215 & 214 & 258 & 72 & 215 & 72 & 291 & 246 \\
\hline \multicolumn{9}{|c|}{ Panel $C: k=1.02$} \\
\hline & \multicolumn{3}{|c|}{ Metals } & \multicolumn{3}{|c|}{ Grains } & \multicolumn{2}{|c|}{ Energy } \\
\hline & Gold & Silver & Copper & Corn & Soybeans & Wheat & Oil & Gas \\
\hline \multirow[t]{2}{*}{$\mu$} & $4.55 \%$ & $2.95 \%$ & $5.95 \%$ & $8.42 \%$ & $10.57 \%$ & $18.70 \%$ & $1.26 \%$ & $13.22 \%$ \\
\hline & $(0.000)$ & $(0.094)$ & $(0.000)$ & $(0.000)$ & $(0.000)$ & $(0.000)$ & $(0.428)$ & $(0.000)$ \\
\hline$\sigma$ & $1.74 \%$ & $7.01 \%$ & $3.68 \%$ & $5.08 \%$ & $9.09 \%$ & $16.52 \%$ & $7.48 \%$ & $16.95 \%$ \\
\hline$S R$ & $261.60 \%$ & $42.11 \%$ & $161.53 \%$ & $165.64 \%$ & $116.88 \%$ & $113.20 \%$ & $16.85 \%$ & $78.00 \%$ \\
\hline Obs & 215 & 214 & 258 & 72 & 215 & 72 & 291 & 246 \\
\hline
\end{tabular}

calculated risk premiums, we find that for most commodities results are comparable to the two-factor base case. Created annualized returns are around $4.5 \%$ for gold, approximately $6 \%$ for copper, while they are clearly higher for the considered grains. Interestingly, obtained 
annualized risk premiums are lower (around 8.5\%) for corn, while they are much higher (around $18.5 \%$ ) for wheat in comparison to the two-factor base case. However, in both cases the results on positive and highly significant convenience yield risk premiums remain valid. Clearly, for silver, obtained returns from the factor portfolio are lower than for the base case (around $3 \%$ in comparison to $4.5 \%$ ), while they are much higher for gas (around 13\%) in comparison to $7 \%$ for the two-factor model. Thus, for silver and natural gas our results seem to be affected by the inclusion of an additional interest-rate factor when creating portfolios that are insulated from spot price risk but subject to convenience yield risk. We find that the choice of the mean-reversion parameter $k$ does not seem to have a a significant impact on the results. Comparing results for Panel $A(k=0.62)$ with Panel $B(k=0.22)$ and Panel $C(k=1.02)$ we obtain very similar results for the estimated convenience yield risk premiums. This is true not only for the sign, but also for the magnitude and significance of the extracted premiums. For example, annualized returns for the constructed portfolios for gold vary between $4.55 \%$ and $4.58 \%$ depending on the choice of $k$, while for wheat estimates for the convenience yield risk premium are between $18.31 \%$ and $18.70 \%$. Overall, we conclude that results on the sign and significance of estimated convenience yield risk premiums are robust also with respect to constructing the futures portfolios based on a three-factor extension of the Gibson and Schwartz (1990) model. In particular, we find that results are insensitive to the choice of the mean-reversion parameter $k$ in the Vasicek interest rate model.

\subsubsection{Benefits for Investors}

In this section we examine benefits of constructing portfolios that are sensitive to convenience yield changes for investors. In particular we calculate monetary utility gains (MUGs) as in 
Ang and Bekaert (2002) for the constructed portfolios. We also examine the correlations between monthly returns from the constructed convenience yield sensitive portfolios across the different classes of commodities as well as against monthly spot returns of the considered commodities.

\section{Monetary Utility Gains}

In the following we examine the benefits of the constructed futures portfolios for investors. Table 6 reports the annualized monetary utility gains (MUGs) of the created convenience yield sensitive portfolios for each of the commodities. The MUG is the monetary compensation (in excess returns over a risk-free investment) that an investor requires to be willing to switch from the portfolio strategy that invests in our convenience yield sensitive futures portfolio to a benchmark portfolio strategy. In this study, we use a risk-free investment as the benchmark strategy, i.e., a strategy that delivers an excess return of zero with certainty. Of course, MUGs depend on the risk aversion of the investor. In Table 6, we report MUGs for investors with constant relative risk aversion. The coefficients of relative risk aversion (RRA) range from 2 to 10. Annualized values of MUGs are reported.

Note that for our calculation of MUGs, we consider different levels of transaction costs for creating and closing out the futures portfolios. Our results in Table 6 are presented for the assumption of no transaction costs (Panel A), typical transaction costs for small transaction sizes (Panel B), and, transaction costs referring to a large transaction size (Panel $C)$, in each of the examined markets. For further information on typical transaction costs in commodity markets, we refer to Marshall et al. (2012). Note that transaction costs for gold futures contracts are typically rather small and range from $1.1 \mathrm{bp}$ to $2.1 \mathrm{bp}$, while for silver we 
Table 6: Annualized monetary utility gains (MUGs) of the created convenience yield sensitive portfolios for each of the commodities. MUGs are reported for different coefficients of relative risk aversion, ranging from $R R A=2$ to $R R A=10$. Panel $A$ reports MUGs under the assumption of no transaction costs, while we also iexamine the results assuming typical transaction costs for small transaction size Panel $B$ and large transaction sizes Panel $C$ for the considered futures markets.

\begin{tabular}{|c|c|c|c|c|c|c|c|c|}
\hline \multicolumn{9}{|c|}{ Panel A: No transaction costs } \\
\hline & \multicolumn{3}{|c|}{ Metals } & \multicolumn{3}{|c|}{ Grains } & \multicolumn{2}{|c|}{ Energy } \\
\hline & Gold & Silver & Copper & Corn & Soybeans & Wheat & Oil & Gas \\
\hline $\mathrm{RRA}=2$ & $4.94 \%$ & $4.26 \%$ & $4.65 \%$ & $11.48 \%$ & $9.81 \%$ & $9.63 \%$ & $0.33 \%$ & $3.43 \%$ \\
\hline $\mathrm{RRA}=4$ & $4.93 \%$ & $3.99 \%$ & $4.49 \%$ & $11.05 \%$ & $9.17 \%$ & $8.26 \%$ & $-0.53 \%$ & $0.07 \%$ \\
\hline $\mathrm{RRA}=6$ & $4.91 \%$ & $3.67 \%$ & $4.33 \%$ & $10.63 \%$ & $8.57 \%$ & $7.06 \%$ & $-1.41 \%$ & $-3.02 \%$ \\
\hline $\mathrm{RRA}=10$ & $4.88 \%$ & $2.78 \%$ & $4.03 \%$ & $9.83 \%$ & $7.49 \%$ & $5.03 \%$ & $-3.31 \%$ & $-8.88 \%$ \\
\hline Obs & 429 & 429 & 261 & 108 & 215 & 108 & 291 & 246 \\
\hline \multicolumn{9}{|c|}{ Panel B: Small transaction size } \\
\hline & \multicolumn{3}{|c|}{ Metals } & \multicolumn{3}{|c|}{ Grains } & \multicolumn{2}{|c|}{ Energy } \\
\hline & Gold & Silver & Copper & Corn & Soybeans & Wheat & Oil & Gas \\
\hline $\mathrm{RRA}=2$ & $4.41 \%$ & $2.82 \%$ & $3.21 \%$ & $9.81 \%$ & $8.80 \%$ & $7.90 \%$ & $-0.87 \%$ & $2.06 \%$ \\
\hline $\mathrm{RRA}=4$ & $4.40 \%$ & $2.55 \%$ & $3.04 \%$ & $9.38 \%$ & $8.15 \%$ & $6.53 \%$ & $-1.73 \%$ & $-1.27 \%$ \\
\hline $\mathrm{RRA}=6$ & $4.38 \%$ & $2.22 \%$ & $2.88 \%$ & $8.96 \%$ & $7.56 \%$ & $5.33 \%$ & $-2.62 \%$ & $-4.36 \%$ \\
\hline $\mathrm{RRA}=10$ & $4.35 \%$ & $1.33 \%$ & $2.58 \%$ & $8.16 \%$ & $6.48 \%$ & $3.30 \%$ & $-4.52 \%$ & $-10.22 \%$ \\
\hline Obs & 429 & 429 & 261 & 108 & 215 & 108 & 291 & 246 \\
\hline Tk in bp & $1.1 \mathrm{bp}$ & $3.0 \mathrm{bp}$ & $(3.0 \mathrm{bp})$ & $3.5 \mathrm{bp}$ & $2.1 \mathrm{bp}$ & $3.6 \mathrm{bp}$ & $2.5 \mathrm{bp}$ & $2.8 \mathrm{bp}$ \\
\hline \multicolumn{9}{|c|}{ Panel C: Large transaction size } \\
\hline & \multicolumn{3}{|c|}{ Metals } & \multicolumn{3}{|c|}{ Grains } & \multicolumn{2}{|c|}{ Energy } \\
\hline & Gold & Silver & Copper & Corn & Soybeans & Wheat & Oil & Gas \\
\hline $\mathrm{RRA}=2$ & $3.93 \%$ & $1.52 \%$ & $1.90 \%$ & $9.04 \%$ & $8.17 \%$ & $6.61 \%$ & $-1.07 \%$ & $1.51 \%$ \\
\hline $\mathrm{RRA}=4$ & $3.92 \%$ & $1.25 \%$ & $1.74 \%$ & $8.61 \%$ & $7.53 \%$ & $5.23 \%$ & $-1.93 \%$ & $-1.84 \%$ \\
\hline $\mathrm{RRA}=6$ & $3.90 \%$ & $0.92 \%$ & $1.58 \%$ & $8.19 \%$ & $6.93 \%$ & $4.03 \%$ & $-2.81 \%$ & $-4.93 \%$ \\
\hline $\mathrm{RRA}=10$ & $3.87 \%$ & $0.03 \%$ & $1.28 \%$ & $7.39 \%$ & $5.85 \%$ & $2.00 \%$ & $-4.71 \%$ & $-10.79 \%$ \\
\hline Obs & 429 & 429 & 261 & 108 & 215 & 108 & 291 & 246 \\
\hline $\mathrm{Tk}$ in bp & $2.1 \mathrm{bp}$ & $5.7 \mathrm{bp}$ & (5.7bp) & $5.1 \mathrm{bp}$ & $3.4 \mathrm{bp}$ & $6.3 \mathrm{bp}$ & $2.9 \mathrm{bp}$ & $4.0 \mathrm{bp}$ \\
\hline
\end{tabular}

have significantly higher transaction costs between 3.0bp and 5.7bp. Since we do not have information on the exact transaction costs for copper, in our analysis we use a conservative estimate of the costs and assume that they are similar to the transaction costs for silver. For grains, we have transaction costs between 2.1bp and 3.4bp for soybeans, between 3.5bp 
and 5.1bp for corn, while costs for transactions in wheat futures range from 3.6bp to 6.3bp. Finally, for energy markets transaction costs are between $2.5 \mathrm{bp}$ and $2.9 \mathrm{bp}$ for oil futures, and between $2.8 \mathrm{bp}$ and $4.0 \mathrm{bp}$ for natural gas futures contracts.

We find that for the assumption of no transaction costs, for metals MUGs range from 4.88\% up to $4.94 \%$ for gold, from $2.78 \%$ up to $4.26 \%$ for silver and from $4.03 \%$ up to $4.65 \%$ for copper, depending on the assumed coefficients of RRA. For grains, we obtain even higher MUGs ranging from $9.83 \%$ to $11.48 \%$ for corn, while they are a bid lower for soybeans $(7.49 \%$ - 9.81\%) and wheat (5.03\% - 9.63\%). Overall, in particular for grains investors would require substantial returns in excess over a risk-free investment to be willing to switch from a portfolio strategy that invests in our convenience yield sensitive futures portfolio. For energy futures, we find that calculated MUGs are predominantly negative such that the created portfolios do not provide a viable alternative to investing in the risk-free asset.

Results remain qualitatively the same when transaction costs are being considered. Calculated MUGs for gold are only diminished by approximately $1 \%$ under the assumption of large transaction size, while they are more substantially reduced for silver and copper. Still, for any choice of the coefficient of RRA, annualized MUGs are still positive, such that investors in metals would require relatively high returns in excess over a risk-free investment to be willing to switch. For grains we get quite substantial annualized MUGs for the created convenience yield sensitive portfolios also when transaction costs are considered. For example, assuming a coefficient of RRA=6, we still get MUGs of $8.19 \%$ for corn, $6.93 \%$ for soybeans and $4.03 \%$ for wheat. On the other hand, for energy commodities, an investment in the risk-free asset is clearly preferable over the created convenience yield sensitive portfolios. Even for small transaction sizes, for any choice of RRA, MUGs are negative both for the created oil and 
Table 7: Correlations between returns from the created convenience yield sensitive portfolios across different classes of commodities and against returns of the spot factor for the same commodity.

\begin{tabular}{lrrrrrrrr}
\hline \hline & \multicolumn{3}{c}{ Metals } & \multicolumn{3}{c}{ Grains } & \multicolumn{2}{c}{ Energy } \\
\hline Gold & Gold & Silver & Copper & Corn & Soybeans & Wheat & Oil & Gas \\
Silver & - & 0.6209 & 0.0750 & 0.0958 & 0.0284 & 0.1092 & -0.0693 & 0.0066 \\
Copper & - & - & 0.0167 & 0.0893 & 0.0860 & 0.0225 & -0.0555 & -0.0164 \\
Corn & - & - & - & -0.2050 & -0.1149 & -0.1230 & 0.0072 & -0.0097 \\
Soybeans & - & - & - & - & 0.0167 & 0.1639 & 0.0551 & 0.2887 \\
Wheat & - & - & - & - & - & -0.0313 & 0.2884 & 0.0210 \\
Oil & - & - & - & - & - & - & 0.2134 & 0.4933 \\
Gas & - & - & - & - & - & - & - & 0.0160 \\
\hline Spot Factor & 0.0827 & 0.1108 & 0.2821 & 0.2220 & 0.2554 & 0.5071 & 0.4357 & 0.6398 \\
\hline \hline
\end{tabular}

natural gas futures portfolios.

Overall, we find substantial monetary utility gains for the constructed convenience yield sensitive portfolios for metals and grains, while MUGs are typically negative for oil and natural gas. While MUGs are reduced when transaction costs are included, investors would still require substantial returns in excess over a risk-free investment to be willing to switch from the created convenience yield sensitive futures portfolios to a risk-free investment.

\section{Relation to Other Risk Factors}

Finally, we have a look at correlations between returns from the constructed futures portfolios and other risk factors, see Table 7 . We also examine returns from the created convenience yield sensitive portfolios across different classes of commodities.

A very nice result for investors is that returns from the constructed portfolios show rather low correlations across different commodities. For 26 out of 28 pairs, correlations between portfolio returns are below 0.3. Only for gold and silver, respectively wheat and gas, returns 
obtained from the convenience yield sensitive portfolios exhibit correlations around 0.6, respectively 0.49 . These results point towards convenience yield risk premiums behaving quite differently through time for the considered commodities. Interestingly, as illustrated in the last row of Table 7, returns from convenience yield sensitive portfolios do also not exhibit high correlations with spot returns from the same commodity. This is a particular nice feature of the constructed portfolios as it points towards the diversification potential of convenience yield risk premiums. The high positive returns, together with low correlations across different commodity classes, and against a spot factor, makes the created convenience yield sensitive portfolios very valuable for investors and risk managers in commodity markets.

\subsection{Conclusions}

This paper investigates convenience yield risk premiums in various commodity markets. While there is an extensive body of literature examining convenience yields in commodity markets, existing research provides only limited knowledge about the convenience yield risk premium. This is the first study to examine convenience yield risk premiums in various commodity markets, directly and in detail.

Based on two-factor (Gibson and Schwartz, 1990) and three-factor models (Schwartz, 1997), we use a direct approach to extract convenience yield risk premiums. We find that convenience yield risk premiums are positive and highly significant for several of the considered commodities. Our finding of positive convenience yield risk premiums is also robust across sub-period samples, different maturity of the considered futures contracts, and when interest rate risk is included into the analysis. However, the magnitude of the premium varies 
strongly between groups of commodities: while we find significant convenience yield premiums for metals and grains, results are insignificant for energy commodities.

Our study has important implications for the risk management of commodity positions and shows that convenience yield risk premiums can be very valuable for investors. For grains, a risk-averse investor realizes monetary utility gains over a risk-free investment of up to $11 \%$ per year from a corresponding trading strategy. Overall we suggest that high positive returns, together with low correlations across different commodity classes and spot returns, makes convenience yield risk premiums very valuable for investors and risk managers in commodity markets. We recommend further investigation of the premiums with respect to the market structure of the considered commodities in future work. 


\section{References}

Ang, Andrew, and Geert Bekaert, 2002, International asset allocation with regime shifts, Review of Financial Studies 15, 1137-1187.

Bakshi, Gurdip, and Nikunj Kapadia, 2003, Delta-hedged gains and the negative market volatility risk premium, Review of Financial Studies 16, 527-566.

Basak, Suleyman, and Anna Pavlova, 2013, A model of financialization of co, Technical report, London Business School.

Basu, Devraj, and Joelle Miffre, 2009, Capturing the risk premium of commodity futures: The role of hedging pressure, Technical report, SKEMA Business School.

Bessembinder, Hendrik, 1992, Systematic risk, hedging pressure, and risk premiums in futures markets, Review of Financial Studies 5, 637-667.

Bessembinder, Hendrik, and Kalok Chan, 1992, Time-varying risk premia and forecastable returns in futures markets, Journal of Financial Economics 32, 169-193.

Bollinger, Thomas, and Axel H. Kind, 2010, Risk premiums in the cross-section of commodity convenience yields, Technical report, University of Basle.

Brennan, Michael J., 1991, The price of convenience and the valuation of commodity contingent claims, in Stochastic Models and Option Values, D. Lund and B. Øksendal (eds.) (North-Holland).

Carr, Peter, and Liuren Wu, 2009, Variance risk premiums, Review of Financial Studies 22, $1311-1341$. 
Casassus, Jaime, Pierre Collin-Dufresne, and Bryan R. Routledge, 2005, Equilibrium commodity prices with irreversible investment and non-linear technology, Working Paper 11864, National Bureau of Economic Research.

Casassus, Jaime, Peng Liu, and Ke Tang, 2012, Maximal affine models for multiple commodities: A note, Technical report, Pontificia Universidad Catolica de Chile.

Casassus, Jamie, and Pierre Collin-Dufresne, 2005, Stochastic convenience yield implied from commodity futures and interest rates, Journal of Finance 60, 2283-2331.

Chang, Eric C., 1985, Returns to speculators and the theory of normal backwardation, Journal of Finance 40, pp. 193-208.

Chng, Michael T., 2009, Economic linkages across commodity futures: Hedging and trading implications, Journal of Banking $\mathcal{E}$ Finance 33, 958-970.

Coval, Joshua D., and Tyler Shumway, 2001, Expected option returns, Journal of Finance 56, 983-1009.

Daskalaki, Charoula, Alexandros Kostakis, and George S. Skiadopoulos, 2012, Are there common factors in commodity futures returns?, Technical report, University of Piraeus.

de Roon, Frans A., Theo E. Nijman, and Chris Veld, 1998, Pricing term structure risk in futures markets, Journal of Financial and Quantitative Analysis 33, 139-157.

de Roon, Frans A., Theo E. Nijman, and Chris Veld, 2000, Hedging pressure effects in futures markets., Journal of Finance 55, 1437-1456. 
Dusak, Katherine, 1973, Futures trading and investor returns: An investigation of commodity market risk premiums, Journal of Political Economy 81, 1387-1406.

Erb, Claude B., and Campbell R. Harvey, 2006, The strategic and tactical value of commodity futures, Financial Analysts Journal 62, 69-97.

Fama, Eugene F., and Kenneth R. French, 1987, Commodity futures prices: Some evidence on forecast power, premiums, and the theory of storage, Journal of Business 60, 55-73.

Gibson, Rajna, and Eduardo S. Schwartz, 1990, Stochastic convenience yield and the pricing of oil contingent claims, Journal of Finance 45, 959-976.

Gorton, Gary, and K. Geert Rouwenhorst, 2006, Facts and fantasies about commodity futures, Financial Analysts Journal 62, 47-68.

Gurkaynak, Refet S., Brian Sack, and Jonathan H. Wright, 2007, The U.S. treasury yield curve: 1961 to the present, Journal of Monetary Economics 54, 2291-2304.

Irwin, Scott H., and Dwight A. Sanders, 2011, Index funds, financialization, and commodity futures markets, Applied Economic Perspectives and Policy 33, 1-33.

Kaldor, Nicholas, 1939, Speculation and economic stability, Review of Economic Studies 7, $1-27$.

Marshall, Ben R., Nhut H. Nguyen, and Nuttawat Visaltanachoti, 2012, Commodity liquidity measurement and transaction costs, Review of Financial Studies 25, 599-638.

Miffre, Joëlle, and Georgios Rallis, 2007, Momentum strategies in commodity futures markets, Journal of Banking \& Finance 31, 1863-1886. 
Prokopczuk, Marcel, and Yingying Wu, 2013, The determinants of convenience yields, Technical report, Zeppelin University and ICMA Center, University of Reading.

Rouwenhorst, K. Geert, and Ke Tang, 2012, Commodity investing, Technical report, Yale ICF Working Paper No. 06-12.

Schwartz, Eduardo S., 1997, The stochastic behavior of commodity prices: Implications for valuation and hedging, Journal of Finance 52, 922-973.

Schwartz, Eduardo S., and James E. Smith, 2000, Short-term variations and long-term dynamics in commodity prices, Management Science 46, 893-911.

Stoll, Hans A., and Robert E. Whaley, 2010, Commodity index investing and commodity futures prices, Journal of Applied Finance 20, 7-46.

Szakmary, Andrew C., Qian Shen, and Subhash C. Sharma, 2010, Trend-following trading strategies in commodity futures: A re-examination, Journal of Banking \& Finance 34, 409-426.

Szymanowska, Marta, Frans A. de Roon, Theo E. Nijman, and Rob van den Goorbergh, 2013, An anatomy of commodity futures risk premia, Journal of Finance forthcoming.

Tang, Ke, and Wei Xiong, 2012, Index investment and the financialization of commodities, Financial Analysts Journal 68, 54-74.

Working, Holbrook, 1949, The theory of price of storage, American Economic Review 39, $1254-1262$. 


\section{CONCLUSION}

This $\mathrm{PhD}$ thesis studies risks and risk premiums in various commodities markets. Commodities and their derivative markets have emerged as important role players in modern financial markets during the last decade. Research on commodities markets is essential to understand how markets behave, and develop trading strategy or formulate risk management. Studies on risks premiums, both static and dynamic, in electricity markets, provide a thorough understanding on how participants hedge risks in electricity markets.

A contango futures premium suggests that market participants are afraid of an increase in electricity prices, paying higher futures prices to hedge their risks. Investigating determinant electricity futures premiums would explore the spot and futures relationship further and also gauge the risk aversion of market participants in electricity markets. This study is an important contribution in interconnected power markets as it discovers the bias in futures prices, as well as market participants' behaviour. To my knowledge, this thesis is the first empirical study to investigate the relationship between spot and futures markets and risk premiums in different regional Australian electricity markets. A study of electricity premiums will generate useful information for investors who consider electricity as an investment instrument. A positive premium suggests that market participants tend to take long hedge, so that there is an opportunity to get profit by writing (taking short position) of electricity futures. A part of this thesis discusses an appropriate model for electricity price spike. This model is important since price spike is revealed as a significant determinant of futures premiums. Special attention must be given when using price spike sample since the observation is systematically selected. Thus, sample selection bias occurs, an issue that has not been researched previously when modelling price spike. Accounting for this selection bias will fill the gap in modelling price spike. An appropriate model for price spike is essential for risk management in power markets, as price spike is one of the risky factors in power prices. The last part of this thesis examines another puzzle in commodities markets, the convenience yield risk premium. Existing finance literature discusses the equity and variance risk premiums puzzle. Indeed, convenience yield risk premium is one of the many essential properties of commodities markets. We need to recognise the sign of a convenience yield risk premium to enable us to know how holders of commodities behave during the fluctuation of convenience yield. The sign also points to how investors should take position 
to gain a profit in commodities derivative markets. Therefore, a detailed study of convenience yield risk premium provides new knowledge in investments, derivative pricing and risk management in commodities markets.

The paper titled 'Risk Premiums in Interconnected Australian Electricity Futures Markets' (Chapter 2) provides a pioneering study focusing on futures markets and risk premiums. This paper discusses the realized or ex-post futures risk premiums in the four major states of Australia: New South Wales (NSW), Queensland (QLD), South Australia (SA) and Victoria (VIC). Using the realized futures premiums model suggested by Redl et al. (2009), we find that Australian electricity markets exhibit significant risk premiums for several of the regions considered. Therefore, we conclude that futures prices cannot be considered as unbiased estimators of realized spot prices. We also conclude that futures prices tend to overstate average spot prices during the delivery period, as average realized futures risk premiums are positive for all markets. This finding is consistent with the literature, suggesting that in electricity markets, short-term futures prices often exceed the actual average spot price during the delivery period (Botterud et al., 2002; Longstaff and Wang, 2004; Hadsell and Shawky, 2006; Diko et al., 2006; Bierbrauer et al., 2007; Daskalakis and Markellos, 2009; Redl et al., 2009).

We also recognise significant positive correlations between the observed risk premiums across different regional markets. Correlations are higher for adjoining regions than for markets that are geographically more distant. Such positive correlations can be explained by interconnectors between the regional markets allowing for export or import of electricity from one market to the other. Using an extended version of Bessembinder and Lemmon's (2002) general equilibrium model, we find that in some of the markets the bias can be at least partially explained by the level, volatility, skewness and kurtosis of spot prices during the month prior to delivery. In particular, we observe that realized risk premiums significantly increase with the level of the spot price. Overall, we conclude that retailers in Australian electricity markets are risk averse and willing to pay an additional risk premium in the futures market to avoid the risk of price shocks and spikes in the spot market.

The paper titled 'The Dynamics of Risk Premiums in Australian Electricity Markets' (Chapter 3) investigates the dynamics of futures premiums in four regional Australian electricity markets (NSW, QLD, SA and VIC). This paper extends the paper titled 'Risk Premiums in Interconnected Australian Electricity Futures Markets' by performing dynamic, instead of static, analysis in these Australian electricity markets. We are inclined to believe 
that the futures premiums will be dynamic, rather than static, as Deaves and Krinsky (1995) recognize that risk premiums may be time varying. We analyze the futures premiums for each quarter contract (Q1, Q2, Q3 and Q4) for different time intervals, starting from the previous 12 months (actually referring to the previous 12-to-11 months) before maturity, to one month (actually referring to 1 month to the last trading day) before maturity. Realizing that the independent observation assumption is violated in our observations, we have adjusted the standard t-test by using the "variance inflation factor" adjustment, as suggested by Wilks (1997). We find that futures premiums tend to exist as time gets closer to maturity. The magnitude and significance of premiums, however, are varied from one region to other regions and also from each quarter to other quarter contracts. Overall, we suggest that the electricity futures premiums are dynamic, rather than static, in the Australian electricity markets.

Further investigating this issue, we have developed a sensible model to capture the dynamics of futures premiums. We argue that time to maturity, recent year mean of the spot prices, volatility and variance estimates of the daily spot price changes, and the number of price spikes in the recent month will explain the dynamics of futures premiums. Overall, we find that futures premiums tend to increase when: (i) the time to maturity becomes smaller, or closer to the maturity, (ii) the higher the recent year moving average daily spot price and (iii) the more price spikes that occur in the recent month. We also find that futures premiums convexity is also supported, considering the regression analysis results.

The paper titled 'Modelling Price Spikes in Electricity Markets - the Impact of Load, Weather and Capacity' (Chapter 4) focuses on price spikes modelling. It is important as it explores one of the explanatory price spikes variables, which explains the dynamics of futures premiums further, as discussed in the paper 'The Dynamics of Risk Premiums in Australian Electricity Markets'. In this paper, we proposed the Heckman (1979) selection model framework, to examine factors driving the frequency and magnitude of price spikes. Our proposed model complements existing studies (Mount et al., 2006; Kanamura and Ohashi, 2008; Huisman, 2009; Janczura and Weron, 2010) which have not considered the sample selection bias problem in modelling price spikes. Indeed, the Heckman selection model allows us to overcome the selection bias problem, as identified by the inverse mills ratio (IMR) variable in the model, in modelling price spikes due to non-random sampling. We applied this framework to four regional electricity markets in Australia and found that for each of these markets, load, relative air temperature and reserve margins are significant 
variables for the occurrence of price spikes, while the load and relative air temperature are significant variables for the magnitude of a spike. In particular, we found that IMR is significant in QLD and SA regions (for natural $\log$ transformation) and in all the markets excepting for VIC (for box cox transformation). We also documented that IMR in the NSW market (for natural $\log$ transformation) is almost significant at a 10 percent level. The significance of IMR indicates that the sample selection bias problem exists. Therefore, we conclude, that in three of the four considered markets, the estimation results of a standard OLS model used to price spike data, tends to be biased.

Further investigating this issue, we compared the performance of the Heckman selection model for the quantification of price spikes with the performance of an OLS model using all prices and an OLS model using price spikes only. We find that for all the considered measures, the Heckman selection model performs best in each of the considered markets. Our results suggest further application of the Heckman selection model to model price spikes in electricity markets.

The paper titled 'Convenience Yield Risk Premiums' (Chapter 5) provides a detailed and better understanding of convenience yield risk premium. This is of central importance for risk management and hedging decisions of companies, as well as for investment decisions of financial institutions. This study may affect recent practices in trading strategies, asset management and risk management. In this paper, we follow more direct approach-based twofactor (Gibson and Schwartz, 1990) and three-factor models (Schwartz, 1997) to extract convenience yield risk premiums. Our approach is motivated by the literature on variance risk premiums (Carr and Wu, 2009). Constructing a security that is only sensitive to convenience yield risk, we are able to extract and analyze the convenience yield risk premiums in various commodities markets. We find that convenience yield risk premiums are positive. We also find that risk premiums are very large for metals and grains. Our empirical results show that there are no significant convenience yield risk premiums for oil and gas.

In summary, we find that realized futures premiums in power markets, and convenience yield risk premiums in commodities markets tend to be positive and significant. The findings imply that market participants in the commodities markets are risk averse. They dislike the uncertainties in power prices and convenience yield. Specifically, they are afraid of increased power prices and decreased commodities convenience yield. This also suggests that most market participants in the commodities markets tend to be long hedgers. Therefore, investment opportunities exist by taking short position in commodities markets. Our findings 
are robust as we have considered seasonality, dynamic analysis, different contracts, subperiod analysis, as well as transaction costs.

Our findings also indicate other implications of risk management and derivative pricing in commodities markets. First, the development of the Heckman selection model is beneficial for managing price spikes in power markets as the proposed model tends to outperform the standard OLS model. Second, positive and significant convenience yield risk premiums will lead future commodities derivative pricing development as none of the existing literature discusses the sign of convenience yield risk premiums. Both findings require further investigation. 


\section{Bibliography}

Bessembinder, H \& Lemmon, ML 2002, 'Equilibrium Pricing and Optimal Hedging in Electricity Forward Markets', The Journal of Finance, vol. 57 no. 3, pp. 1347 - 1381.

Bierbrauer, M, Menn, C, Rachev, ST \& Trück, S 2007, 'Spot and Derivative Pricing in the EEX Power Market', The Journal of Banking \& Finance, no. 31, pp. 3462 - 3485.

Botterud, A, Bhattacharyya, AK \& Ilic, M 2002, 'Futures and Spot Prices - An Analysis of the Scandinavian Electricity Market', Working Paper.

Carr, P \& Wu, L 2009, 'Variance Risk Premiums', The Review of Financial Studies, vol. 22 no. 3 , pp. $1311-1341$.

Daskalakis, G \& Markellos, RN 2009, 'Are Electricity Risk Premia Affected by Emission Allowance Prices? Evidence from the EEX, Nord Pool and Powernext', Energy Policy, no. 3, pp. 2594 - 2604.

Deaves, R \& Krinsky, I 1995, 'Do Futures Prices for Commodities Embody Risks Premiums', The Journal of Futures Markets, vol. 15 no. 6, pp. 637 - 648.

Diko, P, Lawford, S \& Limpens, V 2006, 'Risk Premia in Electricity Forward Markets', Studies in Nonlinear Dynamics \& Econometrics, vol. 10 no. 3, pp. $1-22$.

Gibson, R \& Schwartz, ES 1990, 'Stochastic Convenience Yield and The Pricing of Oil Contingent Claims', The Journal of Finance, vol. 45 no. 3, pp. 959 - 976.

Greene, WH 2011, Econometric Analysis $7^{\text {th }}$ Edition, Pearson Prentice Hall, USA.

Hadsell, L \& Shawky, HA 2006, 'Electricity Price Volatility and the Marginal Cost of Congestion: An Empirical Study of Peak Hours in the NYISO Market 2001-2004', The Energy Journal, vol. 27 no. 2, pp. 157 - 179.

Heckman, J 1979, 'Selection Bias as a Specification Error', Econometrica, vol. 47 no. 1, pp. $153-161$.

Hill, RC, Griffiths, WE \& Lim, GC 2011, Principles of Econometrics $4^{\text {th }}$ Edition, John Wiley \& Sons Inc., New Jersey USA.

Huisman, R, 2009, An Introduction to Models for the Energy Markets. Risk Books, London UK.

Janczura, J, \& Weron, R 2010, 'An Empirical Comparison of Alternate Regime-Switching Models for Electricity Spot Prices', Energy Economics, no. 32, pp. 1059 - 1073.

Kanamura, T \& Ohashi, K 2008, 'On Transition Probabilities of Regime Switching in Electricity Prices', Energy Economics, no. 30, pp. 1158 - 1172.

Longstaff, FA \& Wang, AW 2004, 'Electricity Forward Prices: A High Frequency Empirical Analysis', The Journal of Finance, vol. 59 no. 4, pp. 1877 - 1900.

Mount, TD, Ning, Y \& Cai, X 2006, 'Predicting Price Spikes in Electricity Markets Using a Regime-Switching Model with Time-Varying Parameteres', Energy Economics, no. 28, pp. $62-80$.

Redl, C, Haas, R, Huber, C \& Böhm, B 2009, 'Price Formation in Electricity Forward Markets and the Relevance of Systematic Forecast Errors', Energy Economics, no. 31, pp. $356-364$.

Schwartz, ES 1997, 'The Stochastic Behavior of Commodity Prices: Implications for Valuation and Hedging', The Journal of Finance, vol. 52 no. 3, pp. 923 - 973.

Wilks, DS 1997. 'Resampling Hypothesis Tests for Autocorrelated Fields', Journal of Climate, vol. 10, pp. 65 - 82. 